WANNESSA ROCHA DA FONSECA

\title{
DIRETRIZES PARA ESPECIFICAÇÃO DE SERVIÇOS PARA GOVERNO ELETRÔNICO BASEADO EM REUSO
}




\section{WANNESSA ROCHA DA FONSECA}

\section{DIRETRIZES PARA ESPECIFICAÇÃO DE SERVIÇOS PARA GOVERNO ELETRÔNICO BASEADO EM REUSO}

Tese apresentada à Escola Politécnica da Universidade de São Paulo para obtenção do Título de Doutor em Ciências. 


\section{WANNESSA ROCHA DA FONSECA}

\section{DIRETRIZES PARA ESPECIFICAÇÃO DE SERVIÇOS PARA GOVERNO ELETRÔNICO BASEADO EM REUSO}

Tese apresentada à Escola Politécnica da Universidade de São Paulo para obtenção do Título de Doutor em Ciências.

Área de Concentração: Engenharia de Computação e Sistemas Digitais

Orientador: Professor Dr. Pedro Luiz Pizzigatti Corrêa 
Este exemplar foi revisado e corrigido em relação à versão original, sob responsabilidade única do autor e com a anuência de seu orientador.

São Paulo, 17 de junho de 2014.

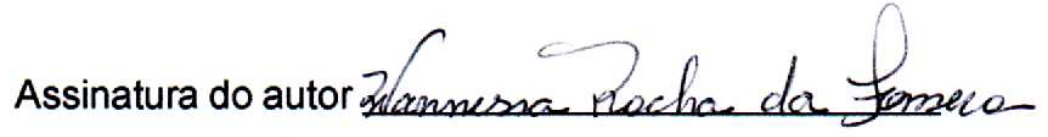

Assinatura do orientador Pecho 2 P $b$ in

\section{Catalogação-na-publicação}

Fonseca, Wannessa Rocha da

Diretrizes para especificação de serviços para governo eletrônico baseado em reuso /W. R. da Fonseca. - versão corr. - São Paulo, 2014. $135 \mathrm{p}$.

Tese (Doutorado) - Escola Politécnica da Universidade de São Paulo. Departamento de Engenharia de Computação e Sistemas Digitais.

1.Computação aplicada (Serviços) 2.Governo eletrônico (Serviços) 3.Arquitetura orientada a serviços 4.Reuso de software I. Universidade de São Paulo. Escola Politécnica. Departamento de Engenharia de Computação e Sistemas Digitais II. $\mathrm{t}$. 
Dedico este trabalho ao meu filho, Rodrigo, ao meu esposo, Evandro, e a minha mãe, Elza. 


\section{AGRADECIMENTOS}

Nessa trajetória de pesquisa, pude contar com a presença de várias pessoas, que me ajudaram das mais variadas formas, contribuindo, motivando e se alegrando a cada passo conquistado.

Portanto, chegou o momento de agradecer, primeiramente a Deus, por estar sempre comigo em todos os momentos.

Agradeço à minha família, pelo torcida e carinho, em especial ao meu filho querido, pelo amor, carinho e paciência durante todos esses anos. Ao meu amado marido, que foi, como sempre, um companheiro e cúmplice de todos os momentos. Mesmo que ele tivesse que se dedicar à sua pesquisa, nunca poupou esforços para me dar atenção e carinho. À minha querida mãe (mãezona), que, além de compreender a minha ausência, foi o meu suporte em vários momentos, principalmente nas minhas viagens, em que ela não mediu esforços para cuidar do meu filho. À minha mãe, o meu muito obrigada!

Agradeço a meu pai, que, mesmo não estando mais entre nós, está sempre comigo, no meu coração.

Agradeço ao meu orientador, professor Dr. Pedro L. P. Corrêa, por me acolher e orientar, pelo estímulo e ensinamento. Obrigada pelas revisões do texto e pela dedicação ao trabalho. Obrigada pela sua amizade!

Agradeço às instituições USP, CEPROMAT, UFMT, CAPES e FAPEMAT por me apoiarem nas atividades do doutorado. Aos coordenadores do DINTER, que promoveram a cooperação entre UFMT e EPUSP, professores Dra. Patricia C. Souza, Dr. Cristiano Maciel, Dr. Carlos Cugnasca e Dr. André R. Hirakawa. Aos professores da USP, que se deslocaram até Cuiabá, em especial às professoras Dra. Lucia V. L. Filgueiras, Dra. Selma S. S. Melnikoff e Cristina Borba.

Agradeço ao Cepromat, por ter participado do convênio número 028/FUFMT/2008, que viabilizou a participação dos funcionários no DINTER e concedeu-me a liberação necessária do trabalho para realização das atividades do curso. Agradeço em especial a Divino Miranda, que me apresentou a oportunidade do curso e me incentivou a iniciar o processo de seleção, a Luciano Bigatão, a Lúcio Flávio Santos e a Weber Souza por não pouparem esforços para formalizar e viabilizar a minha participação no curso.

Aos meus amigos, pelo incentivo e apoio nos momentos de angústias e indecisões. De alguns deles, eu não poderia deixar de citar o nome, pois, de forma 
diferenciada, cada um contribuiu para que eu realizasse esta pesquisa. As amigas Cristiane Carlotto, Patricia Alonso, Ivete Meens e Maria de Lourdes e, em especial, Miriam Lamego, por tantos desabafos, tantos conselhos e pela paciência que teve comigo, o meu muito abrigada!

Aos amigos e parentes, que se fizeram presentes sempre, mesmo quando eu estava em viagem, apoiando minha mãe e proporcionado momentos de alegria e conforto ao meu filho: Maurício Catharino, Rejane Catharino, Janã Pinheiro, Weber Souza, Cristiane Carlotto, Viviane Bronzatti, Charles Fonseca, Lucas Fonseca, Rosi Freiberger, Waldemar Freiberger e Kacima Rampazzo, o meu muito obrigada!

Às pessoas especiais que conheci durante o curso, a Mariza U. Leone, pela ajuda e carinho sempre que precisei; aos colegas do Laboratório de Automação Agrícola, em especial, a Daniel Lins e Andreiwid Corrêa, e do laboratório Interlab, Cleber e Ana Claudia pelo carinho e troca de informação, muito obrigada!

Àqueles cujo nome não mencionei peço desculpas, e aqui o meu sincero agradecimento! 


\section{RESUMO}

A evolução dos processos de negócio para uma visão de serviços alavancou um novo modelo computacional, o modelo orientado a serviços. Nesse modelo, os processos de negócio são modelados e implementados sob a ótica de serviços. O governo mostra-se como um domínio potencial de implantação de soluções orientadas a serviços. Embora as organizações governamentais estejam adotando o uso de serviços a fim de alcançar a interoperabilidade de sistemas de informação de governo, os serviços são geralmente criados a partir dos princípios elementares, sem considerar o reuso de soluções orientadas a serviços concebidas por outras entidades públicas. Assim, esta pesquisa tem como propósito fornecer diretrizes para auxiliar a especificação de serviços de governo eletrônico baseadas em padrões de serviços, para subsidiar o desenvolvimento de sistemas de governo, alinhados aos benefícios de computação orientada a serviços e o reuso de soluções para o governo eletrônico. Esta tese apresenta o MESe-gov, um modelo para especificação de serviços de governo eletrônico e o DESe-gov, um conjunto de diretrizes para especificação de serviços de governo eletrônico. Também é proposto um ciclo de vida de serviço para a especificação de novos serviços a partir dos padrões de serviços. A concepção de serviços, aliada ao conceito de padrões de serviços, ajuda engenheiros de software identificar elementos funcionais recorrentes e reduzir a redundância de esforços para a concepção de serviços com propósitos similares. Nesta pesquisa, foram realizados estudos de casos em que foram aplicadas as diretrizes a partir dos serviços existentes na área financeira do governo. Como resultado, os estudos de casos mostram que as diretrizes auxiliam a especificação de padrões de serviços.

Palavras-chave: Governo Eletrônico. Computação Orientada a Serviços. Serviços. Especificação de Serviços. Padrões de Serviços. 


\section{ABSTRACT}

The evolution of business processes for an insight on services has boosted a new computational model, the service-oriented model. The business processes in the service-oriented computational model are modelled and implemented from the perspective of services. The government appears to be a high potential scenario for the deployment of service-oriented applications. Although government organizations are adopting the use of services in order to achieve interoperability of government systems, those services are usually created from basic principles, without considering the reuse of service-oriented solutions adopted by other public entities. Thus, this research aims to provide guidelines to assist the specification of e-government services based on service patterns, to support the development of government systems, aligned with the benefits of service-oriented computing and the reuse of solutions for e-government. This thesis presents the MESe-gov, a model for the services specification of electronic government and the DESe-gov, a set of guidelines for the services specification of electronic government. A service lifecycle is also proposed for the specification of new services from service patterns. The conception of services combined with the concept of service patterns can help software engineers to identify recurrent functional elements and reduce redundant efforts in the conception of services with the same purposes. In this research, case studies were conducted in which the guidelines from existing services in the government's financial area were implemented. As a result, the case studies show that the guidelines help to specify service patterns.

Keywords: Electronic Government. Service-Oriented Computing. Service. Service Specification. Service Patterns. 


\section{LISTA DE ILUSTRAÇÕES}

1 Escopo do trabalho f . . . . . . . . . . . . . . . . . . . . . . . . . . 18

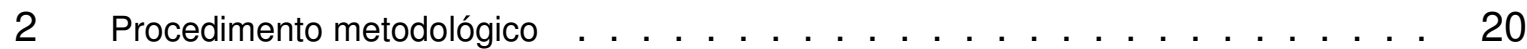

3 Visão conceitual dos elementos computacionais da computação orientada a serviços e seus relacionamentos . . . . . . . . . . . . . . . . . . . . . . . . . . . 24

4 Principais conceitos do Modelo de Referência OASIS . . . . . . . . . . . . . . . 25

5 Camadas de abstração dos serviços . . . . . . . . . . . . . . . . . . . 26

6 Princípios de projeto de serviços . . . . . . . . . . . . . . . . . . . . . 28

$7 \quad$ Ciclo de vida de serviços . . . . . . . . . . . . . . . . . . . . . . . . 32

8 Identificação de serviços de negócio candidatos . . . . . . . . . . . . . 33

9 Organização de uma especificação WSDL . . . . . . . . . . . . . . . . . . . . 42

10 As influências primárias de padrões de projeto SOA . . . . . . . . . . . . . . 46

11 As influências primárias de padrões de Serviços . . . . . . . . . . . . . . . . . . 51

12 Arquitetura da solução proposta . . . . . . . . . . . . . . . . . . . . . . 57

13 Abrangência do governo eletrônico . . . . . . . . . . . . . . . . . . . . . . . . 59

14 Modelo Tradicional de Interação Estado Cidadão . . . . . . . . . . . . . . . . . . 60

15 Modelo Ideal de Interação Estado Cidadão ～. . . . . . . . . . . . . . . . . . . 61

16 Camadas de abstração . . . . . . . . . . . . . . . . . . . . . . . . . . . 69

17 Elementos relacionados a padrões de serviços . . . . . . . . . . . . . . . 70

18 MESe-Gov - Modelo para Especificação de Serviços de e-Governo . . . . . . . . . 75

19 MESe-Gov - Modelo de Especificação de Serviços de e-Governo e suas atividades . 76

20 Atividade - especificar padrões de serviços . . . . . . . . . . . . . . . . . . . 77

21 Fluxo de atualização de padrões de serviços . . . . . . . . . . . . . . . . . . . 81

22 Atividade - criar serviços a partir de padrões de serviços. . . . . . . . . . . . . . . 82

23 Proposta de ciclo de vida de serviços com padrões de serviços. . . . . . . . . . . 83

24 Identificação de serviços de negócios candidatos . . . . . . . . . . . . . . . . . 84

25 Criação de serviços para diferentes inventários a partir de um padrão de serviço . . . 85

26 Criação de vários serviços para um inventário a partir de um padrão de serviço. . . . 86

27 Processo de negócio Agendamento de Diárias . . . . . . . . . . . . . . . . . . 88

28 Processo de negócio Agendamento de Diárias consumindo serviços . . . . . . . . 89

29 Processo de negócio Agendamento de Viagem . . . . . . . . . . . . . . . . . . 92

30 Processo de negócio Agendamento de Viagens consumindo serviços . . . . . . . . 93

31 Criação de serviços para diferentes inventários de serviços a partir do padrão de serviço Previsão Pagamento. . . . . . . . . . . . . . . . . . . . . . . . . . . . 
32 Criação de serviços para o mesmo inventário de serviços a partir do padrão de serviço Previsão Pagamento. . . . . . . . . . . . . . . . . . . . . . . . . . . . . . . . 94

33 Processo de negócio Escala de Férias . . . . . . . . . . . . . . . . . . . 95

34 Processo de negócio Escala de Férias consumindo serviço . . . . . . . . . . . . . 96

35 Criação de serviços para diferentes inventários de serviços a partir do padrão de serviço Recepção de Lote de DF-e. . . . . . . . . . . . . . . . . . . . . . . . . 100

36 Criação de serviços para o mesmo inventário de serviços a partir do padrão de serviço Recepção de Lote de DF-e. . . . . . . . . . . . . . . . . . . . . . . . . . . . 100

37 Carta de apresentação . . . . . . . . . . . . . . . . . . . . . . . . . . 118

38 Interface do questionário - questões sobre o perfil da organização . . . . . . . . . 119

39 Interface do questionário - questões sobre o perfil dos serviços da organização . . . 120

40 Esfera de atuação das organizações . . . . . . . . . . . . . . . . . . . . . . . 122

41 Esfera de atuação das organizações . . . . . . . . . . . . . . . . . . . . 122

42 Experiência com SOA no domínio de governo . . . . . . . . . . . . . . . . 123

43 Esfera de uso dos serviços . . . . . . . . . . . . . . . . . . . . . . . . . . 124

44 Serviços por áreas de governo . . . . . . . . . . . . . . . . . . . . . . 124

45 Serviços monitorados por ferramentas . . . . . . . . . . . . . . . . . . . . . 124

46 Serviços compostos . . . . . . . . . . . . . . . . . . . . . . . . . 124

47 Serviços classificados por forma de publicação . . . . . . . . . . . . . . . . . 125

48 Serviços implementados utilizando Web Services . . . . . . . . . . . . . . . . . 125

49 Percentual de serviços por tecnologia . . . . . . . . . . . . . . . . . . . . . 128

50 Forma de uso de serviços . . . . . . . . . . . . . . . . . . . . . . . . . . . 128

51 Forma de implementação de serviços . . . . . . . . . . . . . . . . . . . . . . . 128

52 Documentação de serviços . . . . . . . . . . . . . . . . . . . . . . . . . . . . 128

53 Monitoramento automático de serviços . . . . . . . . . . . . . . . . . . . . . . 129

54 Composição de serviços . . . . . . . . . . . . . . . . . . . . . . . . . . . . . 129

55 Percentual de tipo de serviço . . . . . . . . . . . . . . . . . . . . . . . . . . . 129 


\section{LISTA DE TABELAS}

1 Comparação de modelos de ciclos de vida de serviços . . . . . . . . . . . . . . 31

2 Atributos para descrição de serviços . . . . . . . . . . . . . . . . . . 38

3 Relação entre abordagens de reutilização de software e conceitos básicos de reutilização de software . . . . . . . . . . . . . . . . . . . . . . . . . . . . . 44 44

4 Serviços versus Padrões de Serviços . . . . . . . . . . . . . . . . . . . . . . 50

5 Relação entre padrão de serviço e conceitos básicos da reutilização de software . . 52

6 Atributos para descrição de padrões . . . . . . . . . . . . . . . . . . . 53

7 Padrões relacionados a serviços . . . . . . . . . . . . . . . . . . . . 54

8 Padrões genéricos de serviço da saúde pública $\ldots \ldots \ldots$

9 Origem dos atributos do template Especificação de Padrão de Serviço . . . . . . . 72

10 Template Especificação de Padrão de Serviço . . . . . . . . . . . . . . . . . . . 74

11 Padrão de serviço: Previsão de Pagamento . . . . . . . . . . . . . . . . . . . . . 91

12 Padrão de serviço: Aprovar Férias ～. . . . . . . . . . . . . . . . . . . . . . . 97

13 Padrão de serviço: Recepção de Lote de DF-e . . . . . . . . . . . . . . . . . . 99 


\section{LISTA DE ABREVIATURAS E SIGLAS}

API Application Programming Interface

CT-e Conhecimento de Transporte Eletrônico

CRUD Create, Read, Update and Delete

BPEL Business Process Execution Language

BPFM Business-Process Family Model

BPM Business Process Modeling

BPMN Business Process Model and Notation

CDM Canonical Data Models

DF-e Documento Fiscal Eletrônico

EAI Enterprise Application Integration

EPC Event-driven Process Chains

e-GIF E-Government Interoperability Framework

e-PING Padrões de Interoperabilidade de Governo Eletrônico

e-Governo Governo Eletrônico

ESB Enterprise Service Bus

DESe-Gov Diretrizes para Especificação de Serviços de e-Governo

G2G Government to Government

G2B Government to Business

G2C Government to Citizen

MEP Message Exchange Patterns

MESe-Gov Modelo para Especificação de Serviços de e-Governo

NF-e Nota Fiscal Eletrônica

NFC-e Nota Fiscal Eletrônica do Varejo

OECD Organisation for Economic Co-Operation and Development

OASIS Organization for the Advancement of Structured Information Standards 
QoS Qualidade de Serviço

SOA Service-Oriented Architecture

SOMA Service-Oriented Modeling and Architecture

SoaML Service Oriented Architecture Modeling Language

SISP Sistema de Administração dos Recursos de Tecnologia da Informação

TIC Tecnologia da Informação e Comunicação

UDDI Universal Description Discovery and Integration

UNPAN $\quad$ United Nations Public Administration Network

URI Uniform Resource Identifier

VCGE Vocabulário Controlado do Governo Eletrônico

UUIDS Unified User Interface Design Specification

UML Unified Modeling Language

WSDL Web Services Description Language

XML Extensible Markup Language 


\section{SUMÁRIO}

1 Introdução 14

1.1 Motivação . . . . . . . . . . . . . . . . . . . . . 16

1.2 Problema . . . . . . . . . . . . . . . . . . . . . . . 17

1.3 Objetivos .............................. 17

1.4 Escopo . . . . . . . . . . . . . . . . . . . 17

1.5 Material e Método . . . . . . . . . . . . . . . . . . . . . . . . . . . . 19

1.6 Organização do Trabalho . . . . . . . . . . . . . . . . . . . . 21

2 Aspectos Conceituais 22

2.1 Considerações Iniciais . . . . . . . . . . . . . . . . . . . . . . . . . 22

2.2 Computação Orientada a Serviços . . . . . . . . . . . . . . . . . . . 23

2.2.1 Serviço . . . . . . . . . . . . . . . . . . . . . 24

2.2.2 Princípios de Projeto de Serviços . . . . . . . . . . . . . . . . . 27

2.2.3 Ciclo de Vida de Serviços . . . . . . . . . . . . . . . . . . . . . . 29

2.2.4 Abordagens para Identificar Serviços . . . . . . . . . . . . . . 34

2.2.5 Especificação de Serviços . . . . . . . . . . . . . . . . 38

2.2.6 Linguagem de Descrição de Serviços . . . . . . . . . . . . . . . 40

2.3 Reuso de Software . . . . . . . . . . . . . . . . . . . . . . . . . . . . . . 42

2.3.1 Padrões de Projeto . . . . . . . . . . . . . . . . . . . . . . . . 45

2.3.2 Padrões de Serviços . . . . . . . . . . . . . . . . . . . . . . 48

2.3.2.1 Reuso de Software e Padrões de Serviços . . . . . . . 50

2.3.2.2 Especificação de Padrões de Serviços . . . . . . . . . 52

2.3.2.3 Trabalhos Relacionados a Padrões de Serviços . . . . 52

2.4 Governo Eletrônico e Serviços . . . . . . . . . . . . . . . . . . . . . . . 58

2.4.1 Serviço Entregue ao Cidadão . . . . . . . . . . . . . . . . . . . . 60

2.4.2 Serviço Entregue as Aplicações . . . . . . . . . . . . . . . . . . 62

2.5 Considerações Finais do Capítulo . . . . . . . . . . . . . . . . . . . 64

3 Modelo e Diretrizes para Especificação de Serviços de e-Governo 66

3.1 Considerações Iniciais . . . . . . . . . . . . . . . . . . . . 66

3.2 Caracterização do Domínio de Governo . . . . . . . . . . . . . . . . . . 66

3.3 A Abstração: Padrão de Serviço . . . . . . . . . . . . . . . . . . . . . . 68

3.4 Padrão de Serviço e Relacionamentos . . . . . . . . . . . . . . . . . . . 69 
3.5 Template Proposto para Especificação de Padrão de Serviço . . . . . . 71

3.6 Modelo Conceitual de Especificação de Serviços de e-Governo . . . . . 73

3.7 Definição das Diretrizes para Especificação de Serviços de e-Governo . 76

3.7.1 Especificação de Padrões de Serviços . . . . . . . . . . . . 77

3.7 .2 Criação de Serviços . . . . . . . . . . . . . . . 81

3.8 Considerações Finais do Capítulo $\ldots \ldots \ldots \ldots \ldots$

4 Estudo de Caso $\quad 87$

4.1 Considerações Iniciais . . . . . . . . . . . . . . . . . . 87

4.2 Caso Registro de Despesas . . . . . . . . . . . . . . . . . . 88

4.2.1 Descrição do Cenário de Negócio . . . . . . . . . . . . 88

4.2.2 Especificação do Padrão de Serviço . . . . . . . . . . . . 89

4.2.3 Criação do Serviço a partir do Padrão de Serviço . . . . . . . 90

4.3 Caso Aprovação Férias . . . . . . . . . . . . . . . . . . . . . . . 94

4.3.1 Descrição do Cenário de Negócio . . . . . . . . . . . . . . 94

4.3.2 Especificação do Padrão de Serviço . . . . . . . . . . . . . . . 94

4.3.3 Criação do Serviço a partir do Padrão de Serviço . . . . . . . . 95

4.4 Caso NF-e . . . . . . . . . . . . . . . . . . . . . . . . . . . 97

4.4.1 Descrição do Cenário de Negócio . . . . . . . . . . . 97

4.4.2 Especificação do Padrão de Serviço . . . . . . . . . . . . . 98

4.4.3 Criação do Serviço a partir do Padrão de Serviço . . . . . . . 99

4.5 Considerações Finais do Capítulo . . . . . . . . . . . . . . . . 102

5 Conclusão 103

5.1 Contribuições . . . . . . . . . . . . . . . . . . . . . . 104

5.2 Desafios de Pesquisa . . . . . . . . . . . . . . . . . 105

5.3 Trabalhos Futuros . . . . . . . . . . . . . . . . . . 105

5.4 Dificuldades Encontradas . . . . . . . . . . . . . . . . 106

5.5 Considerações Finais $\ldots \ldots \ldots \ldots \ldots . \ldots \ldots$

$\begin{array}{ll}\text { Referências } & 109\end{array}$

Apêndice A - Interface do Questionário on-line para Levantamento de $\begin{array}{ll}\text { Serviços } & 117\end{array}$

Apêndice B - Caracterização do Uso de Serviços e SOA no Governo Realizado no Ano de $2013 \quad 121$

B.1 Cenário . . . . . . . . . . . . . . . . . . . . . . 121 
B.2 Metodologia . . . . . . . . . . . . . . . . . . . . . . . . . . . 121

B.3 Dados Coletados . . . . . . . . . . . . . . . . . . . . . . . . . . . . 121

B.3.1 Informações Sobre as Organizações que Responderam o Questionário . . . . . . . . . . . . . . . . . . . . . . . 122

B.3.2 Informações Sobre os Serviços Identificados via Questionário 123 Apêndice C - Levantamento de Serviços e Integrações - Realizado no Ano de 2010 126

C.1 Cenário . . . . . . . . . . . . . . . . . . . . . . . . 126

C.2 Metodologia . . . . . . . . . . . . . . . . . . . . . . . 126

C.3 Dados Coletados . . . . . . . . . . . . . . . . . . . . . . . . 126

C.4 Análise dos Dados . . . . . . . . . . . . . . . . . . . . . 127

Apêndice D - Detalhamento do Esquema de Descrição de Serviços 131

D.1 Atributos para Descrever o Serviço . . . . . . . . . . . . . . . . . 131

D.2 Atributos para Descrever as Operações do Serviço . . . . . . . . . . 132

Apêndice E - Detalhamento do Esquema de Descrição de Padrões 133 


\section{INTRODUÇÃO}

Durante a última década, houve uma revolução na prestação de serviços de governo aos cidadãos, segundo Baqir e lyer (2010). Por meio do uso de Tecnologias da Informação e Comunicação (TIC), especificamente tecnologias baseadas na Web, foi possível desenvolver e implantar sistemas de informação voltados para a gestão de processos de negócio de governo, denominados governo eletrônico (e-governo).

Segundo Lin et al. (2008), o e-governo tem, em síntese, dois objetivos: i) simplificar e tornar os trabalhos eficientes nos departamentos internos do governo; ii) oferecer melhores serviços aos cidadãos. Assim, a construção de sistemas de informação, quer sejam internos ou externos aos departamentos de governo, e a forma de integrá-los adequadamente, estão relacionadas a e-governo.

A evolução dos processos de negócio para uma visão de serviços alavancou um novo modelo computacional, o modelo orientado a serviços. Nesse modelo, os processos de negócio são modelados e implementados sob a ótica de serviços.

A computação orientada a serviços utiliza serviços como princípio para apoiar o desenvolvimento de aplicações distribuídas. Este modelo computacional tem como perspectiva cooperar serviços, cujas aplicações são especificadas em uma rede de serviços com baixo acoplamento, apoiando processos de negócio que podem abranger diferentes organizações e plataformas computacionais (PAPAZOGLOU et al., 2008).

O governo, de uma forma geral, mostra-se como um domínio de alto potencial para utilização de soluções orientadas a serviços, principalmente pelo elevado número de aplicações existentes, pela diversidade tecnológica, pela necessidade de interação entre essas aplicações e pela necessidade de gestão da qualidade dos serviços prestados. Contudo, esse domínio não está isento dos desafios inerentes ao paradigma de desenvolvimento orientado a serviços como, por exemplo, a atividade de concepção de serviços, foco deste trabalho.

Atualmente, um grande número de sistemas de informação é concebido e desenvolvido nas três esferas do Governo Brasileiro (Federal, Estadual e Municipal) e nos três poderes (Executivo, Legislativo e Judiciário), mas, de modo geral, os serviços 
são concebidos a partir dos princípios elementares, muitas vezes sem o reuso de soluções já concebidas em outras esferas e poderes, mesmo existindo atividades e obrigações similares nos poderes e esferas de governo. Assim, os esforços para conceber soluções por meio do paradigma de serviços não são reaproveitados.

Embora existam meios eletrônicos de divulgação de serviços como o caso do catálogo de serviços interoperáveis do Governo Federal brasileiro ${ }^{1}$ (BRASIL, 2013a), esses não são divulgados visando ao reuso da solução, e sim o consumo de serviços. Logo, se observa a falta de subsídios para fomentar o reuso de soluções orientadas a serviços.

No contexto de e-governo, quando usado o termo serviço, facilmente se remete ao termo serviço eletrônico prestado diretamente ao cidadão, por meio de uma interface de usuário final. Neste trabalho, contudo, o termo serviço é utilizado para representar uma interface de software fornecida por uma instituição governamental, a fim de ser consumida por aplicativos de instituições governamentais ou instituições externas ao governo.

As pesquisas na literatura investigada referentes à computação orientada a serviços envolvendo a área de e-governo estão, principalmente, relacionadas à definição de arquitetura orientada a serviços para o cenário de governo e relatos de experiências com o uso da tecnologia. Outra variedade de pesquisas está voltada para a definição, desenvolvimento e padronização de serviços para o usuário final. Contudo, não foi observada uma abordagem com a finalidade de auxiliar na definição de serviços para e-governo a partir de serviços já concebidos, visando explorar a capacidade de reuso de soluções de negócio para sistemas orientados a serviços no domínio de governo.

Uma boa prática no desenvolvimento de sistemas, independente do paradigma, é o reuso de soluções já concebidas e que funcionaram no passado. Segundo Gamma et al. (2000), os melhores projetistas sabem que não devem resolver um problema a partir de princípios elementares ou do zero. Assim, este trabalho propõe um conjunto de diretrizes, a fim de auxiliar na especificação de serviços a partir de soluções de serviços já concebidos, visando subsidiar a reutilização de conceito de serviço no domínio de e-governo. Para subsidiar o reuso, propõe-se a utilização de padrões de serviços.

\footnotetext{
${ }^{1}$ Catálogo de Serviços Interoperáveis disponível em http://catalogo.governoeletronico.gov.br/
} 


\subsection{Motivação}

De modo geral, as entidades públicas no Brasil dedicam esforços para conceber soluções por meio do paradigma de serviços, todavia esses esforços não são reaproveitados. A exemplo, no poder executivo das unidades federativas (26 Estados e o Distrito Federal), cada unidade possui um modelo de processo de negócio e sistemas de informação criados para sua administração, porém muitas atividades do processo de negócio relacionado ao governo são similares e, por isso, serviços são concebidos com propósitos similares.

Um fator motivador está relacionado à questão da evolução tecnológica. $\mathrm{Na}$ maioria das vezes, soluções de sistemas de informação são concebidas visando somente às necessidades específicas, sem se preocupar com a interação com outros sistemas, dentro ou fora da organização. Por isso, o domínio de governo possui uma diversidade tecnológica e sistemas de informação heterogêneos que, normalmente, sofrem com problemas de integração (RAY et al., 2011).

Os trabalhos do Governo Federal Brasileiro relacionados à padronização e interoperabilidade como e-PING (Padrões de Interoperabilidade de Governo Eletrônico) também são fatores motivadores. O e-PING, além de ser um exemplo da relevância de adoção de padrões, também incentiva o uso de Arquitetura Orientada a Serviços (em inglês, Service-Oriented Architecture - SOA) no Governo. São fatores motivadores também:

- Redução de esforços para a concepção de serviços, uma vez que essa concepção, apoiada pelo uso de padrões de serviços, pode ajudar engenheiros de software a identificar elementos funcionais recorrentes e diminuir a redundância de esforços para a concepção e projeto de serviços com os mesmos propósitos;

- A similaridade dos processos de negócio de governo tende a gerar um alto potencial de reuso de soluções de serviços;

- A necessidade de interoperabilidade entre as aplicações de governo.

Por fim, não há evidências na literatura de que esforços despendidos para a concepção de serviços estejam sendo reaproveitados. Se o reaproveitamento de conceito de serviço é realizado, isso é feito de forma empírica e isolada. 


\subsection{Problema}

Uma boa prática no desenvolvimento de sistemas, independente do paradigma, é o reuso de soluções já concebidas que funcionaram no passado. Embora Gamma et al. (2000) abordem o paradigma orientado a objetos, eles ressaltam que os melhores projetistas sabem que não devem resolver um problema a partir de princípios elementares ou do zero. Nesse sentindo, como apoiar o reuso de soluções orientadas a serviços para diminuir a redundância de esforços na especificação de novos serviços no domínio de aplicações de e-governo? Esse questionamento deu origem à tese de que o uso de padrões de serviços possa auxiliar no reuso de conceitos de serviços.

\subsection{Objetivos}

O objetivo principal desta pesquisa é fornecer diretrizes para a especificação de serviços baseadas em Arquitetura Orientada a Serviços utilizando padrões de serviços como uma abordagem para o reuso de conceito de serviço.

Para alcançar este objetivo principal, os seguintes objetivos secundários foram estabelecidos:

- Definir um modelo conceitual para representar os padrões de serviços;

- Conceber e documentar as diretrizes e procedimentos para especificar os padrões de serviços;

- Conceber e documentar as diretrizes e procedimentos para especificar os serviços com base em padrões de serviços;

- Aplicar as diretrizes propostas em estudos de casos em um cenário de Governo.

\subsection{Escopo}

Este trabalho se insere no escopo de aplicações orientadas a serviços, especificamente no domínio de governo eletrônico, tendo como premissa o reuso de soluções já concebidas no domínio de governo. $O$ trabalho está delimitado à atividade de especificação de serviço no domínio de e-governo, visando ao reuso de conceito de serviço.

A Figura 1 ilustra graficamente os elementos que compõem o escopo deste trabalho. 
Figura 1: Escopo do trabalho

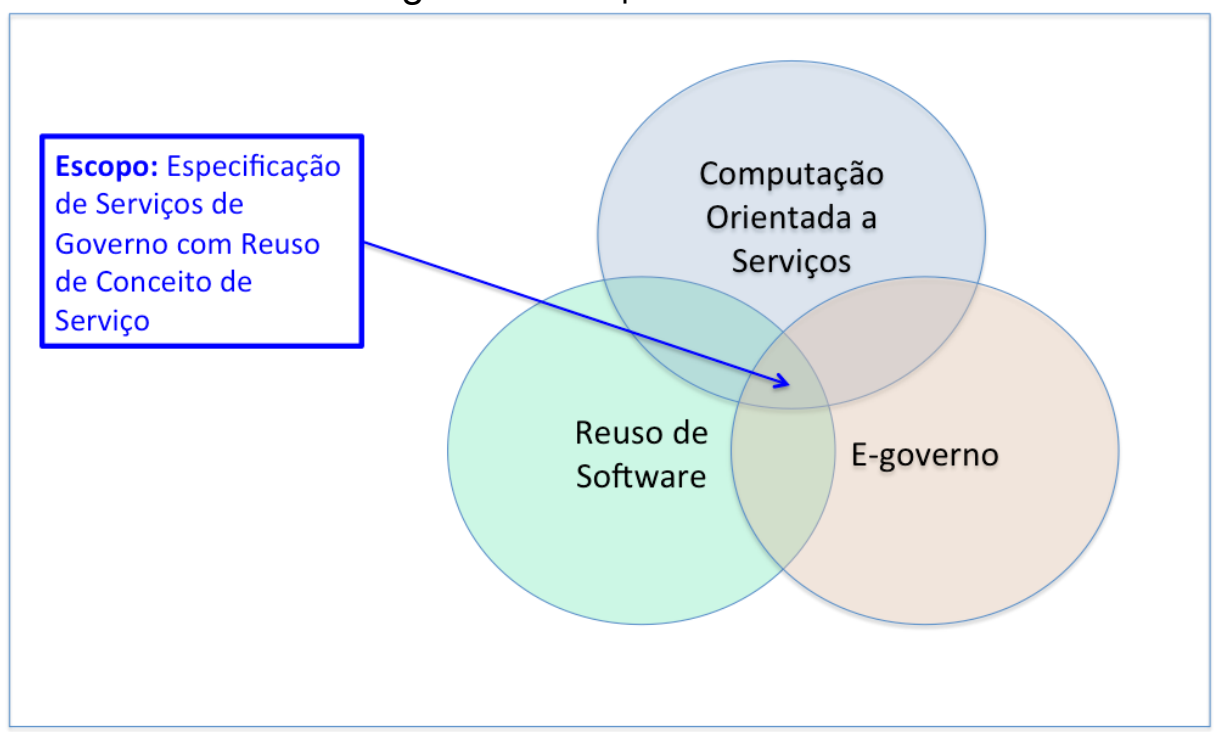

Fonte: Autor (2014)

- Computação orientada a serviços - no paradigma de desenvolvimento orientado a serviços, a atividade foco desta pesquisa é a especificação de serviços. A especificação de serviços é uma atividade do ciclo de desenvolvimento orientado a serviços, na qual os serviços são definidos e especificados com as suas devidas capacidades.

- E-governo - representa o domínio de estudo deste trabalho. O domínio de e-governo foi selecionado primeiro por se tratar de um ambiente de trabalho da autora e também por ser um domínio característico para a implantação de computação orientada a serviços. Além das diversidades tecnológicas, esse cenário apresenta redundância de regras de negócios.

- Reuso de software - No contexto de desenvolvimento de software, a forma mais comum de reuso é por meio do código fonte, mas o reuso pode estar relacionado ao reuso de conceitos e artefatos. O reuso de conceitos já estabelecidos, objetivo da maioria das instituições, independente de serem públicas ou privadas, é o foco deste trabalho. Neste caso, o conceito a ser reutilizado está associado ao serviço.

Por isso, estabelecer a junção das três áreas - computação orientada a serviços, domínio de governo e reuso de conceito de serviço - tem como objetivo subsidiar a especificação de serviços para governo eletrônico, visando o reuso de soluções já concebidas. 


\subsection{Material e Método}

Esta pesquisa é considerada exploratória e de natureza qualitativa.

Conforme Wazlawick (2009), o estilo de pesquisa exploratória,

Não se consegue provar uma teoria nem apresentar resultados estatisticamente aceitos. Mas entram aqui os estudos de caso, as análises qualitativas e as pesquisas exploratórias em áreas emergentes. A argumentação e o convencimento são as principais ferramentas do pesquisador (WAZLAWICK, 2009).

Inicialmente, foi realizada uma revisão bibliográfica exploratória sobre os temas computação orientada a serviços e formas de identificar serviços. Em seguida, realizou-se uma revisão bibliográfica exploratória na área de e-governo e de reuso de software, a fim de buscar aspectos e abordagens de reuso de software.

Entre as formas de reuso identificadas, o uso de soluções padrões foi selecionada por se tratar de uma forma de reusar soluções já experimentadas. Embora o termo padrões de serviços já exista, ainda não há um consenso sobre a forma de sua documentação, como também não há uma única definição e uso desse termo.

Após definido o escopo da pesquisa e objetivos específicos da pesquisa, o procedimento metodológico utilizado para realizar esta pesquisa foi composto pelas atividades apresentadas na Figura 2.

A partir da necessidade de definir um modelo conceitual para representação de padrões de serviços, realizou-se uma pesquisa bibliográfica, para analisar como os padrões de serviços são documentados. Além disso, foram analisadas as informações utilizadas para especificar serviço, pois a representação dos padrões de serviços deve ter como base as informações utilizadas para especificar o serviço. Nessa fase do trabalho, foram definidos os elementos relacionados a padrões de serviços e o template Especificação de Padrão de Serviço.

Uma caracterização a respeito da utilização de SOA no domínio de governo foi realizada no ano de 2013 e, para isso, foi definido o escopo do levantamento e o local onde seria realizado o levantamento. Para realizar a coleta de dados, foi utilizado um questionário eletrônico, elaborado com a ferramenta EmailMeForm (2013). No ano de 2010, foi realizado um levantamento de serviço no poder executivo estadual da Administração Pública do Estado de Mato Grosso, com o objetivo de coletar informações a respeito dos mecanismos de integração, troca de informações ou computação distribuída em sistemas de governo.

A fim de definir as diretrizes e procedimentos para especificar padrões de 
Figura 2: Procedimento metodológico

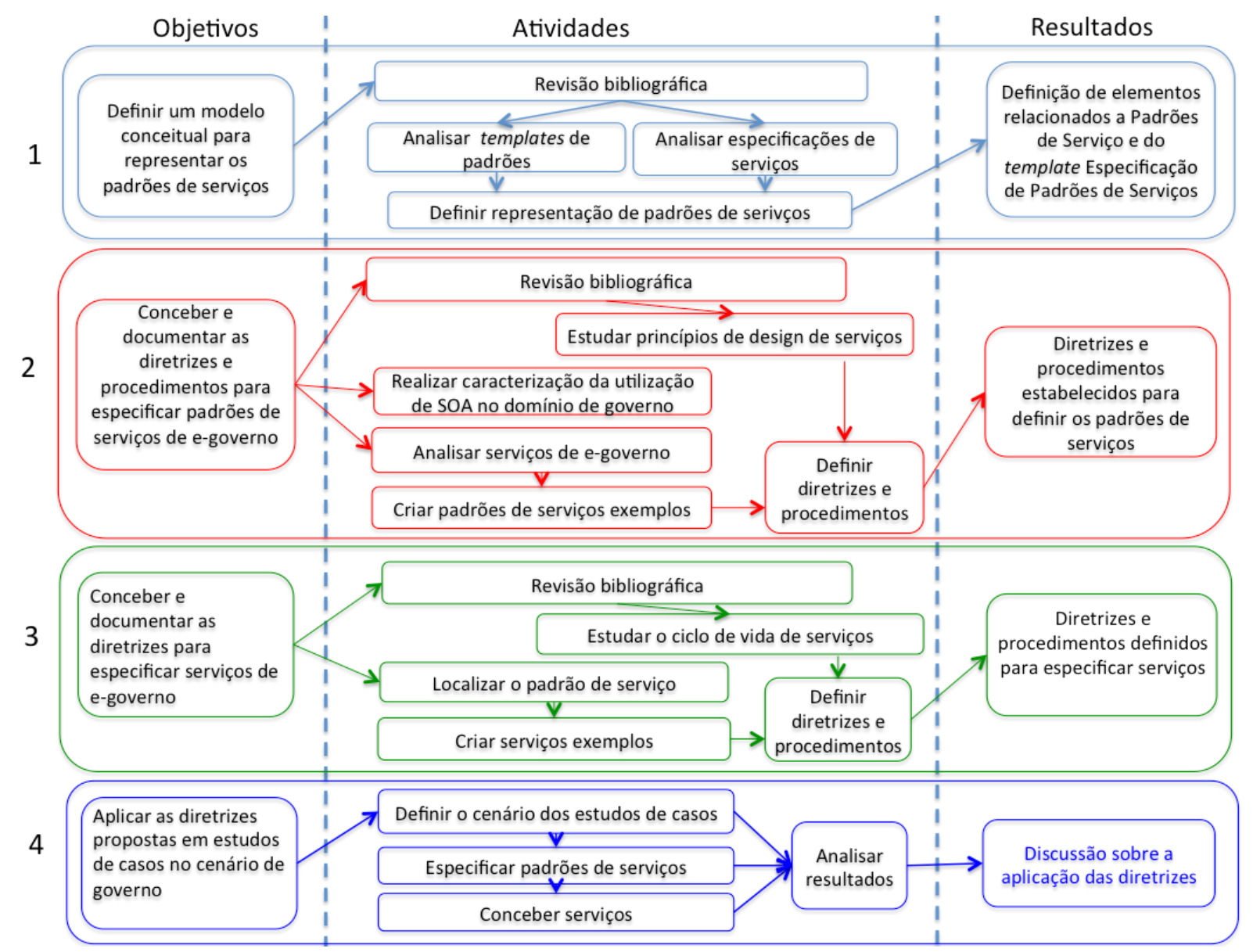

Fonte: Autor (2014)

serviços, foram criados exemplos de padrões de serviços. Inicialmente, foi realizada uma análise de serviços de e-governo, especificamente no Estado de Mato Grosso, para servir de entrada para a atividade de especificação de padrões de serviços. Após a especificação de padrões de serviços, foi possível documentar as diretrizes de padrões de serviços. Nessa fase, a revisão bibliográfica contemplou o estudo a respeito de abstração de conceitos de serviços, e os princípios de design propostos por Erl (2009b) foram estudados, para subsidiar a criação dos padrões de serviços.

A definição de diretrizes e procedimentos para especificar serviços a partir de padrões de serviços foi realizada por meio de um estudo bibliográfico a respeito de ciclos de vida de serviços, com o objetivo de visualizar onde os padrões de serviços poderiam ser utilizados como referência para a especificação de serviços. Alguns serviços foram criados a partir de padrões de serviços especificados, e as diretrizes para esta atividade foram documentadas.

Finalmente, estudos de casos foram realizados, com o objetivo de aplicar as diretrizes estabelecidas para especificar serviços de e-governo. Primeiro, 
definiu-se o cenário de governo a ser utilizado a partir dos serviços levantados, considerando-se também a área de conhecimento da autora do trabalho. Em seguida, foram especificados os padrões de serviços seguindo as diretrizes documentadas, criando-se, assim, a possibilidade de analisar as diretrizes e sugerir trabalhos futuros.

\subsection{Organização do Trabalho}

Este trabalho possui, além desta introdução, 4 capítulos, os quais estão organizados conforme descritos a seguir.

O Capítulo 2 discute aspectos conceituais relacionados aos assuntos da pesquisa, apresenta uma introdução a respeito de computação orientada a serviços, dando ênfase ao elemento serviço. Outros assuntos apresentados são as características e as abordagens de reuso de software, dentre eles, a utilização de padrões de projetos e padrões de serviços. Por fim, esse capítulo descreve o contexto de e-governo que é o cenário da pesquisa.

O Capítulo 3 apresenta uma caracterização do domínio do Governo Brasileiro em relação ao uso de SOA, introduz conceitos sobre os elementos relacionados a padrões de serviços, apresenta o template para especificação de padrão de serviço e o fluxo de atualização de padrões de serviços. Nesse Capítulo, ainda são apresentados o Modelo para Especificação de Serviços de e-Governo (MESe-Gov) e as Diretrizes para Especificação de Serviços de e-Governo (DESe-Gov). As diretrizes estão distribuídas em dois grupos: diretrizes para especificar padrões de serviços e diretrizes para criar novos serviços.

O Capítulo 4 descreve os estudos de casos em que diretrizes DESe-Gov são utilizadas para especificar três padrões de serviços e, em seguida, são apresentados os serviços criados a partir dos padrões de serviços.

No Capítulo 5, em que são apresentadas as conclusões do trabalho, são destacadas as contribuições do trabalho, as dificuldades encontradas durante a pesquisa e os trabalhos futuros que podem ser realizados para dar continuidade à pesquisa.

Finalmente, são apresentadas as referências utilizadas para a elaboração deste trabalho de pesquisa e os Apêndices que fazem parte do trabalho. 


\section{ASPECTOS CONCEITUAIS}

\subsection{Considerações Iniciais}

Neste capítulo, são abordados os conceitos que dão suporte ao desenvolvimento da tese. Inicialmente, é apresentada uma discussão sobre a computação orientada a serviços.

O elemento serviço é o principal foco das discussões e da definição sobre a computação orientada a serviços, por este ser o elemento básico da computação orientada a serviço e o foco desta pesquisa.

Lewis, Smith e Kontogiannis (2010) apresentam uma visão geral do estado atual de investigação e temas que ainda precisam ser abordados sobre o uso e a implementação de sistemas orientados a serviços. A investigação foi realizada com base em um ciclo de vida proposto para os sistemas orientados a serviços que enfatiza a relação entre a estratégia de negócio e a estratégia de SOA. A pesquisa desses autores tem como objetivo central gerar uma taxonomia classificada em temas de investigação, relacionados a aspectos de negócio, engenharia e operações de sistemas orientados a serviços.

No ciclo de desenvolvimento orientado a serviços, uma das principais atividades é a identificação de serviços, pois erros cometidos nessa atividade podem se propagar por todo o projeto (YOUSEF et al., 2009). A identificação de serviço é vista por Kang, Song e Baik (2008), Arsanjani et al. (2008) e Boerner e Goeken (2009) como um pré-requisito para implementação bem sucedida de uma arquitetura orientada a serviços, havendo a necessidade de pesquisas para o desenvolvimento de métodos eficazes para realizar essa tarefa. Marks e Bell (2006) ressaltam que as atividades de identificação, análise e projeto de serviços não são compreendidas quando o assunto é SOA, sendo por isso, geralmente considerado um dos principais desafios de SOA.

Como o objetivo desta pesquisa é subsidiar o reuso de conceitos de serviços, então uma discussão sobre reuso também é pertinente para contextualizar e posicionar a pesquisa. Uma das formas de reuso ocorre por meio do estabelecimento de padrões e, neste contexto, é proposto o uso de padrões de serviços. Por isso, é 
apresentada também uma discussão sobre o conceito de padrões de serviços.

E, finalmente, são discutidas características de e-governo, que são do domínio de estudo desta pesquisa.

\subsection{Computação Orientada a Serviços}

A computação orientada a serviços envolve conceitos entrelaçados que são originários de uma variedade de disciplinas, incluindo sistemas de computação distribuída, arquiteturas de computadores e middleware, computação em grade, engenharia de software, linguagens de programação, sistemas de banco de dados, segurança e representação de conhecimento (PAPAZOGLOU et al., 2007).

O termo computação orientada a serviços às vezes é confundido com o termo SOA e às vezes utilizados como sinônimos, embora sejam distintos. A computação orientada a serviços representa um paradigma de computação distribuída. Esse modelo de computação é composto por elementos, destacando-se, entre eles, projeto orientado a serviços, os serviços, as composições de serviços, o inventário de serviços e SOA. SOA é caracterizada pela introdução de modelo computacional para suportar a criação, a execução e a evolução das soluções orientadas a serviços. Exclusiva para cada ambiente organizacional, a implementação de uma SOA pode possuir combinações diferentes de tecnologias, produtos, Application Programming Interface (API) e infraestrutura de suporte (ERL, 2009b).

Uma visão conceitual dos elementos da computação orientada a serviços e as relações entre eles é apresentada por Erl (2009b), conforme ilustra a Figura 3. Além dos conceitos de serviços e de arquitetura orientada a serviços já apresentados anteriormente, outros conceitos inerentes deste paradigma são: lógica da solução orientada a serviços, que resulta da aplicação dos princípios de projeto orientado a serviços; a composição de serviços, que define um agregado coordenado de serviços, visando automatizar um processo de negócio por meio da reutilização de serviços existentes; o inventário de serviço, que representa uma coleção de serviços que deve estar padronizada e ser governada. Um ambiente corporativo pode ter mais de um inventário de serviços, padronizado, governado e suportado por diferentes arquiteturas tecnológicas orientadas a serviços; e o paradigma do projeto orientado a serviços, caracteriza-se por um conjunto de princípios que suportam a modelagem do projeto de serviços e de composição de serviços.

Segundo Sommerville (2007), a engenharia de software orientada a serviços tem como princípio a construção de programa por meio da composição de serviços 
Figura 3: Visão conceitual dos elementos computacionais da computação orientada a serviços e seus relacionamentos

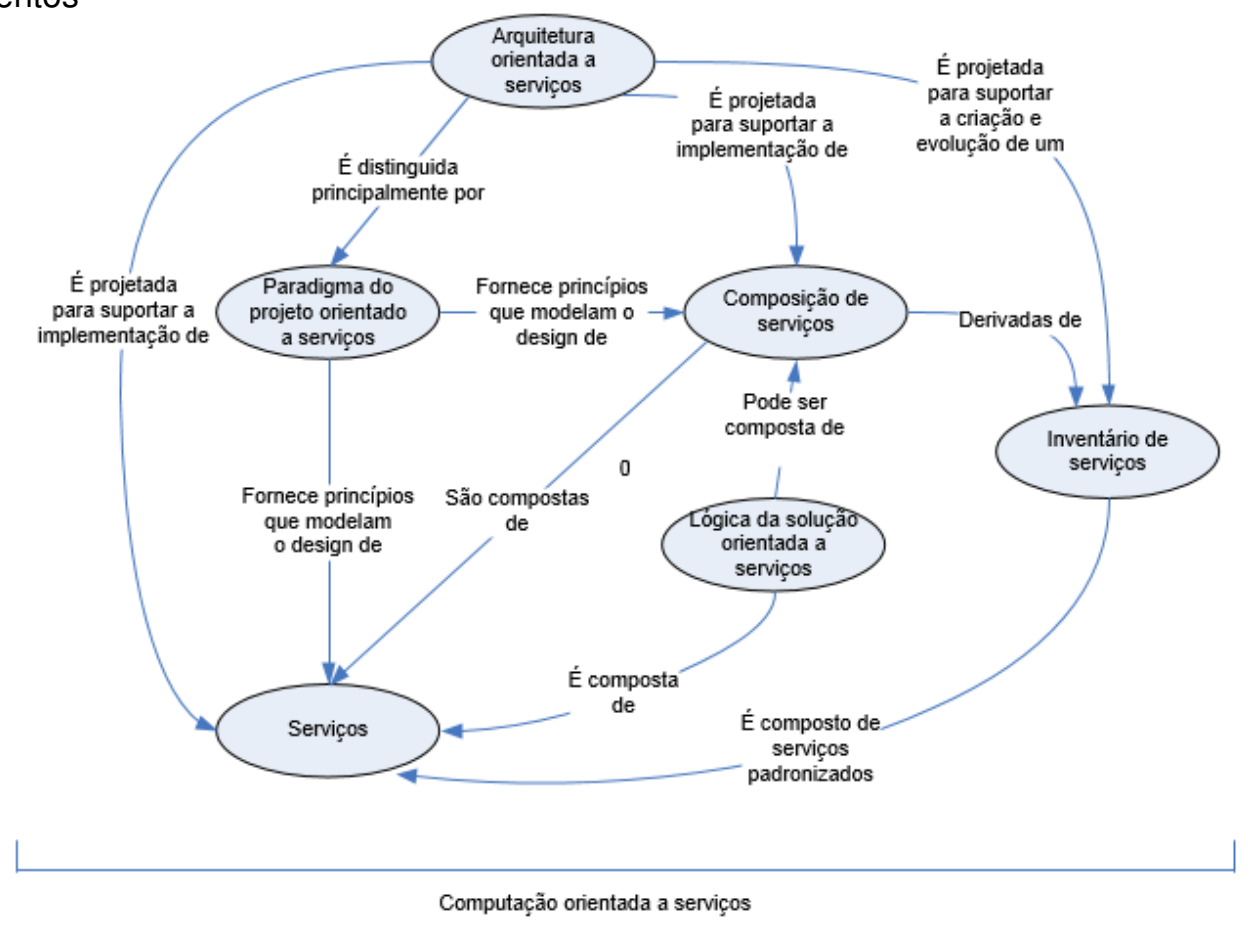

Fonte: Adaptado de Erl (2009b)

independentes que contemplam funcionalidades reusáveis.

\subsubsection{Serviço}

Segundo Erl (2009b), serviços são programas de software independentes que fornecem uma coleção de capacidades relacionadas a um contexto funcional distinto. Segundo Papazoglou et al. (2008), serviços são entidades autônomas e independentes de plataformas computacionais, que podem ser descritos, publicados, descobertos e montados dinamicamente, para desenvolver sistemas distribuídos, interoperáveis e evoluíveis.

Conforme o Modelo de Referência para SOA (OASIS, 2006), serviço é um mecanismo usado para habilitar o acesso a um conjunto de competências, em que o acesso é provido usando uma interface descrita e é consistentemente exercitada com restrições e políticas especificadas pela descrição de serviço. Para descrever melhor o serviço e suas dinâmicas, os principais conceitos contidos no modelo de referência, estão ilustrados na Figura 4.

Segundo OASIS (2006), a descrição do serviço representa as informações necessárias para sua utilização. A visibilidade expõe questões do relacionamento entre o fornecedor e o consumidor do serviço, para que estes possam interagir. A interação com um serviço é a atividade envolvida para fazer uso de uma competência 
Figura 4: Principais conceitos do Modelo de Referência OASIS

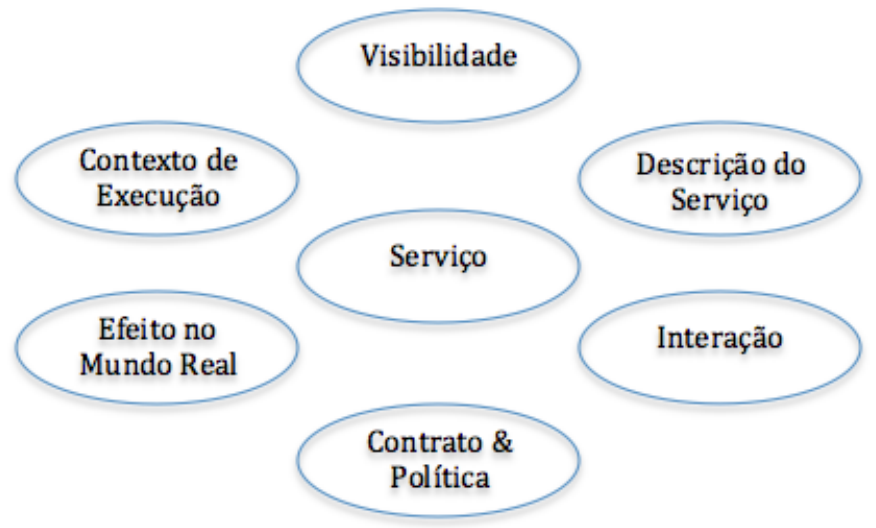

Fonte: Adaptado de OASIS (2006)

de um serviço para obter um efeito do mundo real. Em muitos casos, a interação é realizada pelo envio e recebimento de mensagens ou também é efetuada pela mudança de estado em entidade compartilhada. O efeito no mundo real representa o resultado a ser alcançado pela interação com um serviço. Um contrato representa um acordo entre as partes envolvidas, e uma política representa uma restrição ou condição de uso, distribuição ou descrição de um serviço. O contexto de execução de um serviço é o conjunto de elementos de infraestrutura, entidades de processos, políticas e acordos que são identificados como parte de uma interação com um serviço.

Segundo Erl (2009a) os tipos mais comuns de serviços são:

Serviço Utilitário - um tipo de serviço que fornece lógica de processamento genérica e não classificada como lógica de negócio.

Serviço Entidade - um tipo de serviço centrado no negócio que é derivado de uma ou mais entidades de negócio. Geralmente, as capacidades inerentes a esses serviços são as operações CRUD (Create, Read, Update, Delete) tradicionais operações criar, ler, atualizar, excluir.

Serviço Tarefa - um tipo de serviço de negócio, com escopo funcional específico a um único propósito da lógica do processo de negócio. É um serviço com escopo funcional associado a uma tarefa ou a um processo de negócio específico que controla uma composição.

O serviço tarefa tende a ter menor potencial de reuso por ser considerado responsável por compor outros serviços, enquanto os serviços entidade e utilitário são 
considerados mais reusáveis por serem passíveis de utilização em vários processos de negócio da empresa. A Figura 5 ilustra a relação entre estes tipos de serviços.

Figura 5: Camadas de abstração dos serviços

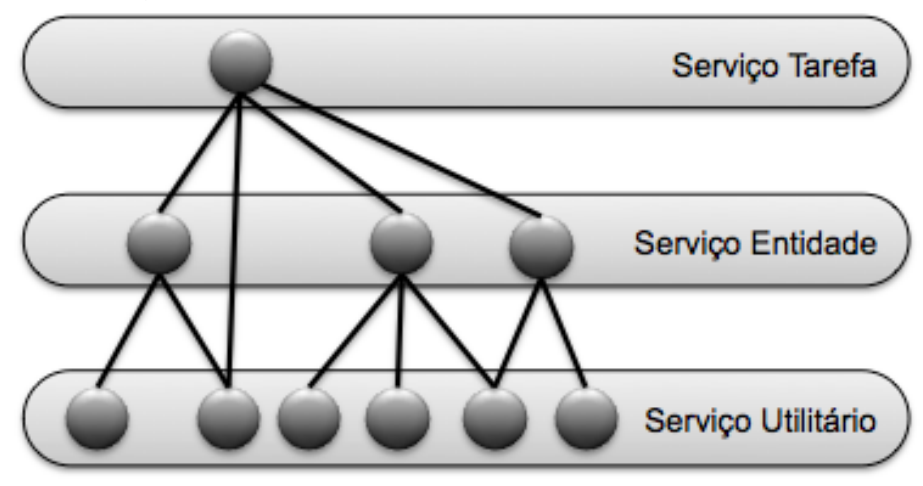

Fonte: Adaptado de Erl (2009b)

Especificamente sobre serviços utilitários de infraestrutura, também chamados de técnicos, Josuttis (2007) ressalta que, do ponto de vista puramente da SOA, estes não são serviços, pois os serviços devem sempre representar algum tipo de funcionalidade de negócio. Este pesquisador ressalta ainda que, quando a organização utiliza serviços para resolver detalhes técnicos, ela precisa conhecer essa distinção, pois serviços desse tipo não representam funcionalidades de negócio.

Segundo Marks e Bell (2006), os serviços devem atender a alguns critérios ou atributos para fornecer melhor valor à organização, tais como: granularidade alta, contrato de serviço bem definido, baixo acoplamento, detectável, durável, combinável, alinhado ao negócio, reusável e interoperável. Especificamente sobre a alta granularidade, os autores ressaltam que um serviço deve representar uma função de negócio, processos ou transações e encapsular outros componentes ou serviços de baixa granularidade.

A granularidade de serviço está relacionada à quantidade de capacidades que o serviço contempla, conforme Kim e Doh (2009). De forma semelhante, Erl (2009b) descreve que a granularidade do serviço refere-se ao escopo funcional do serviço, representando a quantidade de lógica associada ao contexto do serviço. Segundo esses autores, quanto menor a granularidade dos serviços em um inventário, maior é o número de serviços necessários para uma composição.

Não há uma regra estabelecida a respeito da definição da granularidade dos serviços. De um lado, sabe-se que serviços com baixa granularidade podem ser mais facilmente reutilizados em outros contextos; por outro lado, esses serviços podem gerar maior complexidade de composição. Já os serviços com alta granularidade, embora sejam capazes de cumprir atividades complexas, são menos flexíveis e com 
menor chance de reuso (BOERNER; GOEKEN, 2009). Conforme Kim e Doh (2009), serviço com alta granularidade geralmente requer menos tráfego de rede.

Bell (2008) ressalta a necessidade de proceder análise da granularidade do serviço na atividade de análise e descoberta de serviços, pois auxilia na observação da sua habilidade de alcançar os objetivos de negócio e de tecnologia, revelando o escopo funcional e fatores de reutilização. Além disso, ainda permite que alguns recursos sejam consolidados, bem como entender o seu valor para a organização. A análise da granularidade pode apresentar resultados imprecisos, pois não é uma ciência exata. No entanto, essa análise possibilita chegar a visualização de serviços que oferecem soluções estratégicas versus táticas, avaliar as condições de consumo do serviço e ainda identificar a sua escala de reutilização.

Além da granularidade referente ao escopo funcional de serviços, Erl (2009b) apresenta outras diferentes formas de granularidades: granularidade da capacidade - refere-se ao escopo funcional de uma capacidade do serviço; granularidade dos dados - refere-se ao volume de dados que são trocados por uma capacidade do serviço; e granularidade da restrição - refere-se ao nível de detalhes da lógica de validação definido para uma capacidade de serviço. Geralmente, quanto mais específicas são as limitações e maior o número delas, mais fina é a granularidade da restrição.

Segundo Kim e Doh (2009), a dificuldade a respeito do estabelecimento da granularidade de serviço ocorre em função de o serviço poder suportar uma atividade de negócio, várias atividades ou mesmo um processo de negócio inteiro. Então, a granularidade de serviço está relacionada à determinação tanto do número de serviços necessários para cumprir o processo de negócio, como a cobertura de cada serviço. Uma atividade de negócio é vista como a menor unidade que faz sentido para um usuário, mas não descreve um fluxo de negócio completo.

\subsubsection{Princípios de Projeto de Serviços}

Conforme Erl (2009b), um princípio representa uma boa prática que deve ser adotada para se alcançar um objetivo. Um princípio de projeto representa uma diretriz recomendável para dar forma à lógica da solução orientada a serviços.

Os princípios de projeto podem ser agrupados em duas categorias: os princípios que adicionam características específicas de projeto, e os princípios que modelam e regulam a aplicação de outros princípios. Conforme ilustra a Figura 6, os princípios à direita adicionam características físicas ao projeto do serviço, enquanto 
os princípios à esquerda agem mais como influências reguladoras para que tais características sejam implementadas de maneira apropriada.

Figura 6: Princípios de projeto de serviços

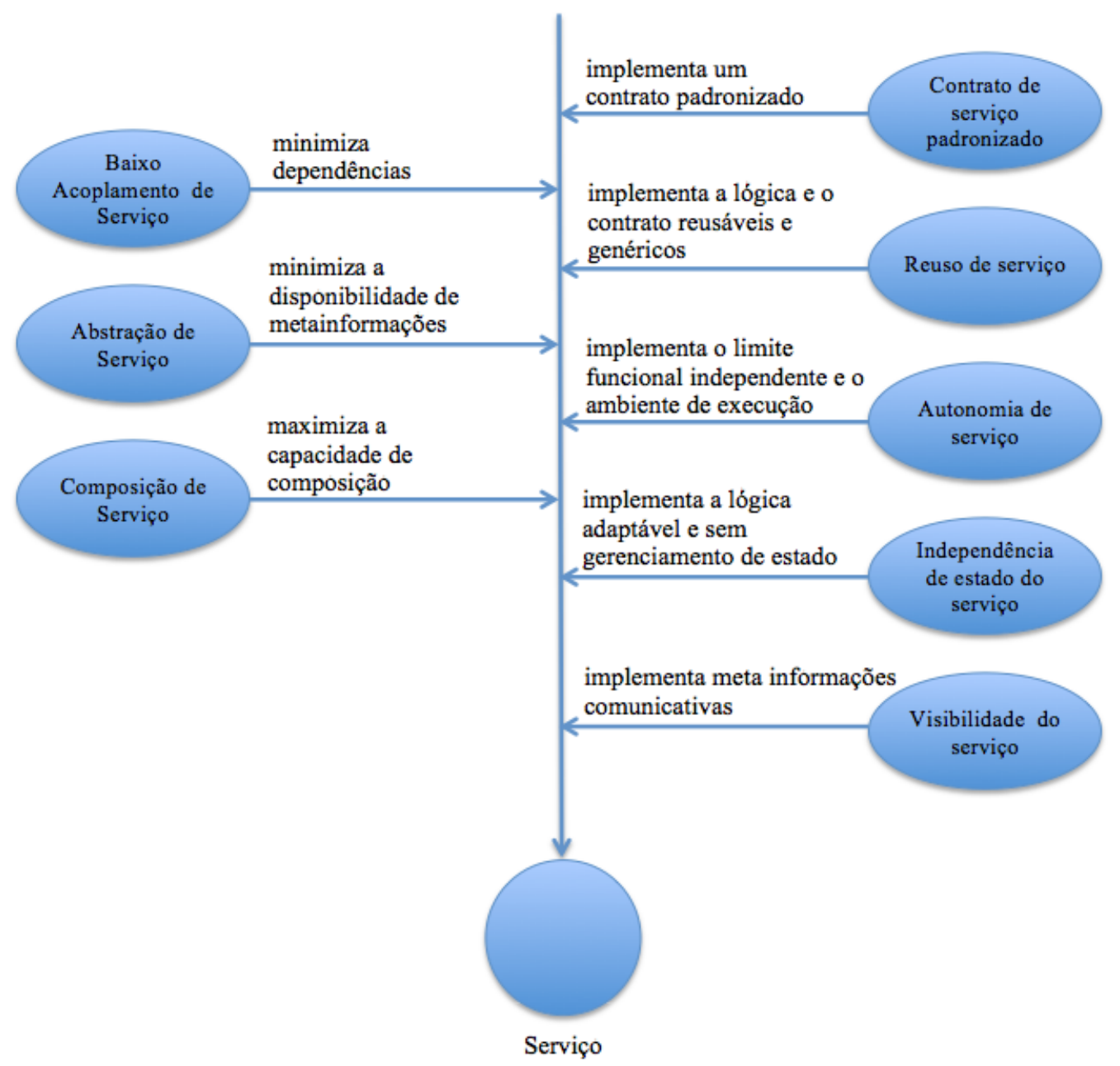

Fonte: Adaptado de Erl (2009b)

Em relação às características físicas do projeto, é recomendado: (1) o baixo acoplamento de serviço, para que serviços e consumidores possam evoluir causando mínimo impacto sobre o outro; (2) somente as informações essenciais do serviço devem ser publicadas em seu contrato, e as demais informações consideradas privadas não devem ser disponibilizadas, a fim de se evitar o acesso desnecessário a detalhes do serviço; e ainda, (3) os serviços devem ser projetados para que possam participar de composições, independente do seu tamanho ou complexidade. Os objetivos estratégicos desse princípio estão fortemente relacionados ao princípio de reuso, pois a composição de serviços acaba sendo uma forma de reuso de serviço. Por meio da composição, é possível atingir o objetivo final da computação orientada a serviços, que é ter inventário de serviços altamente reusáveis, para atender novas 
demandas de negócio.

A composição de serviços pode seguir duas abordagens: orquestração e coreografia. A orquestração, realizada por meio de um serviço controlador, representa um processo de negócio executável que pode resultar em uma longa transação, envolvendo atividades do processo de negócio. Nessa abordagem, as interações de processos de negócios são sempre controladas a partir da perspectiva de uma das partes empresariais envolvidas no processo. Coreografia está associada à troca de mensagens públicas, as regras de interação e acordos que ocorrem entre múltiplos processos de negócios, em vez de um processo de negócio específico executado a partir da perspectiva de um controlador (PAPAZOGLOU et al., 2008).

Os princípios que agem como influências reguladoras postulam que: (1) dentro de um inventário de serviços, todos os contratos dos serviços devem ser padronizados, contendo declarações das funcionalidades, tipos de dados, modelos de dados e políticas; (2) a capacidade de reuso do serviço seja alcançada e, para que isso ocorra, a lógica do serviço deve ser a mais genérica possível, o contrato do serviço deve ser flexível o bastante para processar vários tipos de mensagens de entrada e saída, e ainda os serviços devem ser projetados de modo a facilitar o acesso simultâneo por consumidores; (3) um serviço autônomo concentra-se na sua lógica e nos recursos que ele pode precisar em tempo de execução; (4) os serviços devem ser criados sempre que possível, sem reter informações de estado, pois a dependência de estado de serviço pode comprometer a escalabilidade do serviço; e (5) os serviços devem ser facilmente descobertos e interpretados, suas capacidades e propósitos devem ser claramente expressos, para que estes possam ser entendidos.

Esses princípios, de alguma maneira, suportam ou contribuem para a interoperabilidade de serviços. A interoperabilidade de serviços representa um objetivo fundamental da orientação a serviços e estabelece a base para atingir os benefícios estratégicos da computação orientada a serviços.

\subsubsection{Ciclo de Vida de Serviços}

Os ciclos de vida tradicionais para o desenvolvimento de software, tais como, ciclo de vida cascata, desenvolvimento evolucionário, desenvolvimento de software baseado em Componentes (SOMMERVILLE, 2007) não podem ser aplicados diretamente no desenvolvimento orientado a serviços, em função dos novos papéis arquiteturais e tarefas de desenvolvimento contidas no ciclo de desenvolvimento orientado a serviços (GU; LAGO, 2007). Os papéis arquiteturais são, por exemplo, os 
fornecedores e consumidores de serviços. Alguns novos desafios também precisam ser considerados no paradigma orientado a serviços, como, por exemplo, alinhar os requisitos de negócio com soluções de TIC e gerenciar os serviços distribuídos além das fronteiras da organização.

Segundo Sommerville (2007), a engenharia de software orientada a serviços tem como princípio a construção de programa por meio da composição de serviços independentes que contemplam funcionalidades reusáveis. Especificamente para a engenharia de serviços, o processo apresenta aspectos comuns com a engenharia de componentes, pois os serviços devem ser desenvolvidos visando ao reuso. Conforme Gu e Lago (2007), não há um consenso para um modelo de ciclo de vida de serviços e, na maioria das vezes, as que existem são abstratas.

Entre os ciclos de vida relacionados a serviços, as principais referências encontradas na literatura são os descritos a seguir:

- Marks e Bell (2006) apresentam um ciclo de vida de serviços em que as atividades de identificação, análise e projeto de serviço são detalhadas. Os autores dão atenção especial ao controle de granularidade do serviço a ser desenvolvido.

- Gu e Lago (2007) apresentam um ciclo de vida orientado a stakeholders: fornecedor de serviços, broker de serviços e consumidor de serviços. As fases do ciclo de vida são: Projeto, Execução e Mudança de Serviço. Porém, não foi observada no ciclo de vida a presença de uma atividade de identificação e análise de serviços. Após a modelagem de negócio, a atividade subsequente é a de projeto de serviços.

- Arsanjani et al. (2008) apresentam um método para o desenvolvimento de soluções orientadas a serviços, o Service-Oriented Modeling and Architecture (SOMA). Nesse método é proposto um ciclo de vida de desenvolvimento de soluções orientadas a serviços e é organizado pelas seguintes fases: Transformação e modelagem de negócio, Identificação, Especificação, Realização, Implementação e Implantação, monitoramento e gestão de serviços. Nesse ciclo de vida, as atividades inerentes à Identificação e Especificação de serviços são apresentadas de forma detalhada, conforme descrito na Seção 2.2.4.

- No ciclo de vida proposto por Erl (2009b), o foco principal são as atividades de análise e projeto em que os serviços são identificados e especificados. O autor ressalta a necessidade do uso de princípios de projeto SOA e descreve de forma detalhada a modelagem de serviços. 
Na Tabela 1 estão descritos os aspectos analisados nos ciclos de vida e organizados segundo os seguintes critérios:

Nível de detalhe do ciclo de vida: representa o nível de detalhe descrito no ciclo de vida, podendo ser baixo, médio ou alto.

Detalhamento da atividade de identificação de serviços: se os ciclos de vida analisados apresentam uma descrição detalhada da atividade de identificação de serviços.

Contempla fases no ciclo de vida: se o ciclo de vida analisado está descrito e organizado por fases.

Aborda tecnologia: se o ciclo de vida analisado contém referência a uso de alguma tecnologia específica.

Tabela 1: Comparação de modelos de ciclos de vida de serviços

\begin{tabular}{|c|c|c|c|c|}
\hline Modelo & $\begin{array}{l}\text { Nivel de } \\
\text { detalhe do } \\
\text { ciclo de vida }\end{array}$ & $\begin{array}{l}\text { Detalhamento da } \\
\text { atividade de } \\
\text { identificação e } \\
\text { análise de serviços }\end{array}$ & $\begin{array}{l}\text { Contempla fases } \\
\text { no ciclo de vida }\end{array}$ & $\begin{array}{l}\text { Aborda } \\
\text { tecnologia }\end{array}$ \\
\hline Gu e Lago (2007) & Médio & Não & Sim & Não \\
\hline Marks e Bell (2006) & Alto & Sim & Sim & Não \\
\hline $\begin{array}{l}\text { Arsanjani et al. } \\
(2008)\end{array}$ & Alto & Sim & Sim & Sim \\
\hline Erl (2009b) & Médio & Sim & Não & Sim \\
\hline
\end{tabular}

Fonte: Autor (2014)

Entre os ciclos de vida de serviços analisados, será utilizado como base neste trabalho o modelo de ciclo de vida proposto por Marks e Bell (2006) para demonstrar o uso de padrões de serviços. A escolha foi feita considerando: (1) que esse modelo apresenta diversas fontes de identificação de serviços; e (2) é uma alternativa mais abstrata de desenvolvimento orientado a serviços, pois não está vinculado a uma tecnologia específica.

Marks e Bell (2006) propõem um ciclo de vida para serviços, conforme Figura 7, que compreende a evolução dos serviços desde a sua concepção até a sua maturidade, passando pela sua execução. Esse ciclo de vida de serviços é iterativo e dividido em dois domínios: domínio do problema, em que as atividades resultam nos serviços de negócio candidatos ou potenciais; e domínio da solução, partindo dos serviços de negócio candidatos, esse domínio contempla as atividades de projeto de serviços, implementação e integração, que resultam em uma solução física de serviços.

Esse ciclo de vida contempla as fases Motivação, Conceituação, Modelagem e Realização de serviços e Gestão do Ciclo de Vida de Serviços. A motivação consiste 
Figura 7: Ciclo de vida de serviços

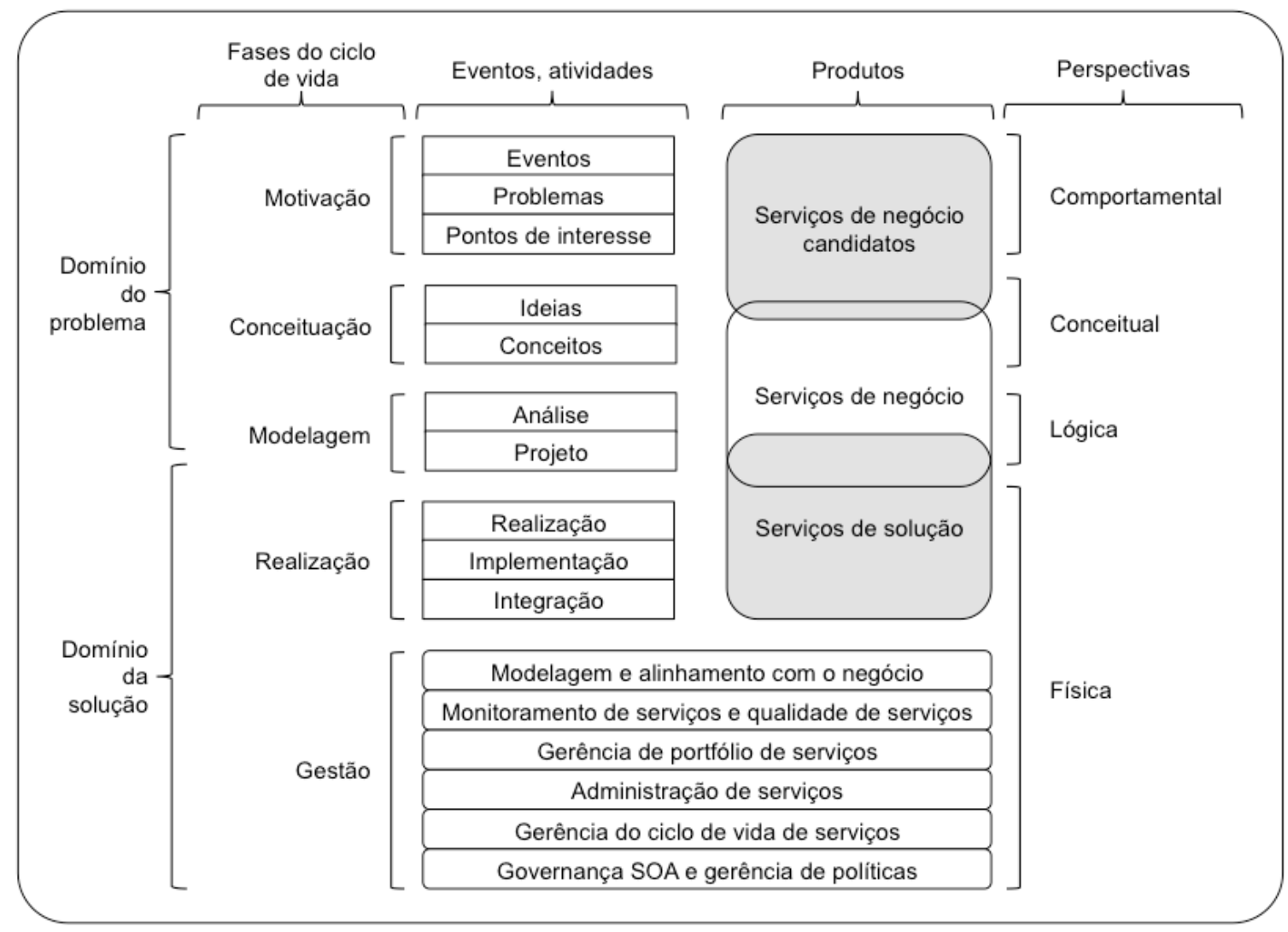

Fonte: Adaptado de Marks e Bell (2006)

nas forças motivadoras, eventos (tendências de mercado, ameaças competitivas, etc.), necessidades de negócio e de TIC e problemas que influenciam a criação de novos serviços. Na fase de conceituação, são levantadas ideias e definidos os conceitos. As ideias são as soluções iniciais imaginadas para atendimento das motivações levantadas na fase anterior, enquanto os conceitos são ideias formalizadas e estabelecidas em propostas de soluções para o negócio. A fase de modelagem dos serviços envolve atividades de análise e projeto dos serviços de negócio candidatos. Na fase de realização, finaliza-se o projeto dos serviços, os serviços são implementados e se realiza a integração de serviços. A saída da fase de realização são as soluções de serviços que se tornarão serviços físicos quando estiverem implementados. Na fase de gestão, as atividades de gerenciamento e suporte de serviços abrangem todas as fases do ciclo de vida do serviço. Isso significa que existem atividades de gestão que devem ser executadas desde o levantamento das motivações para implantação de SOA até quando existirem serviços rodando. Nessa fase, as atividades são centradas em modelagem e alinhamento com o negócio, operação e gestão de serviços, monitoramento de serviços e qualidade de serviços, gerência de portfólio de serviços, administração de serviços, gerência de ciclo de vida 
e governança SOA, e gerência de políticas.

Marks e Bell (2006) ressaltam que às vezes é desafiador definir os serviços iniciais no contexto de SOA, mas isso não deveria acontecer. A atividade de identificação de serviços de negócio candidatos deve ser conduzida de forma top-down, inicialmente, com foco em serviços de negócio candidatos, com a orientação de que sejam identificados serviços que deem suporte ao modelo de processo de negócio. Não é preciso considerar inicialmente o ambiente físico ou técnico, uma vez que o objetivo se concentra nos esforços em serviços com alto valor para a organização, classificados por valor ao negócio, impacto ao negócio, potencial de reutilização e viabilidade técnica.

Segundo Marks e Bell (2006), o processo de transição da modelagem de negócio SOA, identificação de serviços e modelagem de serviços é ilustrado na Figura 8. Para identificar novos serviços de negócio candidatos, geralmente há seis possíveis caminhos: processo de negócio, entidades de negócios, experiência no domínio de negócio, serviços pré-existentes, aplicações de negócio existentes e projetos orçados. A respeito do uso de projetos orçados, o autor ressalta que se basear em um conjunto de prioridades de negócios estabelecidas no projeto pode não ser o ideal, pois as prioridades de negócio podem mudar em função da análise dos serviços.

Figura 8: Identificação de serviços de negócio candidatos

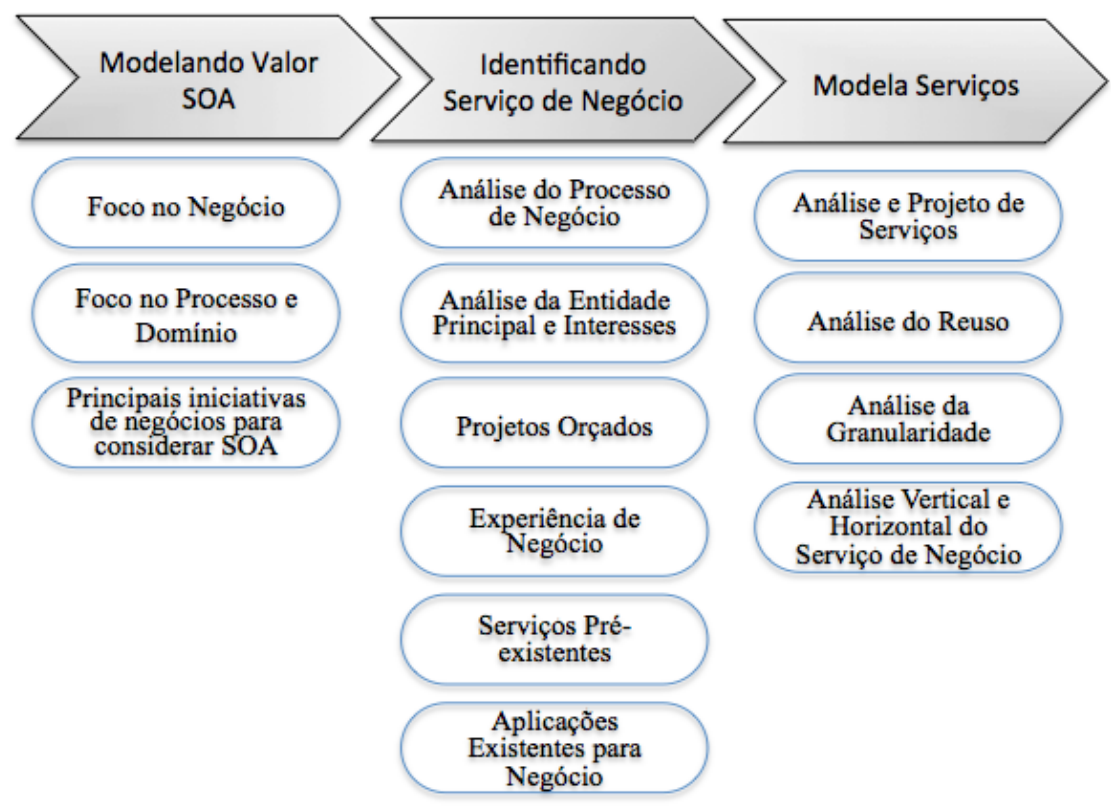

Fonte: Adaptado de Marks e Bell (2006)

Após a identificação dos serviços de negócios candidatos, os serviços devem ser analisados antes de serem projetados para a implementação. O principal foco dessa análise é transformar os serviços candidatos em serviços de negócios finais e, 
para isso, primeiro, avalia-se as funcionalidades de cada serviço de negócio candidato e elabora o mapa de granularidade dos serviços, posicionando os serviços de acordo com a sua escala de granularidade e, em seguida, são aplicadas operações lógicas sobre os serviços de negócio candidatos. As operações lógicas (união, intersecção, decomposição, subconjunto, entre outras) são aplicadas com o objetivo de agregar e fragmentar os serviços de negócio candidatos, reorganizando as suas operações e dando origem aos serviços de negócio finais. Na atividade de análise de serviços, o objetivo também é controlar a granularidade e o potencial de reuso dos serviços de negócio candidatos.

Considerando que o objetivo desta pesquisa é auxiliar a especificação de serviços de negócio, não serão descritas as demais atividades do ciclo de vida de serviços. Na atividade de projeto, inicia-se a transformação dos serviços de negócio em serviços de soluções concretas.

\subsubsection{Abordagens para Identificar Serviços}

Embora a identificação de serviços possa utilizar diferentes abordagens, top-down, bottom-up e a junção das duas abordagens, denominada meet-in-the-middle, Inaganti e Behara (2007) ressaltam que a abordagem top-down dirigida a processo de negócio - é a prática mais recomendada para iniciar a adoção de SOA nas corporações.

Com o objetivo de sistematizar a tarefa de identificação e definição de serviços, algumas estratégias ou caminhos citados na literatura são discutidos a seguir.

Serviços podem ser originados a partir da decomposição do processo de negócio, funções de negócio e metas. A decomposição do processo de negócio tem como objetivo subdividir o processo de negócio em subprocessos ou decompor em tarefas e atividades granulares. As tarefas de nível mais baixo podem consistir de pequenas e coesas unidades lógicas de trabalho que são suportadas pelas funcionalidades oferecidas por serviços distintos. De forma similar, a decomposição funcional de negócio e de metas tem por objetivo chegar as funções e metas de níveis mais detalhados que possam ser traduzidos em serviços (HUBBERS; LIGTHART; TERLOUW, 2007).

Serviços baseados em entidade de negócio podem ser identificados comumente exigindo funções do tipo CRUD. Essa abordagem depende da utilização de modelos de dados canônicos (ou em inglês, Canonical Data Models - CDM), que 
padronizam as informações trocadas entre serviços (HUBBERS; LIGTHART; TERLOUW, 2007).

Outra estratégia para identificar serviços se baseia em componentes, pois a essência destes é dividir as funcionalidades de tecnologia de informação e comunicação em unidades com o máximo de coesão interna e o mínimo de acoplamento. $O$ benefício do estabelecimento de serviços de componentes refere-se à atividade de identificação de serviço, que é bastante simplificada. A maior parte do trabalho de análise se realiza como parte do método de desenvolvimento baseado em componentes (HUBBERS; LIGTHART; TERLOUW, 2007).

Serviços também podem ser identificados a partir de funcionalidades existentes em sistemas legados e transformar essas funcionalidades em serviços para uma plataforma SOA, apresentam os seguintes desafios: (1) definir o que pode ser migrado dos sistemas legados para a plataforma SOA; (2) como os códigos reutilizáveis dos sistemas legados podem ser identificados; e (3) como o código reutilizável pode ser migrado e integrado para arquitetura orientada a serviços (CHEN et al., 2009).

Outra abordagem é a análise do uso de aplicações front office, que tem como objetivo selecionar um conjunto de aplicações que apoiem os processos de negócio e definir uma lista de operações realizadas pelo conjunto de aplicações. Em seguida, devem-se eliminar as operações redundantes e combinar as funções comparáveis em serviçOS (HUBBERS; LIGTHART; TERLOUW, 2007).

Quando se utiliza a abordagem de identificação de serviços baseada em infraestrutura, os serviços nem sempre podem ser identificados de forma independente da infraestrutura técnica que está sendo usada. Nesse caso, os serviços estão vinculados e dependentes de recursos técnicos (HUBBERS; LIGTHART; TERLOUW, 2007). Geralmente, esses serviços são classificados como serviços utilitários.

Segundo Mani et al. (2008), o projeto de interface de usuário também pode ser utilizado para identificar serviços de negócio e de informação. Essa abordagem consiste em buscar, no projeto de interface de usuário, as necessidades dos serviços de informações a partir dos dados que são exibidos nessa interface e identificar as necessidades de serviços de negócio a partir dos fluxos de navegação entre as interfaces e das relações entre a interface do usuário e do modelo de processo de negócio. Para possibilitar extrair essas informações, foi proposta uma linguagem de especificação de projeto de interface - Unified User Interface Design Specification (UUIDS) - que permite que um modelo de interface de usuário possa ser especificado no âmbito dos dados e modelo de processo de negócio. 
Hubbers, Ligthart e Terlouw (2007) destacam, ainda, o uso de requisitos não funcionais como entrada para a identificação de serviços. Esses requisitos segundo esses pesquisadores, podem ser utilizados em conjunto com outras estratégicas. A partir de um conjunto de serviços candidatos, deve ser verificado se os requisitos não funcionais podem ser atendidos ou se os serviços precisam ser redefinidos.

Trabalhos na literatura abordam a atividade de identificação de serviços no ciclo de desenvolvimento orientado a serviços, destacando-se entre eles:

- Azevedo et al. (2009) propõem o uso de heurísticas para identificar serviços, as quais direcionam a identificação de serviços a partir de modelos de processos de negócio, modelado em Event-driven Process Chains (EPC).

- Um guideline é proposto por Shirazi, Fareghzadeh e Seyyedi (2009), para possibilitar a identificação de serviços, utilizando duas abordagens: top-down e bottom-up. O objetivo dessa proposta é utilizar a abordagem bottom-up para identificar os serviços das aplicações e serviços de entidade, e a abordagem top-down para reconhecer os serviços de negócios e serviços voltados para tarefas.

- No trabalho de Dwivedi e Kulkarni (2008), o objetivo é identificar os serviços a partir de mapas de processos de negócio especificados em Unified Modeling Language (UML), utilizando hierarquias de serviços.

- A proposta de Yousef et al. (2009) é gerar um modelo de serviços utlizando um framework denominado BPAOntoSOA. Este framework é conduzido por ontologia, que tem como entrada uma arquitetura de processo de negócio da organização, no qual os processos de negócio são modelados utilizando a Business Process Model and Notation (BPMN).

- Arsanjani et al. (2008) apresentam um conjunto de técnicas complementares para identificação de serviços, citando três delas: (1) Goal-Service Modeling - a recomendação é definir os serviços alinhados aos objetivos de negócio da organização; (2) Decomposição do domínio - realizada por meio de uma análise top-down de domínios de negócio e modelagem de processos de negócio para que sejam identificados os serviços, componentes e fluxos; e (3) Análise do ativo existente - realizada por meio da análise bottom-up do portfólio de aplicativos existentes e dos padrões que podem ser utilizados para expor serviços candidatos. Após aplicadas as técnicas descritas, o método contempla também as atividades de refatoração e racionalização do serviço, no qual 
a granularidade de serviço é determinada.

- Kang, Song e Baik (2008) propõem um método de identificação de serviços utilizando ontologias para linha de produtos. Trata-se de um método composto pelas atividades: (1) agrupamento de características e conceitos relacionados ao serviço, dando origem aos serviços candidatos; (2) refinamento dos serviços candidatos, a fim de que os serviços sejam altamente coesos e fracamente acoplados; e (3) avaliação dos serviços, classificando-os segundo seus níveis de reusabilidade na linha de produto de software.

- Inaganti e Behara (2007) propõem uma metodologia para identificar serviços, utilizando duas abordagens: (1) top-down, orientada a processo de negócio e a casos de uso; e (2) bottom-up, análise das aplicações existentes.

- Kannan e Srivastava (2008) apresentam uma abordagem para abstração de serviços a partir de diagramas da UML. A proposta é extrair conceitos de domínio a partir de diagramas de classe e de sequência, e extrair abstrações de serviços a partir de diagrama de interação, como, por exemplo, o diagrama de sequência.

Nas abordagens de identificação de serviços apresentadas, foram observados os seguintes artefatos de software utilizados como entrada para a análise: modelo de processo de negócio, casos de uso, interface do usuário, entidades de negócio, regras de negócio, diagrama de fluxo de dados, sistemas legados (documentação e código fonte) e metas da organização. Os trabalhos que utilizam os processos de negócio para extrair os serviços têm os modelos elaborados, utilizando a notação: BPMN, EPC e Diagrama de Atividade da UML.

Conforme Ma et al. (2009), apesar de a maioria das metodologias de projeto para SOA defender que serviços sejam identificados a partir da decomposição top-down dos processos de negócio, a qualidade dos serviços identificados nessas metodologias depende da experiência individual do projetista.

Neste trabalho, que propõe uma abordagem complementar para identificação e especificação de serviços, outro artefato será utilizado como entrada para a identificação de serviços: o catálogo de padrões de serviços. 


\subsubsection{Especificação de Serviços}

Com o objetivo de entender os atributos utilizados para descrever serviço, foram analisados: o template Documentação de Serviços de Interoperabilidade do Governo Federal do Brasil ${ }^{1}$ (BRASIL, 2013a) e as informações recomendadas por Erl (2009b). Na Tabela 2, estão todos os atributos indicados pelas duas propostas de documentação de serviços.

Tabela 2: Atributos para descrição de serviços

\begin{tabular}{|c|c|c|}
\hline Atributos & $\begin{array}{l}\text { Documentação de } \\
\text { Serviços de } \\
\text { Interoperabilidade } \\
\text { (BRASIL, 2013) }\end{array}$ & $\begin{array}{l}\text { Especificação } \\
\text { de Serviços } \\
\text { (Erl, 2009b) }\end{array}$ \\
\hline Identificação do Orgão (Poder e Esfera, Contato do órgăo) & $\mathrm{X}$ & - \\
\hline $\begin{array}{l}\text { Identificação do Sistema (Sigla do Sistema, Nome do } \\
\text { Sistema, Descriçåo, Estruturante, Contato do Sistema) }\end{array}$ & $\bar{X}$ & - \\
\hline \multicolumn{3}{|l|}{ Serviço } \\
\hline Nome do Serviço & $\bar{X}$ & $\bar{X}$ \\
\hline Data de inicio de capacidade do Serviço & $\mathrm{X}$ & - \\
\hline Descrição do Serviço & $\mathrm{X}$ & $\mathrm{X}$ \\
\hline Versåo do Serviço & $\mathrm{X}$ & $\bar{X}$ \\
\hline Requisitos e orientaçóes para o acesso & $\bar{X}$ & - \\
\hline Acordo de Nivel de Serviço (ANS) proposto & $\mathrm{X}$ & - \\
\hline Contato do Serviço & $\bar{X}$ & - \\
\hline Assunto do Serviço & $\bar{X}$ & - \\
\hline $\begin{array}{l}\text { Classificaçåo do Serviço (Base de dados oficial, Acesso } \\
\text { público, Propriedade das Tecnologias em uso) }\end{array}$ & $\mathrm{X}$ & - \\
\hline Endereço da Documentaçăo do Serviço & $\bar{X}$ & - \\
\hline Endereço do arquivo WSDL & $\mathrm{X}$ & - \\
\hline Tabela de Erros & $\mathrm{X}$ & \\
\hline Modelo de Serviço & - & $\bar{X}$ \\
\hline Requisitos QOS & - & $\bar{X}$ \\
\hline Palavras-Chave & - & $\mathrm{X}$ \\
\hline Status & - & $\bar{X}$ \\
\hline Administrador & - & $\mathrm{X}$ \\
\hline Versão do Serviço & $\mathrm{X}$ & $\mathrm{X}$ \\
\hline \multicolumn{3}{|l|}{ Operaço̊es } \\
\hline Nome da Operação & $\bar{X}$ & $\bar{X}$ \\
\hline Nome da Operação na interface do serviço & $\mathrm{X}$ & - \\
\hline Descriçăo da Operação & $\mathrm{X}$ & $\bar{X}$ \\
\hline Parâmetro(s) de entrada e Parâmetro(s) de saída & $\mathrm{X}$ & $\mathrm{X}$ \\
\hline Papel da Composiçăo & - & $\bar{X}$ \\
\hline Capacidade dos Membros da Composição & - & $\mathrm{X}$ \\
\hline Requisitos de QoS & - & $\mathrm{X}$ \\
\hline Palavras-chave & - & $\bar{X}$ \\
\hline Versão da capacidade & - & $\bar{X}$ \\
\hline Status da capacidade & - & $\bar{X}$ \\
\hline Administrador da capacidade & - & $\mathrm{X}$ \\
\hline Tipo de serviço & $\bar{X}$ & - \\
\hline Endereço eletrônico (arquivo ou serviço) & $\bar{X}$ & - \\
\hline
\end{tabular}

Fonte: Autor (2014)

A descrição detalhada dos atributos propostos por Erl (2009b) estão descritos no Apêndice $\mathrm{E}$.

\footnotetext{
${ }^{1}$ Template Documentação de Serviços de Interoperabilidade disponível em http://catalogo.governoeletronico.gov.br/
} 
Ao descrever os atributos que devem ser utilizados para representar os serviços, Erl (2009b) utiliza o termo capacidade para descrever as funções que um serviço pode oferecer. Esse autor ressalta que um serviço dispõe de capacidades, independentemente de como o serviço seja implementado, enquanto a operação de um serviço representa a implementação de uma capacidade do serviço em Web Service. Neste trabalho, para representar as funcionalidades que um serviço pode oferecer, será utilizado o termo operação. Já o termo capacidade, neste trabalho, é usado conforme o seguinte conceito descrito em OASIS (2012): um efeito do mundo real que um prestador de serviços é capaz de fornecer a um consumidor de serviços.

As informações básicas coincidentes nas duas propostas de documentação de serviços são: nome, descrição e versão do serviço, e as informações para contatar o responsável pelo serviço. A forma de descrever as operações dos serviços tem alguns aspectos coincidentes nos dois trabalhos: nome da operação, descrição da operação, parâmetros de entrada e parâmetro de saída da operação.

O template Documentação de Serviços de Interoperabilidade possui informações específicas sobre o domínio de governo, como: (1) a identificação do órgão; (2) assunto do serviço, que se refere a identificação das áreas temáticas referentes às informações disponibilizadas no serviço; (3) classificação do serviço quanto à base de dados oficial, ao acesso público e à propriedade das tecnologias em uso; e (4) informações sobre a identificação do sistema fornecedor do serviço. São requeridas também informações sobre data de início de operação do serviço, requisitos e orientações para o acesso ao serviço e acordo de nível de serviço, no qual deve conter as garantias sobre o funcionamento do serviço.

O fato de o template Documentação de Serviços de Interoperabilidade ser utilizado para descrever serviços interoperáveis, independente de tecnologia, as informações a seguir somente são preenchidas caso o serviço seja implementado em Web Services: endereço da documentação do serviço, endereço do Web Services Description Language (WSDL), tabela de erros, nome da operação do serviço, nome da operação na interface do serviço, descrição da operação do serviço e parâmetro(s) de entrada e parâmetro(s) de saída. Caso o serviço não seja um Web Service as seguintes informações são preenchidas: (1) tipo do serviço, se é download de dados (FTP, download, etc..) ou protocolo de comunicação entre computadores, e (2) endereço eletrônico de acesso ao serviço ou arquivo.

Nas suas recomendações, Erl (2009b) acrescenta as seguintes informações para descrever os serviços: (1) modelo de serviço para representar entidade, recurso, tarefa, tarefa orquestrada ou variação personalizada (simbologia adaptada); 
(2) requisitos de qualidade de serviço (QoS), que representa a qualidade esperada dos vários requisitos, características ou limitações as quais afetam o serviço como um todo; (3) uma ou mais palavras-chave definidas com base na taxonomia ou no vocabulário oficial do inventário de serviços; e (4) situação do serviço quanto às fases do ciclo de vida de desenvolvimento do serviço.

Em relação às informações das operações do serviço, Erl (2009b) recomenda que, além do nome, descrição e parâmetros de entrada e saída, as operações devem conter: (1) informações sobre a composição do serviço (papel da composição e operações dos membros da composição). A execução da lógica da operação pode adicionar papéis temporários ao serviço, como, por exemplo, membro da composição, controlador da composição, subcontrolador da composição, etc. Quando a operação que está sendo documentada depende de outras operações de serviço, estas devem ser listadas no atributo Operações dos Membros da Composição; (2) descrição dos detalhes da qualidade da operação do serviço, sendo que, em alguns casos, a qualidade da operação precisa ser derivada dos detalhes dos requisitos no nível do serviço; (3) As palavras-chave da operação; (4) versão da operação; (5) situação da operação; e (6) nome do administrador da operação. Frequentemente, o administrador do serviço é o administrador das operações, porém segundo Erl (2009b), quando vários peritos do negócio e especialistas em tecnologia trabalham em conjunto em um dado serviço, pode haver responsáveis distintos para as operações do serviço.

Esses atributos analisados deram suporte à definição do template Especificação de Padrão de Serviço.

\subsubsection{Linguagem de Descrição de Serviços}

Segundo Papazoglou e Heuvel (2007), Web Service é um recurso tecnológico baseado no conceito de computação orientada a serviços, com a promessa de aumentar o compartilhamento, reuso e interoperabilidade dos serviços.

Web Service tem independência de plataforma e linguagens de programação, possibilidade de expor funcionalidades de aplicações como serviço pela Internet e uso de padrões abertos.

As características e funcionalidades da tecnologia de Web Service, segundo Wang e Qian (2005), contemplam:

- portabilidade e interoperabilidade da computação distribuída;

- reusabilidade e escalabilidade de componentes distribuídos;

- reduz a complexidade da composição e implantação de componentes; 
- permite a publicação de funções de aplicações proprietária, por meio de interface de serviços.

Quando o serviço é implementado utilizando Web Services, ele possui o descritor da interface Web Services Description Language (WSDL). O WSDL é uma linguagem baseada em Extensible Markup Language (XML), que descreve a interface do serviço, funcionando como um contrato, o qual apresenta a descrição das operações e suas obrigatoriedades.

Conforme W3C (2014), a descrição do serviço desempenha um papel importante ao permitir o acesso a um serviço. A maioria das linguagens de descrição de serviços é projetada para ser consumida por máquinas, permitindo a automatização de estrutura de códigos e a busca e classificação de serviços. Por outro lado, as pessoas também podem utilizar essas descrições.

Segundo Sommerville (2007), a especificação do WSDL define três aspectos do Web Service, o que o serviço faz, como ele se comunica e onde encontrá-lo.

A Figura 9 ilustra a organização da especificação WSDL, conforme Sommerville (2007). Todas as partes do WSDL são descritas em XML e são constituídas de:

- uma introdução que, usualmente, define os namespaces ${ }^{2} \mathrm{XML}$ utilizados e pode, opcionalmente, ser utilizada uma seção com informações sobre o serviço;

- uma interface abstrata, que pode conter, opcionalmente, uma descrição de tipos usados nas mensagens trocadas pelos serviços;

- uma descrição da interface de serviços, as operações oferecidas pelo serviço;

- uma descrição de ligação (binding) usada pelo serviço, que representa o protocolo utilizado para enviar e receber mensagens. Estabelece como as mensagens são empacotadas em uma mensagem e qual protocolo de comunicação será utilizado;

- uma especificação de endpoints ${ }^{3}$ expresso como identificador de recurso uniforme (Uniform Resource Identifier - URI), que representa o endereço de um recurso que pode ser acessado por meio da Internet.

Conforme W3C (2014), o WSDL fornece, por meio do uso de XML Schema, o formato e os valores dos dados que entram e saem do serviço, define também

\footnotetext{
${ }^{2}$ Namespace XML são qualificadores para nomes (SOMMERVILLE, 2007). São utilizados para garantir que nomes dos elementos dos documentos XML sejam únicos (SILVA, 2001).

${ }^{3}$ Endpoints é uma localização física de um serviço (SOMMERVILLE, 2007).
} 
Figura 9: Organização de uma especificação WSDL

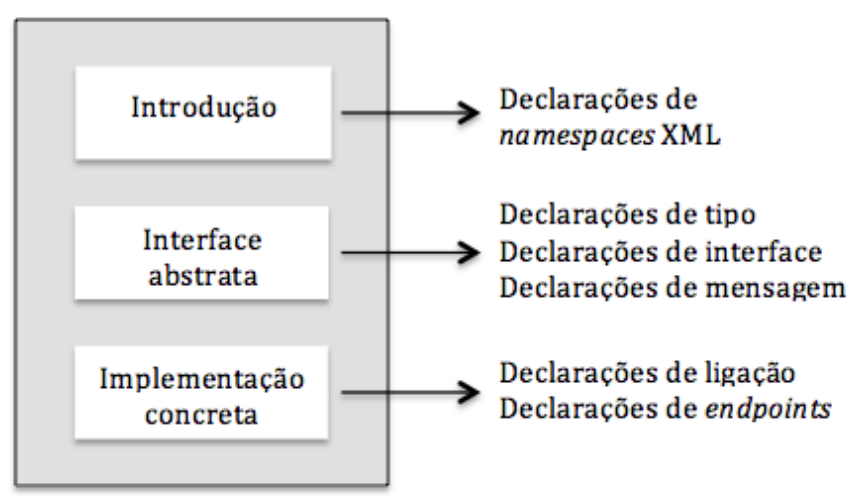

Fonte: Adaptado de Sommerville (2007)

os endpoints, operações suportadas, padrões de troca de mensagens (Message Exchange Patterns - MEP), tudo relativo à descrição operacional dos endpoints dos Web Services.

Segundo Erl (2009b), o contrato de um Web Service é composto por WSDL, XML schema e WS Policy.

O WS Policy descreve as políticas em uso ao acessar um serviço, mediante declarações de políticas (W3C, 2014) .

Conforme Sommerville (2007), o principal problema do WSDL é não possuir informação sobre a semântica do serviço ou características não funcionais. Por isso, depende de o interessado no serviço deduzir o que o serviço realmente faz e o significado de cada informação trocada nas mensagens de entrada e saída. Mesmo que sejam utilizados nomes significativos e que existam documentações de serviços, ainda assim pode haver uma interpretação indevida e mau uso do serviço.

O uso de Web Services, em soluções de governo eletrônico brasileiro, vem crescendo, como se pode constatar nos seguintes projetos que utilizam serviços no Brasil: (1) a Nota Fiscal Eletrônica (NF-e) (BRASIL, 2012b) e (2) o Conhecimento de Transporte Eletrônico (CT-e) (REHEM; OLLER, 2012).

\subsection{Reuso de Software}

Existem abordagens que buscam a reutilização de software, por exemplo, as abordagens baseadas em componentes, linha de produtos de aplicação, padrões de projetos e frameworks de aplicação (SAMETINGER, 1997). Os padrões de projetos são aplicados em várias áreas, como arquitetura de software, orientação a objetivos, orientação a serviços e SOA. De modo geral, padrões são soluções reutilizáveis para 
problemas de projeto recorrentes (LI et al., 2009).

Visando à definição de serviços reutilizáveis e flexíveis, Moon, Hong e Yeom (2008) propõem a concepção de serviços de domínio (serviço de alto nível de abstração) a partir do modelo de família de processos de negócios (ou em inglês, business-process family model - BPFM). BPFM, definido como um modelo de processo de negócio comum, pode ser reutilizado como um núcleo para o desenvolvimento de processos de negócio em linhas de produtos (PARK et al., 2009).

Conforme Freeman (1983) apud (KRUEGER, 1992), os tipos de artefatos de software que podem ser reutilizados não estão limitados às partes do código fonte, mas podem sim incluir estruturas de design, estruturas de implementação em nível de módulo, especificação, documentação e assim por diante.

De modo geral, os conceitos básicos propostos por Biggerstaff e Richter (1987) apud (KRUEGER, 1992) estão presentes na maioria das abordagens de utilização de software, cujos conceitos são: abstração, seleção, adaptação e integração.

Krueger (1992) apresentou um trabalho em que avaliou o uso desses conceitos em abordagens de reutilização, tais como geradores de aplicações, linguagens de alto nível e arquiteturas de sistemas. Para cada abordagem de reutilização de software investigada:

- Abstração - Que tipo de artefatos de software são reutilizados e quais abstrações são usadas para descrever os artefatos?

- Seleção - Como os artefatos reutilizáveis são selecionados para serem reutilizados?

- Adequação - Como os artefatos generalizados são adaptados para a reutilização?

- Integração - Como os artefatos reutilizáveis são integrados para criar um sistema de software completo?

Conforme Lucrédio (2009), a abstração e a seleção estão fortemente relacionados à experiência do especialista como engenheiro de software e ao talento individual.

Atualmente, as abordagem de reutilização usam diferentes técnicas para busca e localização de artefatos reutilizáveis, como índices e catálogos. Lucrédio, Prado e Almeida (2004) apresentam uma pesquisa bibliográfica a respeito de mecanismos de pesquisa e recuperação de componentes de software. Caldiera e Basili (1991) ressaltam que a eficiência e custo benefício do reuso demanda um 
grande catálogo de objetos reutilizáveis disponíveis.

Lucrédio (2009) também apresenta um trabalho utilizando estes quatro conceitos em relação às abordagens de reutilização: desenvolvimento baseado em componentes, linguagens específicas de domínio, programação generativa, e outras técnicas, como Frameworks, Padrões e Reengenharia de Software. Na Tabela 3, são apresentadas duas abordagens de reutilização, componentes e padrões de software.

Tabela 3: Relação entre abordagens de reutilização de software e conceitos básicos de reutilização de software

\begin{tabular}{|l|l|l|l|l|}
\hline \multicolumn{1}{|c|}{ Conceitos } & Abstração & Seleção & Adaptação & Integração \\
\hline $\begin{array}{l}\text { Abordagens } \\
\text { baseado em } \\
\text { Componentes }\end{array}$ & $\begin{array}{l}\text { Encapsulamento das } \\
\text { funções realizadas } \\
\text { pelo componente e } \\
\text { utilização de } \\
\text { interfaces bem } \\
\text { definidas }\end{array}$ & $\begin{array}{l}\text { Os componentes } \\
\text { geralmente são } \\
\text { catalogados e sua } \\
\text { localização é } \\
\text { apoiada pelo uso de } \\
\text { mecanismos } \\
\text { automáticos de } \\
\text { busca }\end{array}$ & $\begin{array}{l}\text { Parametrização e } \\
\text { modificação } \\
\text { interna }\end{array}$ & $\begin{array}{l}\text { Acoplamento de } \\
\text { interfaces } \\
\text { requeridas com as } \\
\text { interfaces providas } \\
\text { pelo restantes da } \\
\text { aplicação }\end{array}$ \\
\hline $\begin{array}{l}\text { Padrões de } \\
\text { Software }\end{array}$ & $\begin{array}{l}\text { Generalização e } \\
\text { representação de } \\
\text { soluções recorrentes }\end{array}$ & $\begin{array}{l}\text { Busca por um } \\
\text { padrão por meio da } \\
\text { comparação do } \\
\text { problema }\end{array}$ & $\begin{array}{l}\text { Após a } \\
\text { instanciação do } \\
\text { padrão, o mesmo } \\
\text { é adaptado para a } \\
\text { situação }\end{array}$ & $\begin{array}{l}\text { Alteração do } \\
\text { restante do sistema } \\
\text { para acomodar o } \\
\text { padrão. }\end{array}$ \\
\hline
\end{tabular}

Fonte: Lucrédio (2009)

Conforme Lucrédio (2009), é preciso utilizar formas intuitivas para representar o conhecimento. Essas representações devem ser menos dependentes quanto possível, do código fonte, pois o código fonte é uma linguagem demasiadamente densa de tal maneira que é difícil identificar, extrair e reutilizar o conhecimento apenas por meio da sua leitura. Por outro lado, quando se representa a conhecimento por modelagem, às vezes esses documentos não são atualizados ao longo do projeto.

Segundo Sametinger (1997), existem aspectos relacionados ao reuso de software que estabelecem as características e a maneira como os itens são reutilizados: (1) Essência - define a natureza dos itens a serem reutilizados; (2) Escopo - define a forma e a extensão do reuso; (3) Modo - define como o reuso é conduzido; (4) Técnica - define a abordagem que é usada para implementar o reuso; (5) Intenção - define como os elementos serão utilizados; e (5) Produto - define o que é reusado. O aspecto essência representa a natureza do que será reutilizado como, por exemplo, ideias e conceitos.

O potencial de reutilização em uma organização que utiliza serviços tende a crescer rapidamente. Nesse contexto, surge o conceito de portfólios de serviços, com a finalidade de permitir a reutilização de serviços e facilitar o planejamento. Portfólio de 
serviços é mais do que um catálogo de serviços, pois esse instrumento forma a base para o desenvolvimento futuro, inclui métricas de avaliação de serviços, descrições de características dos serviços necessários e os prestadores de serviços, informações de contexto, as dependências entre os serviços, monitoramento e mecanismo de feedback e ferramentas de apoio à decisão (FEENSTRA; JANSSEN, 2008).

\subsubsection{Padrões de Projeto}

Um padrão fornece uma solução comprovada para um problema comum documentado individualmente num formato consistente, geralmente como parte de um conjunto maior. A solução fornecida por um determinado padrão pode não representar necessariamente a única solução adequada para o problema. Na verdade, pode haver padrões que fornecem soluções alternativas para o mesmo problema. Tendo em vista que cada solução terá suas próprias exigências e consequências, cabe ao profissional escolher a solução. O padrão é parte fundamental da vida cotidiana, soluções comprovadas já são utilizadas para solucionar problemas comuns. Porém, quando os padrões são relacionados especificamente a sistemas automatizados, estes são denominados Padrões de Projeto (ERL, 2009a).

Segundo Erl (2009a), os padrões de projeto são úteis devido às seguintes razões: representam soluções testadas para problemas de projeto comuns; organizam a inteligência do projeto em um formato normalizado e que pode facilmente ser referenciado; são geralmente repetíveis pela maioria dos profissionais de TIC envolvidos com projeto; podem ser usados para garantir a consistência na forma como os sistemas são projetados e construídos, podem se tornar a base para normas de projeto; são usualmente flexíveis e opcionais; podem ser utilizados como apoio para o ensino por meio da documentação dos aspectos específicos de projeto de sistema; e podem ser apoiados por meio da aplicação de outros padrões de projeto que fazem parte da mesma coleção.

Embora os padrões de projeto forneçam soluções de projetos que já foram previamente validadas, sua simples utilização não garante que os problemas de projeto sejam sempre resolvidos. Conforme Erl (2009a), muitos fatores pesam para o êxito do uso de padrões de projeto, incluindo restrições impostas pelo ambiente de implementação, a competência dos profissionais, divergências nos requisitos de negócios e assim por diante. Todos eles representam aspectos que influenciam o grau em que padrões podem ser aplicados com sucesso.

Alguns conceitos relacionados a padrões são apresentados por Erl (2009a). 
Dentre estes, são destacados alguns importantes para o estudo apresentado neste trabalho: padrão composto representa um padrão de alta granularidade, composto por um conjunto de padrões com granularidade baixa; e catálogo de padrões de projeto uma coleção documentada de padrões de projeto relacionados.

A orientação a serviços tem suas origens em projetos de plataformas de computação distribuída. Muitos padrões de projeto SOA têm suas origens e são influenciados pelos conceitos e abordagens de projeto e pelos padrões de projeto já estabelecidos. Conforme ilustrado na Figura 10, os padrões de projeto de SOA são influenciados pelos padrões de projeto das áreas: orientação a objeto, Enterprise Application Integration (EAI), arquitetura de aplicação empresarial e arquitetura de software. Esses padrões de certa forma são influenciados pela linguagem de padrões original criada por Alexander et al. (1977).

Figura 10: As influências primárias de padrões de projeto SOA

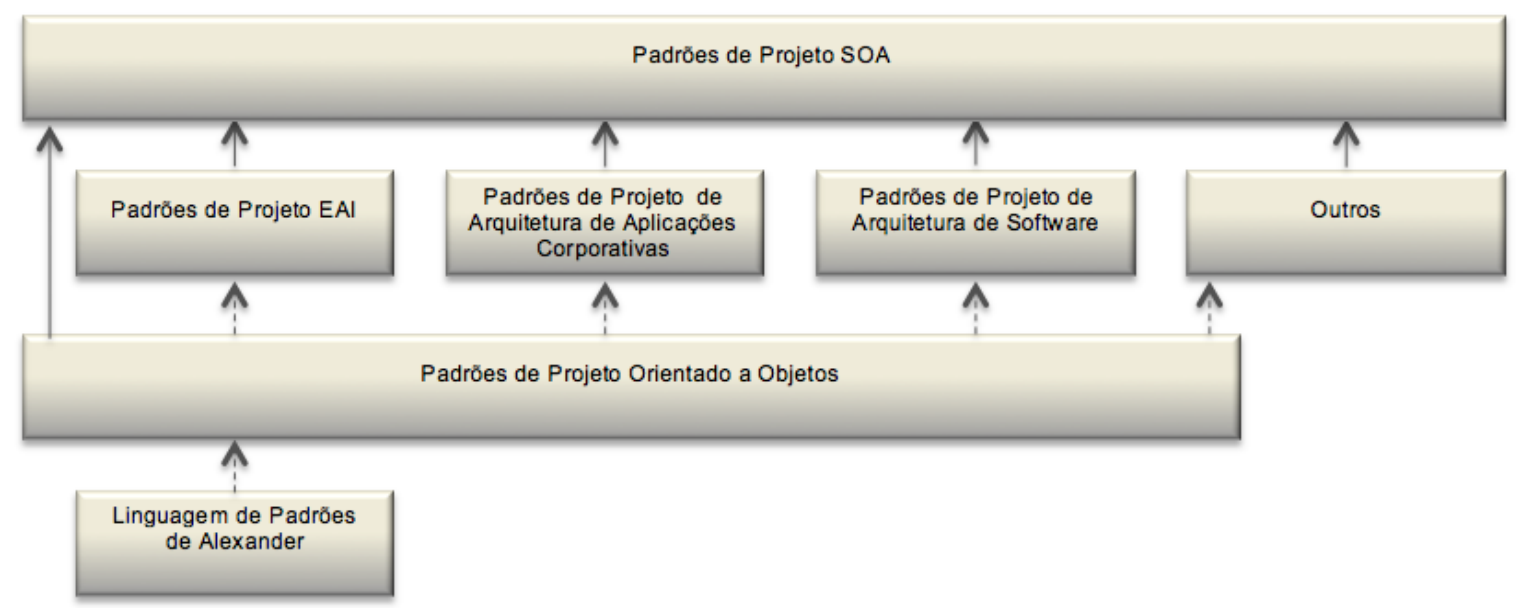

Fonte: Adaptado de Erl (2009a)

Os padrões discutidos por Alexander et al. (1977) são oriundos da construção civil, com o objetivo de registrar soluções comuns observadas em diferentes projetos arquitetônicos. Os padrões relacionados à arquitetura e áreas afins foram organizados em uma série pré-definida chamada "sequência", e o resultado foi uma linguagem arquitetônica de padrões que inspirou a comunidade de TIC a criar seus próprios padrões para o projeto de sistemas automatizados. Alexander defende também a importância da clareza da documentação dos catálogos de padrões.

Os padrões de projeto orientados a objetos contribuíram para consolidar a orientação a objetos. Os padrões de projeto estabelecidos na orientação a objetos são a base de alguns dos padrões no catálogo de padrões de projeto SOA.

Os padrões de arquitetura de software definem seus subsistemas, especificando suas responsabilidades, regras e orientações para a organização dos 
relacionamentos entre os subsistemas (BUSCHMANN et al., 1996). Um exemplo de padrão arquitetural é o Model-View-Controller.

Após a computação distribuída ter se tornado uma plataforma estabelecida para o projeto de soluções, foi concebido um conjunto de padrões arquiteturais corporativos, muitos dos quais foram construídos sobre os conceitos e padrões orientados a objetos. Pelo fato da orientação a serviços ser um paradigma de projeto para computação distribuída, ela tem como base os padrões e conceitos fundamentais relacionados à arquitetura de aplicação corporativa em geral. Fowler (2006) publicou um catálogo de padrões para arquiteturas de aplicações corporativas, no qual apresenta padrões para decompor aplicações corporativas em camadas. São apresentados padrões relacionados à lógica de domínio, fontes de dados, apresentação Web, entre outros.

Catálogos de padrões trataram o uso de mensagens para cumprir os requisitos de integração originados durante a era EAI. Portanto, a orientação à mensagem da EAl é outra forte influência observada na orientação a serviços. Entre os padrões de projeto SOA propostos por Erl (2009a), existem padrões de interação de serviços com base na utilização de mensagens, para, principalmente, apoiar cenários de composição de serviços.

A coleção de padrões de projeto SOA, proposta por Erl (2009a), representa soluções para problemas encontrados na definição, implementação e catalogação de serviços. Esses padrões são agrupados nas seguintes categorias:

- Padrões de projeto de inventário de serviços,

- Padrões de projeto de serviços e

- Padrões de projeto de composição de serviços.

Os padrões de projeto de inventário de serviços são relacionados ao escopo, estrutura e padronização de inventário. São 24 padrões de projeto de inventários de serviços, dentre estes, os padrões mais relacionados a esta pesquisa são: Normalização de Serviços, Centralização de Lógica e Camadas de Serviços. O padrão Normalização de Serviços estabelece que serviços diferentes não devem ter sobreposição de limites funcionais, ou seja, não devem conter lógicas semelhantes. O padrão Camadas de Serviços estabelece a necessidade de definição de camadas de serviços no inventário de serviços. Para classificar os serviços em camadas, Erl (2009a) propõe os tipos de serviços Tarefa, Entidade e Utilitário, conforme descrito na Seção 2.2.1.

Os padrões de projeto de serviços são relacionados a identificação e definição 
de serviços. São 31 padrões de serviços, dentre estes os mais relacionados ao tema desta pesquisa são: Decomposição Funcional e Encapsulamento de Serviço. O padrão Decomposição Funcional estabelece que um grande problema de negócio deve ser decomposto em problemas menores para que estes possam ser resolvidos por um serviço específico.

Os padrões de projeto de composição de serviços fornecem os meios para montar e compor a lógica de serviço que foi decomposta, particionada, e simplificada por meio da aplicação de padrões estabelecidos na categoria padrões de projeto de serviços. São apresentados 23 padrões de composição de serviços, sendo que os mais relacionados ao tema desta pesquisa são os padrões: Composição da Capacidade e Recomposição da Capacidade. O padrão Composição da Capacidade estabelece que quando um serviço necessita acesso à lógica fora do seu contexto, esta lógica, deve ser consumida na forma de composição. O padrão Recomposição da Capacidade estabelece que uma capacidade deve ser projetada para ser reutilizada em composições de serviços e assim, aumentar o potencial de reutilização da lógica.

Embora os padrões e os princípios de projeto forneçam orientação de projeto visando alcançar os objetivos estratégicos de SOA, a relação entre os princípios de projeto SOA (descritos na Seção 2.2.2) e os padrões de projeto SOA (descritos nesta seção) pode ser sintetizada da seguinte forma: enquanto os princípios são diretrizes altamente recomendáveis para dar forma à lógica da solução orientada a serviços e podem ser aplicados coletivamente, os padrões de projeto fornecem solução para problemas comuns encontrados durante a aplicação de princípios de projeto orientado a serviços. Os padrões de projeto podem ser vistos como fornecedores de suporte para a realização dos princípios de projeto e seus objetivos associados.

\subsubsection{Padrões de Serviços}

Um conceito importante a ser estabelecido neste trabalho é o de padrões de serviços. Esta seção apresenta como esse termo tem sido utilizado na literatura e no final estabelece a definição a ser utilizada nesta pesquisa.

Fu et al. (2009) registram que o termo padrões de serviços tem algumas semelhanças com padrões de projeto definido por Gamma et al. (2000), ambos são soluções validadas em problemas recorrentes e projetados para reutilizar experiência anterior. Fu et al. (2009) ressaltam que os padrões de projeto são focados na reutilização da experiência de especialista na atividade de projeto, enquanto o conceito de padrões de serviços foi projetado para superar os desafios impostos pela falta de 
formas sistemáticas de reaproveitamento de experiências anteriores em interações de serviço, objetivando facilitar a automatização das composições de serviços.

Fki, Tazi e Dupuy (2010) definem padrões de serviços como um serviço abstrato que apresenta uma descrição genérica e reutilizável. Esses autores objetivam demonstrar que o mecanismo de composição pode ser guiado por um modelo de intenções do usuário e apoiado por um conjunto de padrões de serviços. Consideram o padrão como um nível intermediário de abstração que visa preencher a lacuna entre a intenção do usuário e os potenciais serviços concretos que a realizam.

Nazih e Alaa (2011) apresentam padrões genéricos de serviço para área da saúde pública egípcia, com o objetivo de integrar hospitais e Governo. Nesse trabalho, abordam dois tipos comuns de padrões: padrões arquitetônicos, que refletem atributos estruturais da arquitetura de software, e padrões de projeto, que fornecem representações comportamentais e funcionais de arquitetura de software.

Neste trabalho, o conceito de padrões de serviços adotado é similar ao definido por Fki, Tazi e Dupuy (2010), ou seja, é entendido como um serviço abstrato que apresenta uma descrição genérica e reutilizável. Em acréscimo, será considerado que padrões de serviços descrevem serviços atômicos e serviços compostos.

Traçando um comparativo entre serviços e padrões de serviços, pode-se dizer que: i) enquanto o objetivo de serviço é fazer parte de um inventário reusável, o objetivo do padrão de serviço é fazer parte de um catálogo de padrões de serviços referenciável; ii) enquanto um serviço é representado pelos artefatos: especificação de serviços, código fonte, WSDL e código de implantação, o padrão de serviço é representado somente pelo documento de Especificação de Padrão de Serviço; e iii) o reuso de serviço está diretamente relacionado à quantidade de invocações do serviço para atender processos de negócio distintos, o reuso de padrão de serviço está relacionado à quantidade de vezes que este foi utilizado como base para especificar novos serviços. O padrão de serviço, cujo objetivo é ser mais abstrato que o serviço, não é implementável, e sim, utilizado como referência para a definição de novos serviços. Uma interface de serviços descreve como o serviço deve ser consumido, enquanto um padrão de serviço é utilizado para definir novos serviços a partir deste. A Tabela 4 ilustra algumas diferenças entre os termos serviços e padrões de serviços utilizados neste trabalho.

No ciclo de desenvolvimento orientado a serviços, a unidade de software a ser reutilizada é o serviço. Ao inserir o conceito de padrões de serviços, no ciclo de desenvolvimento orientado a serviços, o objetivo é o reuso do conceito e da lógica do serviço representados por meio do padrão de serviço. 
Tabela 4: Serviços versus Padrões de Serviços

\begin{tabular}{|c|c|c|}
\hline & Serviços & Padrões de Serviços \\
\hline Objetivo & $\begin{array}{l}\text { Fazer parte de um inventário } \\
\text { de serviços reusáveis }\end{array}$ & $\begin{array}{l}\text { Fazer parte de um catálogo de } \\
\text { padrões de } \\
\text { referenciado }\end{array}$ \\
\hline $\begin{array}{l}\text { Artefatos } \\
\text { Relacionados }\end{array}$ & $\begin{array}{l}\text { - Especificação do serviço } \\
\text { - } \text { Código fonte } \\
\text { - } \text { WSDL } \\
\text { - Código de implantação }\end{array}$ & $\begin{array}{l}\text { Especificação do padrão de } \\
\text { serviço }\end{array}$ \\
\hline Reuso & $\begin{array}{l}\text { Invocação direta dos serviços } \\
\text { por mais de uma aplicação } \\
\text { consumidora ou reuso por } \\
\text { meio da composição de } \\
\text { serviços }\end{array}$ & $\begin{array}{l}\text { Reuso do conceito e da lógica } \\
\text { abstraída de serviço e } \\
\text { representada no padrão de } \\
\text { serviço }\end{array}$ \\
\hline
\end{tabular}

Fonte: Autor (2014)

O uso de padrões de serviços tem como objetivo auxiliar na especificação de novos serviços reutilizando os conceitos já utilizados em outras áreas de governo. Assim, o catálogo de padrões de serviços de governo serve de base de consulta para localizar padrões de serviços que possam ser adequados ao processo de negócio.

O diagrama apresentado por Erl (2009a) na Seção 2.3.1 ilustra que os padrões de projeto de SOA são influenciados pelos padrões de projeto de outras áreas. De forma similar, a Figura 11 ilustra a influência dos conceitos já estabelecidos nos padrões de projeto SOA sobre os padrões de serviços e, consequentemente, sobre os serviços especificados a partir dos padrões de serviços, que é a proposta deste trabalho.

\subsubsection{Reuso de Software e Padrões de Serviços}

Os conceitos de reutilização de software, abstração, seleção, adaptação e integração apresentados na Seção 2.3, geralmente presentes na maioria das abordagens de reutilização de software, também podem ser observados no contexto de padrões de serviços. Para avaliar o uso desses conceitos de reutilização de software na abordagem de padrões de serviços, as quatro perguntas foram respondidas:

- Abstração - Quais tipos de artefatos de software são reutilizados e quais abstrações são representadas pelos artefatos? O objetivo é definir serviço abstrato. O serviço abstrato é denominado neste trabalho como um Padrão de Serviço. O artefato que representa o padrão de serviços é a especificação de padrão de serviços;

- Seleção - Como os artefatos reutilizáveis são selecionados para serem 
Figura 11: As influências primárias de padrões de Serviços

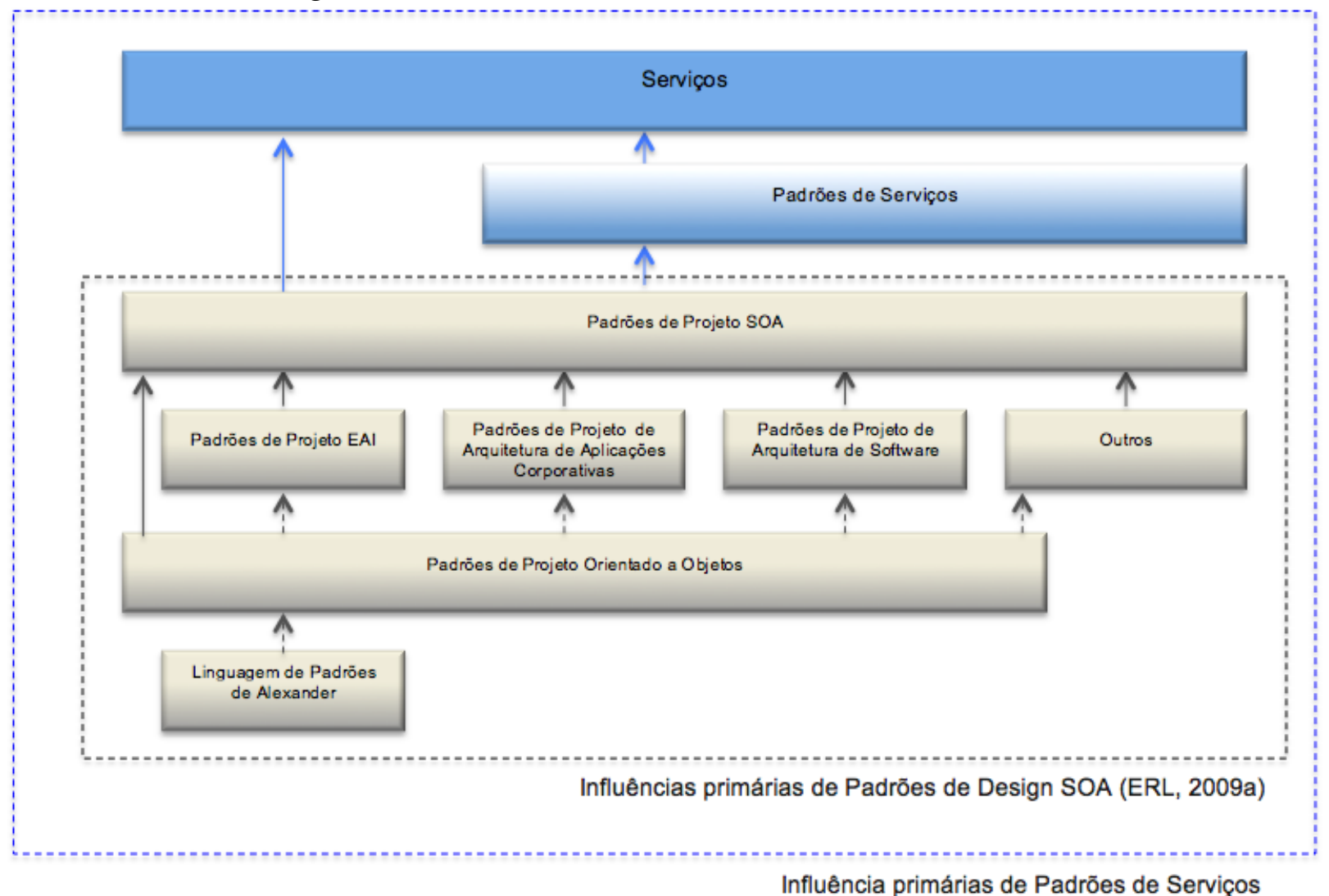

Fonte: Adaptado de Erl (2009a)

reutilizados? Os padrões de serviços estarão registrados no catálogo de padrões de serviços de e-governo. O padrão de serviço será localizado a partir de uma pesquisa no catálogo por meio da comparação do problema que está buscando solução;

- Adaptação - Como os artefatos generalizados são adaptados para a reutilização? O conceito de serviço será reutilizado assim como a sua estrutura (suas operações e mensagens). O padrão de serviço será utilizado como referência para concepção de um novo serviço, os serviços criados poderão sofrer mudanças para atender a novos requisitos;

- Integração - Como os artefatos reutilizáveis são integrados para criar um sistema de software completo? A interface especificada no padrão de serviço define a maneira pela qual os serviços produzidos a partir dos padrões irão se integrar a aplicação consumidora.

A Tabela 5 resume os quatro conceitos de reutilização e a abordagem padrão de serviço. 
Tabela 5: Relação entre padrão de serviço e conceitos básicos da reutilização de software

\begin{tabular}{|l|l|l|l|l|}
\hline \multicolumn{1}{|c|}{ Conceitos } & Abstração & Seleção & Adaptação & Integração \\
\hline $\begin{array}{l}\text { Abordagem } \\
\text { Padrões de }\end{array}$ & $\begin{array}{l}\text { Generalização e } \\
\text { representação de } \\
\text { soluções } \\
\text { recorrentes }\end{array}$ & $\begin{array}{l}\text { Busca por um } \\
\text { padrão por meio } \\
\text { da comparação do } \\
\text { problema. }\end{array}$ & $\begin{array}{l}\text { Utiliza o padrão como } \\
\text { referência para } \\
\text { concepção de um novo } \\
\text { serviço. O padrão de } \\
\text { serviço não é instanciado }\end{array}$ & $\begin{array}{l}\text { A interface do } \\
\text { padrão de serviço } \\
\text { define a forma de } \\
\text { integração }\end{array}$ \\
\hline
\end{tabular}

Fonte: Autor (2014)

\subsubsection{Especificação de Padrões de Serviços}

Conforme Li et al. (2009), uma boa descrição do padrão pode ajudar a compreender imediatamente a essência do padrão, a qual problema o padrão está endereçado e qual solução está sendo proposta. A estrutura básica Contexto-Problema-Solução proposta por Alexander et al. (1977) fornece um bom ponto de partida para um formato de descrição que atenda aos requisitos acima (LI et al., 2009).

Foram analisados os atributos para descrever padrões de serviços apresentados no trabalho de Tchuta e Chunhua (2011), Li et al. (2009), Fu et al. (2009) e Fki, Tazi e Dupuy (2010), conforme descrito na Tabela 6. Os atributos apresentados na tabela estão descritos no Apêndice E.

Entre os trabalhos analisados, de modo geral, os padrões contêm um conjunto de informações padronizadas: nome do padrão, problema e solução. Embora o nome dos atributos, conforme Tabela 6, utilizado pelos autores não seja idêntico, foi observado que esse conjunto de informações sempre está presente na descrição dos padrões.

Tchuta e Chunhua (2011) não propõem um conjunto de atributos para descrição do padrão de serviço, porém eles descrevem o padrão utilizando uma estrutura de informações.

Fki, Tazi e Dupuy (2010) ressaltam que, independente dos atributos utilizados para descrever um padrão de serviço, o objetivo é descrevê-lo como um serviço abstrato, para que possa ser implementado e disponibilizado como um serviço.

\subsubsection{Trabalhos Relacionados a Padrões de Serviços}

Na Seção 2.3.2, o termo padrão de serviço foi definido e, para isso, alguns trabalhos relacionados já foram mencionados. Nesta Seção, porém, objetiva-se apresentar uma classificação dos trabalhos relacionados e descrever de forma mais 
Tabela 6: Atributos para descrição de padrões

\begin{tabular}{|l|c|c|c|c|}
\hline Atributos & $\begin{array}{l}\text { Li et al. } \\
(2009)\end{array}$ & $\begin{array}{l}\text { Fu et al. } \\
(2009)\end{array}$ & $\begin{array}{l}\text { Fki, Tazi } \\
\text { e Dupuy } \\
(2010)\end{array}$ & $\begin{array}{l}\text { Tchuta } \\
\text { Chunhua } \\
(2011)\end{array}$ \\
\hline Nome do padrão & $\mathrm{X}$ & $\mathrm{X}$ & $\mathrm{X}$ & $\mathrm{X}$ \\
\hline Contexto & $\mathrm{X}$ & $\mathrm{X}$ & - & $\mathrm{X}$ \\
\hline Problema & $\mathrm{X}$ & - & - & $\mathrm{X}$ \\
\hline Solução & $\mathrm{X}$ & - & - & $\mathrm{X}$ \\
\hline Estrutura & $\mathrm{X}$ & - & - & $\mathrm{X}$ \\
\hline Dinâmica & $\mathrm{X}$ & - & - & - \\
\hline Implementação & $\mathrm{X}$ & - & - & - \\
\hline Consequência & - & - & - & $\mathrm{X}$ \\
\hline Justificativa & - & - & - & $\mathrm{X}$ \\
\hline Exemplo de código & - & - & - & $\mathrm{X}$ \\
\hline Participantes e responsáveis & - & - & - & $\mathrm{X}$ \\
\hline Estratégia & - & - & - & $\mathrm{X}$ \\
\hline Considerações sobre os testes & - & - & - & $\mathrm{X}$ \\
\hline Padrões relacionados & - & $\mathrm{X}$ & - & - \\
\hline Intenção & - & $\mathrm{X}$ & - & - \\
\hline Catálogo & - & $\mathrm{X}$ & - & - \\
\hline Template do serviço & - & - & $\mathrm{X}$ & - \\
\hline Objetivo & - & - & $\mathrm{X}$ & - \\
\hline Atividades & - & - & $\mathrm{X}$ & - \\
\hline Tipo do serviço & - & - & $\mathrm{X}$ & - \\
\hline Regras & - & - & $\mathrm{X}$ & - \\
\hline Requisito & & & & \\
\hline & - & & - & \\
\hline
\end{tabular}

Fonte: Autor (2014)

detalhada alguns dos trabalhos.

Os trabalhos selecionados a partir de uma pesquisa bibliográfica na literatura especializada no assunto, a respeito do uso padrões de serviços, são apresentados na Tabela 7.

A análise dos trabalhos subsidiou o entendimento a respeito das abordagens propostas e também o mapeamento das seguintes informações:

Domínio específico de aplicação: se os padrões apresentados nos trabalhos são utilizados para revolver um problema de negócio específico ou um problema de projeto de serviços que pode ser aplicado em qualquer área de negócio.

Descrição do padrão: se o trabalho descreve um conjunto de atributos para descrever o padrão de serviço. Esse item está detalhado na seção 2.3.2.2.

Modelo de representação do padrão: quais são modelos utilizados para representar o padrão de serviço.

Em geral, todos os padrões descritos nos trabalhos apresentados procuram subsidiar o reuso de soluções, tanto soluções para um problema de projeto de 
Tabela 7: Padrões relacionados a serviços

\begin{tabular}{|c|c|c|c|c|}
\hline Fonte & Abordagem & \begin{tabular}{|l} 
Dominio \\
Especifico
\end{tabular} & $\begin{array}{l}\text { Descriçăo } \\
\text { do } \\
\text { Padrăo }\end{array}$ & $\begin{array}{l}\text { Simbologia de } \\
\text { representaçăo }\end{array}$ \\
\hline $\begin{array}{l}\text { Fki, Tazi } \\
\text { e Dupuy } \\
\text { (2010) }\end{array}$ & \begin{tabular}{|ll}
\multicolumn{3}{|l|}{ Apresenta uma abordagem } \\
para composiçăo & de \\
serviços, com base no \\
modelo de intençăo & do \\
usuário, ontologia & de \\
domínio e modelo & de \\
padrão de serviço. &
\end{tabular} & \begin{tabular}{|l|} 
Năo \\
\end{tabular} & Sim & $\begin{array}{lr}\text { Diagrama de } & \text { classes } \\
\text { conceituais, } & \text { que } \\
\text { representa os } & \text { conceitos } \\
\text { do padrăo. } & \end{array}$ \\
\hline $\begin{array}{l}\text { Fu et al. } \\
(2009)\end{array}$ & $\begin{array}{l}\text { Abordagem baseada em } \\
\text { padrões de serviços para } \\
\text { dar suporte a composiçס̃es } \\
\text { de serviços, usando } \\
\text { ontologia. }\end{array}$ & Nã̃o & Sim & $\begin{array}{l}\text { Diagrama que representa } \\
\text { as camadas hierárquicas } \\
\text { do padrăo proposto. }\end{array}$ \\
\hline $\begin{array}{l}\text { Li et al. } \\
(2009)\end{array}$ & $\begin{array}{l}\text { Apresenta um padrăo de } \\
\text { serviço de reputaçấo como } \\
\text { uma soluçăo para o } \\
\text { problema de confiança na } \\
\text { prestaçăo de serviços na } \\
\text { SOC. }\end{array}$ & $\begin{array}{l}\text { Sim } \\
\text { (Segurança) }\end{array}$ & Sim & $\begin{array}{l}\text { Diagrama de Classes. } \\
\text { Diagrama de sequência } \\
\text { para representar as } \\
\text { interações entre os } \\
\text { serviços. }\end{array}$ \\
\hline $\begin{array}{l}\text { Nazih e } \\
\text { Alaa } \\
\text { (2011) }\end{array}$ & $\begin{array}{l}\text { Apresenta padrōes } \\
\text { genéricos de serviços para } \\
\text { o sistema de saúde pública } \\
\text { egípcia. }\end{array}$ & $\begin{array}{l}\text { Sim (Saúde } \\
\text { Pública) }\end{array}$ & Nẵo & $\begin{array}{l}\text { Lista de padrōes } \\
\text { genéricos de serviços. } \\
\text { Camadas de abstração } \\
\text { do serviço. Diagrama de } \\
\text { sequência r para } \\
\text { representar as interaçб̌es } \\
\text { entre atores do sistema. }\end{array}$ \\
\hline $\begin{array}{l}\text { Tchuta } \\
\text { e } \\
\text { Chunhu } \\
\text { a (2011) }\end{array}$ & $\begin{array}{l}\text { Apresenta um padrão para } \\
\text { criação de serviços } \\
\text { atômicos. }\end{array}$ & Năo & Sim & $\begin{array}{l}\text { Camadas de } \\
\text { implementaçăo do padrão } \\
\text { de serviços expressas por } \\
\text { meio de diagrama de } \\
\text { classe. Diagrama de } \\
\text { sequência para } \\
\text { representar as interaçôes } \\
\text { entre as camadas de } \\
\text { serviços. }\end{array}$ \\
\hline
\end{tabular}

Fonte: Autor (2014)

serviços, como problema de domínio de negócio específico. Os padrões definidos por Nazih e Alaa (2011) e Li et al. (2009) apresentam padrões de serviços relacionados a domínio de negócio específico: Nazih e Alaa (2011) apresentam padrões de serviços para área de negócio da saúde e Li et al. (2009) para área de negócio segurança. Esses trabalhos são totalmente aderentes ao foco desta pesquisa, por isso foram selecionados para serem descritos de modo mais detalhado a seguir. Os demais trabalhos abordam o uso de padrões de serviços voltados para soluções de projeto de serviços não vinculados a um domínio de negócio específico.

Nazih e Alaa (2011) propõem padrões genéricos de serviço para o sistema de saúde pública egípcia, com o objetivo de integrar hospitais e interação com o governo, com a proposta de desenvolver um protótipo que se assemelha aos serviços genéricos 
e mostrar que os serviços são passíveis de reutilização, personalizáveis de acordo com as condições de casos particulares e escaláveis para atender a qualquer nível de demanda. O desenvolvimento da pesquisa proposta foi dividido nos seguintes passos:

Coleta de requisitos: levantamento e análise dos requisitos do sistema de saúde pública.

Análise e identificação de padrões: é feita a análise dos dados recolhidos para especificar as funcionalidades esperadas. Foi documentada a Cadeia de Valores da Saúde, a fim de diminuir a complexidade do sistema e especificar abstrações genéricas de operações do sistema. A partir da cadeia de valores têm-se os diferentes atores do sistema (Governo, Empresas de Seguros, Farmácias, Hospitais/Clínicas, Médicos, Enfermeiras e Paciente) e cada ator tem o seu papel específico e atividades típicas.

Projeto genérico e implementação do protótipo: Trata-se de projetar o barramento de serviço G2G e implementar um protótipo para aplicar os padrões definidos. Esse trabalho propõe um protótipo utilizando o conceito de separação de preocupações, no qual a implementação do serviço é dividida em camadas para garantir que os detalhes do serviço sejam fracamente acoplados, o que induz a flexibilidade em nível arquitetônico.

Avaliação e validação: A avaliação foi feita por meio do uso de métricas de software para medir a reutilização, acoplamento, escalabilidade e abstração dos padrões genéricos de serviços propostos. Se os padrões propostos atenderem estes atributos de qualidade, então os padrões estão validados.

No estudo de caso são apresentados os padrões comuns e reusáveis de serviços identificados durante a análise de requisitos, conforme Tabela 8.

Para mostrar a interação entre os padrões de serviços foi utilizado o diagrama de sequência da UML. Para implementar os padrões de serviços os autores optaram em separar as preocupações em uma estrutura de quatro camadas: camada de negócio, camada de dados, camada de lógica e camada de interface de serviços.

Nesse trabalho, foi apresentada uma proposta de padrões genéricos de serviços para área da saúde, porém, especificamente sobre os padrões, não foram apresentados os critérios usados para defini-los e, tão pouco, a forma de registrá-los. Somente apresenta a lista de serviços considerados padrões, assim como a estrutura de camadas de serviços a ser seguida para desenvolvimento.

Li et al. (2009) apresentam um padrão de serviço de reputação como uma solução para o problema de confiança na prestação de serviços em ambiente 
Tabela 8: Padrões genéricos de serviço da saúde pública

\begin{tabular}{|l|l|}
\hline Ator & Serviços utilizados pelo ator \\
\hline Governo & $\begin{array}{l}\text { Histórico de doenças tratadas } \\
\text { Detalhes do cidadăo paciente } \\
\text { Detalhes do sindicato médico }\end{array}$ \\
\hline Empresas de Seguro & $\begin{array}{l}\text { Detalhes financeiros do paciente } \\
\text { Histórico médico do paciente }\end{array}$ \\
\hline Farmácias & $\begin{array}{l}\text { Detalhes dos medicamentos / drogas } \\
\text { Histórico de doenças tratadas }\end{array}$ \\
\hline Hospitais / Clínicas & $\begin{array}{l}\text { Histórico de doenças tratadas } \\
\text { Detalhes financeiros do paciente } \\
\text { Detalhes do cidadăo paciente }\end{array}$ \\
\hline Médicos & $\begin{array}{l}\text { Histórico médico do paciente } \\
\text { Detalhes de doenças } \\
\text { Histórico de doenças tratadas }\end{array}$ \\
\hline Enfermeiras & $\begin{array}{l}\text { Histórico médico do paciente } \\
\text { Detalhes de doenças } \\
\text { Detalhes do cidadăo paciente }\end{array}$ \\
\hline Paciente & Histórico médico do paciente \\
\hline
\end{tabular}

Fonte: Nazih e Alaa (2011)

de computação orientada a serviços, com objetivo de incentivar a confiança em transações de serviço usando o comportamento passado como um indicador do provável comportamento futuro. O padrão de serviço abrange os aspectos de projeto tanto conceituais quanto técnicos de um serviço de reputação e propõe resolver o problema de confiança na prestação de serviços em computação orientada a serviços. Segundo os autores, o padrão foi capturado a partir da experiência dos próprios autores em projetar sistema de reputação.

O padrão de serviço de reputação foi descrito utilizando uma estrutura de descrição de padrão, contendo as seguintes informações:

Contexto - o ambiente da computação orientada a serviços é uma rede dinâmica e autônoma de prestadores e consumidores de serviços, ou seja, qualquer parte da rede pode se comportar de forma autônoma, geralmente sem envolver qualquer administração centralizada. Os prestadores de serviços fornecem serviços para os consumidores, publica funções de serviço, bem como anuncia a QoS por meio do Service Registry, que faz parte de um agente (Broker) de serviços. Os consumidores dos serviços devem procurar o Service Registry para obter os serviços disponíveis e suas descrições, incluindo informações de requisitos funcionais e não funcionais. 
Problema - o consumidor em potencial de um serviço tem uma ideia de que tipo de serviço necessita e pode consultar o Service Registry para obter os serviços disponíveis que podem implementar a função de negócio necessária, juntamente com a informação QoS anunciada dos serviços. No entanto, o consumidor não pode facilmente prever a QoS que uma instância de determinado serviço irá proporcionar, porque, em parte, o consumidor não pode confiar no serviço ou em seus fornecedores. Como estabelecer a confiança entre consumidores e prestadores de serviços? Como os consumidores sabem qual o serviço que eles podem contar?

Solução - a solução consiste em usar um sistema de reputação e envolvê-lo como um serviço que possa ser então integrado no ambiente de computação orientada a serviços. A Figura 12 ilustra como o serviço de reputação irá funcionar. Os consumidores de serviços invocam o serviço de reputação via cliente Web Service no lado do consumidor e, antes que um consumidor invoque um serviço em potencial, ele invoca o serviço de reputação para verificar a reputação do serviço e decide sobre a possibilidade de executá-lo. Após completar a chamada do serviço desejado, o consumidor irá chamar o serviço de reputação novamente para adicionar uma avaliação. Os autores apresentam ainda o diagrama de classes do padrão de serviço de reputação e o diagrama de sequência para representar a interação entre fornecedores de serviços, serviço de reputação e consumidores de serviços.

Estrutura - descreve os subsistemas que compõem o padrão de reputação.

Dinâmica - descreve a interação entre o serviço de reputação e os demais serviços. Implementação - estabelece as diretrizes para a implementação do padrão.

Consequências - apresenta os benefícios que o padrão oferece e potenciais responsabilidades.

Figura 12: Arquitetura da solução proposta

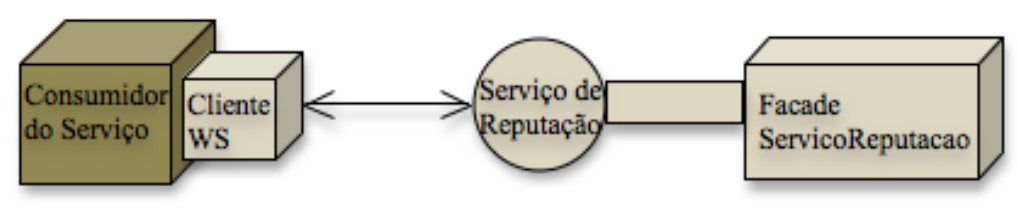


Com o uso de padrão de serviço de reputação, espera-se melhorar a modularização e o reuso.

Este trabalho apresenta, de forma detalhada, a descrição do padrão e a sua representação gráfica.

Os trabalhos a respeito de padrões de serviços geralmente abordam aspectos estruturais do projeto de o serviço ou apresentam exemplos de padrões de serviços. Não foram observados métodos para auxiliar a definição de padrões de serviços no domínio de governo, visando ao reuso de conceitos de serviços.

\subsection{Governo Eletrônico e Serviços}

A Internet oferece oportunidade de construção de sistemas que usam essa tecnologia para auxiliar a integração do governo e a interação com a sociedade. A Organisation for Economic Co-Operation and Development (OECD) (OECD, 2003) define e-governo como sendo o uso de TIC e, em particular a Internet, como ferramenta para atingir um governo melhor.

Segundo Grönlund (2002), e-governo visa: (1) facilitar o acesso dos cidadãos e empresas às informações e serviços do governo, (2) aumentar a qualidade dos serviços pelo aumento da velocidade, integridade e eficiência do processo e (3) melhorar os processos democráticos.

As ações de e-governo alinham-se, basicamente, para permitir a conexão eletrônica entre o próprio governo, cidadãos e organizações. A Figura 13 ilustra a abrangência de e-governo e suas possíveis interações: governo para governo (G2G), governo para cidadão (G2C) e governo para negócios (G2B). G2G representa a integração entre os serviços governamentais, visando mudança de processo de trabalho e gestão, G2C representa a interação direta do governo com o cidadão, por meio de serviços prestados aos cidadãos e G2B representa interação entre governo e empresas não governamentais.

Segundo OECD (2005), as operações de governo são classificadas em back office e em front office. As back office referem-se às operações internas de uma organização. Essas funções de governo que normalmente não interagem com entidades externas, por exemplo, como calcular benefícios ou aplicação das leis ambientais. Já as front offices referem-se às operações de governo acerca das informações e serviços prestados, nas interação entre o governo e os cidadãos e consumidores de serviços. Se os canais de comunicação e processos de back office estiverem integradas, será melhor a qualidade dos serviços de governo e a entrega 
Figura 13: Abrangência do governo eletrônico

G2C

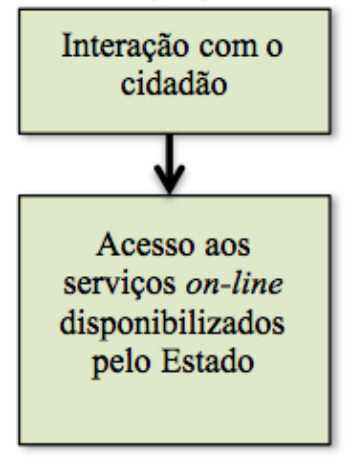

FOCO: Internet
G2G

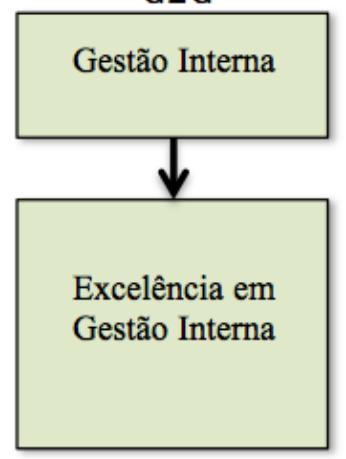

FOCO: Intranet
G2B

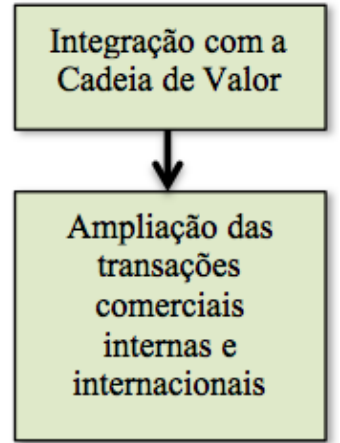

FOCO: Extranet

Fonte: Adaptado de Maciel (2008)

de serviços ao cidadão. Conforme Bekkers (2005), as colaborações em back office geralmente enfrentam dificuldades devido a problemas de falta de interoperabilidade.

A inovação de serviços bem sucedida e a prestação de serviços multi-canal dependem de estratégias, políticas e arquiteturas que permitem que dados, sistemas de $\mathrm{Tl}$, processos de negócios e canais de distribuição operem, de modo que os serviços possam ser devidamente integrados. Se os canais e processos de back office são integrados, diferentes canais podem complementar-se, melhorando a qualidade dos serviços e a entrega de serviço ao governo e ao cidadão simultaneamente (GOTTSCHALK; SOLLI-SAETHER, 2009).

Nesse contexto, Lin et al. (2008) ressaltam que a construção de sistemas de informação, quer sejam internos ou externos aos departamentos de governo, e a forma de integrá-los adequadamente estão relacionados a e-governo.

Conforme descrito em UNPAN (2012), às vezes é difícil alcançar a interoperabilidade em organizações governamentais. Em algumas situações, as entidades governamentais relutam para mudar os processos de trabalho existentes, dispor seus dados e serviços aos parceiros externos e renegociar suas operações com as partes externas.

Atualmente, o termo serviço relacionado TIC e a e-governo é abrangente, e por vezes utilizado para:

- Serviço eletrônico (e-service) prestado diretamente ao cidadão, por meio de uma interface de usuário final. Segundo Scupola, Henten e Nicolajsen (2010), um dos principais grupos de e-service é o relacionado a governo, em que os serviços são de natureza não comerciais voltados à sociedade;

- Serviço desenvolvido segundo os preceitos do paradigma orientado a 
serviços que representam programas de software. Esses programas, fisicamente independentes, fornecem uma coleção de capacidades relacionadas a um contexto funcional distinto.

Quando o governo oferece um serviço eletrônico ao cidadão por meio de um aplicativo, esse aplicativo pode estar consumindo um serviço ou não, isso depende da abordagem utilizada para o desenvolvimento da aplicação.

Neste trabalho, o termo serviço é utilizado para representar uma interface de software fornecida e consumida pelas instituições governamentais ou consumidas pelas organizações externas ao governo, por meio de aplicações clientes.

\subsubsection{Serviço Entregue ao Cidadão}

Barros, Cepik e Canabarro (2010) traçam um comparativo entre o modelo tradicional de interação Estado-Cidadão e o modelo ideal de interação Estado-Cidadão, conforme apresentado nas Figuras 14 e 15, respectivamente.

No modelo tradicional de interação, cada organização define seus processos de negócio e trâmites de relacionamento, sem estabelecer relações internas com outras organizações. Dessa forma, quando um cidadão precisa de algum serviço público fornecido pelo Estado, o cidadão solicita o serviço. Todavia, caso sejam necessários outros serviços intermediários e interações com outras agências ou órgão públicos para o fornecimento apropriado do serviço, o próprio cidadão deve recorrer a diferentes serviços públicos. Conforme a Figura 14, caso o cidadão precise do serviço $\mathrm{A}$, este precisa recorrer a serviços intermediários $\mathrm{B}$ e C.

Figura 14: Modelo Tradicional de Interação Estado Cidadão

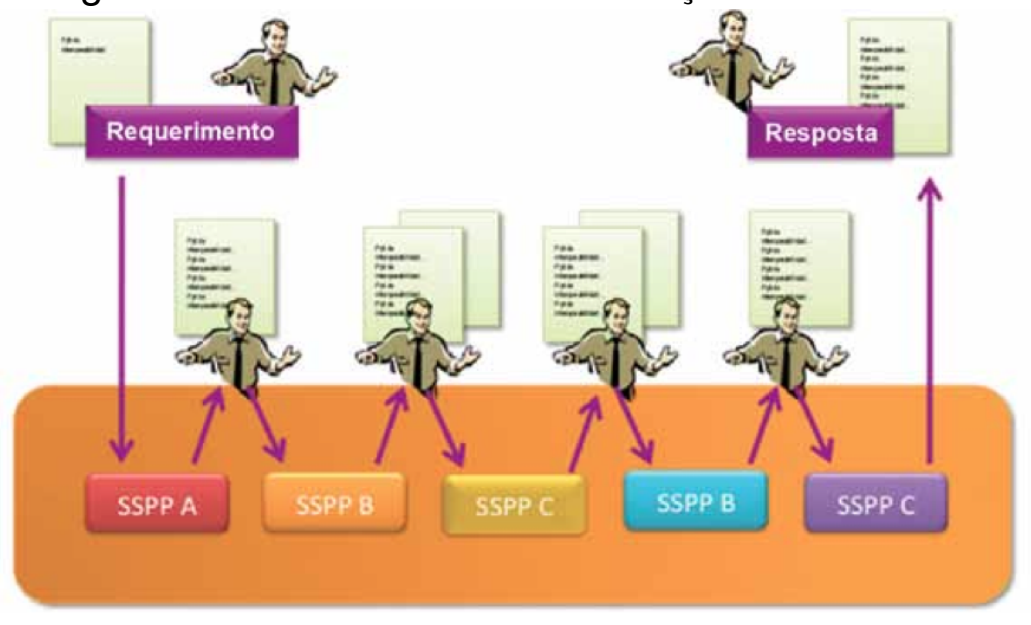

Fonte: Barros, Cepik e Canabarro (2010)

No modelo de interação ideal, tem como premissa um ponto único de 
atendimento ao cidadão. A partir deste ponto único, a solicitação é realizada e, caso sejam necessárias informações intermediárias para entregar o que foi requerido pelo cidadão, este não precisa intervir. Conforme a Figura 15, as interações com os serviços B, C e D não precisam ser realizadas diretamente pelo cidadão, pois as instituições públicas para atender a demanda inicial do cidadão "conversam" entre si.

Figura 15: Modelo Ideal de Interação Estado Cidadão

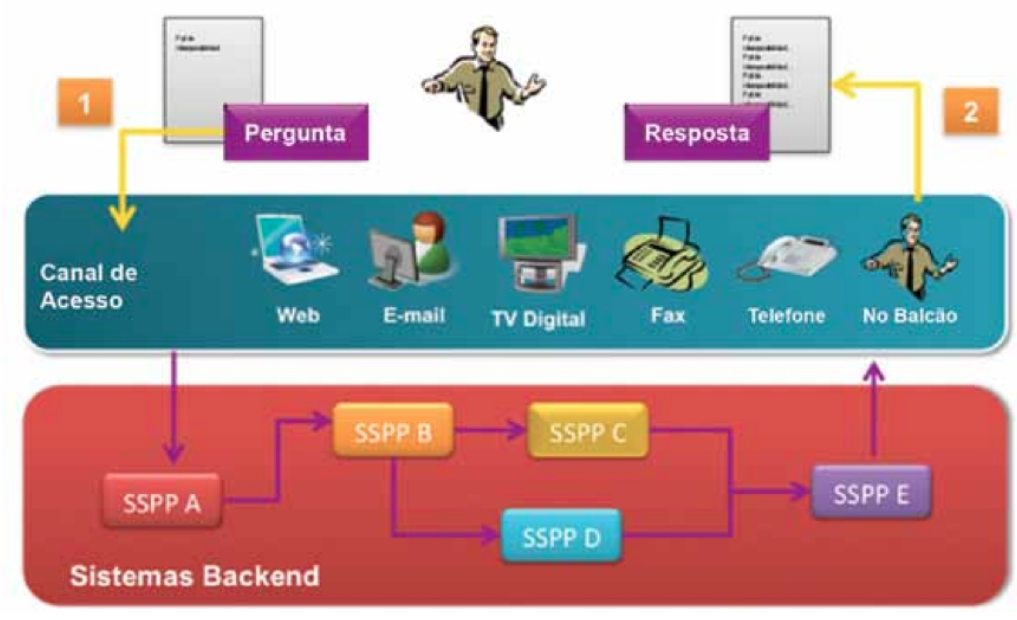

Fonte: Barros, Cepik e Canabarro (2010)

Conforme Ray et al. (2011), a fim de buscar os serviços do governo, o cidadão deve estar atento à estrutura e funcionamento do governo para localizar o departamento que oferece o serviço e isso pode exigir várias visitas à agência e ainda assim precisar submeter, mais de uma vez, a mesma informação em diferentes agências para se valer de um serviço. Um ponto único online governamental é a solução para esses problemas (WIMMER, 2002).

Santos (2010) também ressalta que o ambiente ideal para transações de e-governo se configura como um único ponto de acesso a informações e serviços. Dessa forma, se faz necessário a adoção de padrões, visando à integração dos sistemas e compartilhamento de informações entre órgãos e instâncias de governo.

A avaliação ou melhoria na prestação de serviços ao cidadão tem sido fonte de pesquisas. Miyamaru et al. (2008) abordam o uso de padrões de tarefas para prestação de serviços públicos para o cidadão por meio de mídias, e Dijk et al. (2007) apresentam um caso de uso na Holanda a respeito da necessidade de o cidadão conhecer e ter habilidades para usar os serviços de e-governo.

Em relação a disponibilização de serviços de e-governo, o relatório da United Nations Public Administration Network (UNPAN) (UNPAN, 2012) apresenta um modelo de quatro estágios para identificar os tipos de serviços de e-governo disponibilizados. 
Neste relatório, também é apresentado o índice de desenvolvimento em 190 países, que são membros das Nações Unidas. Entre esses, o Brasil ocupou a 59ª posição na colocação geral e 5⿳亠丷a posição na América do Sul.

\subsubsection{Serviço Entregue as Aplicações}

Segundo Ray et al. (2011), as agências governamentais fazem suas próprias decisões operacionais de TIC autônoma e adotam tecnologias e soluções de Sistemas de Informação com especificações relevantes para a sua necessidade particular, sem atentarem para as necessidades de promover a interação com outros sistemas de informação dentro ou fora dos limites da organização. Como resultado, atualmente aplicações autônomas e informações heterogêneas sofrem de problemas de integração.

Em um trabalho sobre integração de aplicações empresarias (EAI) Du (2010) ressalta que, as aplicações em monopólios estatais tem muitas funções similares, mas estas funções pertencem a níveis hierárquicos diferentes dentro da corporação. Este tipo de sistema é chamado de Sistema de Aplicação Vertical. Muitas vezes as funções são desenvolvidas repetidas vezes na mesma aplicações ou em varias aplicações em diferentes departamentos. A consequência é investimento de TIC em funções repetitivas e a qualidade do software utilizado pode variar muito.

E-governo apresenta-se como domínio propício para implantação de soluções orientadas a serviços, devido ao grande número de sistemas existentes, pela diversidade tecnológica, heterogeneidade nos ambientes de desenvolvimento e execução dessas aplicações, pela necessidade de integração entre os sistemas e necessidade de gestão da qualidade dos serviços prestados.

Conforme Feenstra e Janssen (2008), centenas de serviços estão sendo desenvolvidos simultaneamente em diversos projetos em áreas diferentes do governo. $\mathrm{Na}$ verdade, os investimentos no desenvolvimento de serviços deveriam ser subsidiados pela previsão de retorno com a implementação de um serviço e o seu potencial de reuso.

Neste contexto, o domínio de governo mostra-se com alto potencial de reuso de serviços e de conceitos de serviços. O reuso do serviço está relacionado ao consumo do serviço implantado, pois este pode ser consumido por aplicações distintas. O reuso de projeto de serviços está relacionado ao reuso de soluções de negócios para a criação de novas aplicações, pois o domínio de governo possui processos de negócios similares nos poderes e esferas de governo. 
Desafios do desenvolvimento de serviços com a finalidade de implementar a interoperabilidade G2G são tradados por Klischewski e Askar (2010). Esses desafios estão relacionados a fatores como, a definição do escopo do serviço e a definição da granularidade da interface do serviço.

Os governos estão adotando estratégias diferentes para atingir a interoperabilidade de sistemas de informação, dentre as quais está a definição de framework de interoperabilidade de governo eletrônico. Esses frameworks são desenvolvidos de forma independente e variam amplamente na abordagem e conteúdo (RAY et al., 2011). Geralmente são compostos por um conjunto de políticas, diretrizes e melhores práticas relacionadas com a interoperabilidade dos sistemas de informação do governo, incluem especificações técnicas, semânticas e organizacionais que as agências devem seguir ao implantar soluções de TIC para apoiar suas ações em e-governo (RAY et al., 2011). O E-government Interoperability Framework (e-GIF), do governo do Reuno Unido, se tornou referência de framework de interoperabilidade (UK, 2004).

Uma pesquisa realizada em e-GIFs de 30 países, apresentada em (CSTransform, 2011), ilustra que, em relação à integração de dados, 88\% dos e-GIFs utilizam protocolos de integração SOAP para troca de mensagens, $82 \%$ utilizam XML, $72 \%$ WSDL e $65 \%$ UDDI $^{4}$. Esses resultados indicam que os governos estão adotando a arquitetura orientada a serviços por meio dos padrões da indústria para Web Services.

O Governo Federal Brasileiro desenvolveu o e-PING que define um conjunto mínimo de premissas, políticas e especificações técnicas que regulamentam a utilização da TIC no governo federal, estabelecendo as condições de interação com os demais poderes e esferas de governo e com a sociedade em geral (BRASIL, 2014). As áreas cobertas pelo e-PING são: interconexão, segurança, meios de acesso, organização e intercâmbio de informações, e integração para e-governo. Especificamente para a área de Integração para e-governo, o objetivo é aproximar e explorar fronteiras entre aspectos tecnológicos, semânticos e organizacionais, buscando inserir diretrizes e políticas de melhoria de gestão pública na visão de plataformas tecnológicas interoperáveis. Como diretriz técnica para integração de sistemas de informação, recomenda-se o uso de SOA. Alguns produtos disponibilizados são: guia de interoperabilidade e catálogo de interoperabilidade, composto por catálogo de serviços (Web Service) e catálogo de padrão de dados.

\footnotetext{
${ }^{4}$ Universal Description Discovery and Integration (UDDI) para registro e descoberta de serviços, definidos por meio de elementos XML (Bichler e Lin 2006).
} 
O Guia de Interoperabilidade de e-governo elaborado pelo United Nations Development Program (UNDP, 2007) tem sugerido que "SOA is the best underlying paradigm with which to begin to roll out e-government services that can be used in cross-agency and cross-border situations". A adoção de SOA também é recomendada pelo e-PING (BRASIL, 2014) como uma diretriz técnica para promover a integração de sistemas de informação.

Aguair et al. (2010) ressaltam que a definição de padrões, normas e métodos comuns facilitam e têm o objetivo de melhorar a interação entre os diversos poderes e esferas do governo e também com a sociedade de modo geral. Para o avanço nas ações de governo, é essencial que exista comunicação e integração entre os aspectos gerenciais e tecnológicos.

Conforme descrito em (BRASIL, 2014),

As políticas e especificações claramente definidas para
interoperabilidade e gerenciamento de informações são fundamentais
para propiciar a conexão do governo, tanto no âmbito interno como
no contato com a sociedade e, em maior nível de abrangência, com o
resto do mundo - outros governos e empresas atuantes no mercado
mundial (BRASIL, 2014).

Trabalhos abordam tecnologias, padrões e serviços para processos de negócios de e-governo visando à interoperabilidade, tais como: Lima, Medeiros e Falcão (2010), que apresentam um projeto de implementação de uma arquitetura orientada a serviços na Agência Estadual de Tecnologia da Informação de Pernambuco e Lampathaki et al. (2007), que propõem uma planilha de descrição de serviço para facilitar a localização e composição de serviço para o governo local, regional e central, buscando resolver problema de interoperabilidade.

Geralmente, as pesquisas relacionadas a e-governo são multidisciplinares (ASSAR; BOUGHZALA; BOYDENS, 2011) e (GIL-GARCIA; PARDO, 2006), envolvendo disciplinas como política, gestão e tecnológica da informação.

\subsection{Considerações Finais do Capítulo}

O presente capítulo apresentou os principais aspectos conceituais envolvidos na pesquisa em questão.

Diante do levantamento bibliográfico apresentado, pode-se afirmar a relevância do uso da computação orientada a serviços no domínio de e-governo, por ser este um cenário propício para usufruir dos benefícios da computação orientada a serviços. 
Para apresentar o termo padrão de serviço, foi feita uma breve discussão sobre os padrões de projeto, com o objetivo de mostrar a distinção entre os dois termos. Os padrões de projeto, descritos na Seção 2.3.1, são específicos para o reuso de soluções de projeto; já os padrões de serviços, descritos na Seção 2.3.2, são destinados ao reuso de soluções de negócio, pois são abstrações de serviços que podem ser reutilizadas no desenvolvimento de novos serviços.

Ciclos de vida de serviços foram analisados e escolhido o ciclo de vida que será utilizado como base neste trabalho, o modelo de ciclo de vida proposto por Marks e Bell (2006) para demonstrar o uso de padrões de serviços.

Conceitos de reutilização de software apresentados foram importantes para posicionar o conceito de padrões de serviços como apoio ao reuso, embora somente o uso de padrão de serviço não garanta o reuso. Conforme Almeida et al. (2004), o sucesso da reutilização de software não está relacionado somente aos aspectos técnicos. Segundo esses autores, é preciso considerar também aspectos, tais como: educação, treinamento, incentivos e gestão organizacional.

Na revisão da literatura, foi observado também investimentos de pesquisa na atividade de identificação e especificação de serviços no contexto da computação orientada a serviços. De modo geral, as abordagens para identificar serviços são realizadas a partir da análise de processo de negócio. Alguns trabalhos na literatura ressaltam a experiência das pessoas como fator que contribui para a identificação e especificação de serviços.

Não foi observado até o presente momento um processo de engenharia de software orientado a serviços que contemple a especificação de serviços a partir padrões de serviços, visando reaproveitar o conceito de serviço de negócio. 


\section{MODELO E DIRETRIZES PARA ESPECIFICAÇÃO DE SERVIÇOS DE E-GOVERNO}

\subsection{Considerações Iniciais}

Este capítulo faz uma caracterização da utilização de SOA no governo, com o objetivo de avaliar a importância de trabalhos que apoiem o desenvolvimento de aplicações baseadas neste paradigma.

Considerando as características inerentes ao domínio de e-governo, especialmente a redundância de regras de negócio nas esferas e poderes de governo, esta pesquisa visa subsidiar o reuso de conceitos de serviços para a concepção de novas soluções orientadas a serviços.

A fim de apoiar a especificação de serviços de e-governo, foi proposto um modelo de especificação de serviços para o domínio de e-governo (MESe-Gov) e um conjunto de diretrizes para especificação de serviços para o domínio de governo (DESe-Gov).

O capítulo também apresenta uma proposta para documentar padrões de serviços e, para cumprir tal objetivo, foram analisados outros trabalhos que apresentam propostas para documentação de serviços e de padrões de serviços. A partir dessa análise, alguns atributos foram eleitos para compor o template Especificação de Padrão de Serviço.

\subsection{Caracterização do Domínio de Governo}

Um levantamento de serviços no domínio de governo foi realizado no ano de 2013, visando coletar informações a respeito do uso de serviços (Web Services) e SOA.

O objetivo estabelecido para este levantamento foi traçar um perfil das organizações em relação ao uso de serviços e SOA no domínio de governo e obter informações sobre serviços que pudessem servir de insumo para a definição de padrões de serviços. As informações sobre a metodologia e coleta de dados do 
levantamento de serviços e a descrição dos dados quantitativos estão registrados no Apêndice B.

O questionário foi enviado para 125 organizações e respondido por 14 organizações, tendo uma taxa de rejeição de 88,8\%. Entre as organizações que responderam o questionário, $64 \%$ são da esfera estadual, $22 \%$ da esfera municipal e $14 \%$ da esfera federal. Todas as organizações que responderam ao questionário são do poder executivo.

O uso de serviços em uma organização, geralmente, se inicia como uma solução para integração de aplicações, mas desvinculadas de demais recursos de SOA (SONIC, 2005), como, por exemplo, barramento de serviços, monitoramento de serviços, etc. Com base nos dados coletados no levantamento de serviços, pode-se constatar a veracidade desta afirmação. Embora o número de questionários respondidos não tenha sido alto, foi possível observar que organizações públicas desenvolvem serviços, mas nem sempre têm experiência com SOA. Os números apurados na pesquisa indicam que somente 35\% possui experiência com SOA, por outro lado, é possível observar que $96 \%$ dos serviços foram implementados utilizando a tecnologia de Web Services.

O percentual de serviços implementados, utilizando a tecnologia de Web Services, também serve para confirmar a tendência anunciada pelos autores Papazoglou e Heuvel (2007) a respeito do uso Web Services. Isso representa um fator positivo, pois, além de todos os benefícios dos Web Services já discutidos, é possível extrair informações a respeito dos serviços publicados a partir dos descritores WSDL, podendo subsidiar a coleta de dados de maneira automatizada.

Os dados da pesquisa evidenciam que existe baixo uso de composição de serviços, pois $90 \%$ dos serviços não utilizam composição. O baixo uso de composição de serviços remete a serviços atômicos, indicando que há pouco reuso dos serviços implantados no governo. A composição é uma forma de reuso de serviço, em que vários processos de negócio podem utilizar o mesmo serviço.

Outra característica observada é que somente $20 \%$ dos serviços são monitorados com o apoio de ferramentas. Isso indica o uso de serviços com predominância para integração, pois, como os fornecedores de serviços geralmente conhecem os consumidores dos serviços e vice-versa, os problemas da ausência de monitoramento dos serviços, por vezes, resolvidos via comunicação entre as partes envolvidas após falha no funcionamento do serviço.

Outro fato que reforça a afirmação do uso de serviço com predominância para integração é o resultado da pesquisa em relação à forma de publicação do serviço. 
Mecanismos de armazenamento e localização de serviços são pouco utilizados, sendo que $92 \%$ dos serviços são localizados ou invocados diretamente pelo endereço de acesso (URL, Portas, etc), e somente $2 \%$ utilizam repositórios para catalogação e descoberta de serviços, como, por exemplo, UDDI. Os resultados analisados mostram ainda que $4 \%$ não sabiam responder a pergunta e 4\% não responderam a pergunta. O entendimento é que não tem ocorrido a necessidade de divulgação dos serviços, pois os possíveis consumidores normalmente são conhecidos.

No ano de 2010, também foi realizado um levantamento de serviço especificamente no poder executivo estadual da Administração Pública do Estado de Mato Grosso, com o objetivo de coletar informações a respeito dos mecanismos de integração, troca de informações ou computação distribuída em sistemas de governo. Pretendia-se com esse levantamento identificar cenários tecnológicos, metodológicos, padronizações e modelos arquiteturais utilizados, permitindo estabelecer pontos comuns ou divergentes em relação à utilização de serviços e SOA. As informações sobre metodologia, dados coletados, análise dos dados do levantamento realizado em 2010 estão descritos no Apêndice C.

Se comparados os resultados do levantamento realizado em 2013 com o levantamento realizado no ano de 2010, fica evidente a mudança no cenário tecnológico no poder Executivo do Estado do Mato Grosso. Em 2010, existiam serviços implementados utilizando componentes particulares de integração desenvolvidos pelas próprias instituições e outras tecnologias, como EntireX Broker ${ }^{1}$. Atualmente, essas mesmas organizações já implantaram ou têm alguma experiência em uso de serviços com Web Services.

\subsection{A Abstração: Padrão de Serviço}

O conceito de padrão de serviço é utilizado, neste trabalho, como um serviço abstrato que apresenta uma descrição genérica e reutilizável.

A abstração, conforme Larman (2007), é

$\mathrm{O}$ ato de se concentrar nas qualidades essenciais ou gerais de coisas semelhantes. Também são as características essenciais resultantes de alguma coisa (LARMAN, 2007).

Neste trabalho, o objetivo não é buscar características semelhantes em um conjunto de serviços para se especificar o padrão de serviço, mas sim buscar as características essenciais do serviço e representá-las com um padrão.

\footnotetext{
${ }^{1}$ Middleware desenvolvido pela Software AG para disponibilizar rotinas do ambiente Natural/ADABAS na forma de serviços cliente/servidor
} 
O conceito de serviço associado ao padrão de serviço pode ser reaproveitado em outro cenário de governo, ou seja, reutilizado para resolver problemas semelhantes em outro cenário. Isso é possível porque, no domínio de governo, existem muitas regras de negócio semelhantes distribuídas em diferentes esferas e poderes do governo.

Para ilustrar os níveis de abstração, a Figura 16 apresenta, no nível mais baixo, os serviços concretos, que equivalem à implementação dos serviços. No segundo nível, as abstrações são representadas por meio de especificações de serviços, WSDL e representações gráficas UML ou Service Oriented Architecture Modeling Language (SoaML). No terceiro nível, está a abstração de padrões de serviços proposta neste trabalho e representada por meio do template Especificação de Padrão de Serviço.

Figura 16: Camadas de abstração

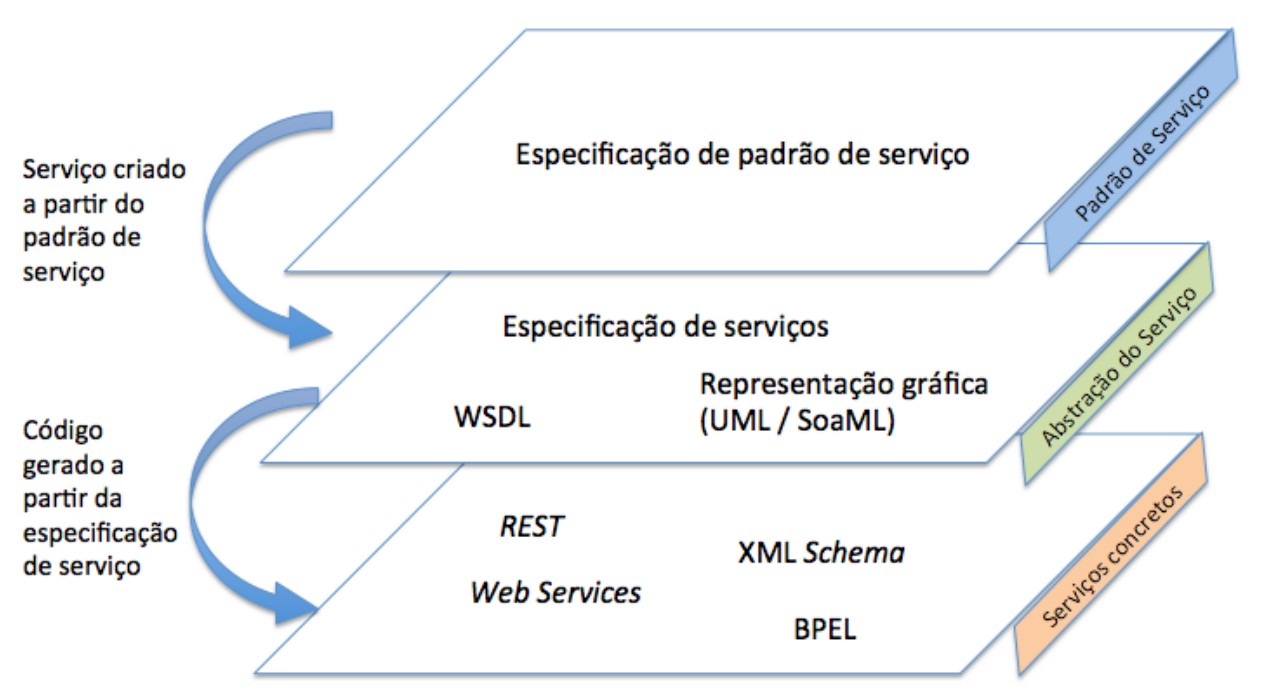

Fonte: Autor (2014)

\subsection{Padrão de Serviço e Relacionamentos}

Uma proposta de visão conceitual dos padrões de serviços e seus elementos relacionados é ilustrada na Figura 17. A partir da demanda originada, geralmente representada por um modelo de processo de negócio, o catálogo de padrões de serviços do governo pode ser consultado para localizar padrões de serviços.

Cada padrão de serviço contém:

1. Descrição do padrão de serviço - representa as informações descritivas do padrão de serviço: nome, descrição, palavras-chave, 
versão, contato, problema, solução, tipo do serviço, padrões relacionados e catálogo a que o padrão de serviço pertence;

2. Modelo de Composição - é usado em situações em que um padrão de serviço é produzido por meio da composição de outros padrões existentes. O objetivo é representar a relação entre o padrão de serviço descrito e outros padrões de serviços utilizados na composição;

3. Interface do Serviço - representa o conjunto de operações visíveis do serviço;

4. Descrição da operação - descrição textual da operação do serviço;

5. Especificação da lógica da operação - o objetivo é mostrar uma representação gráfica do processamento realizado na operação do serviço.

O padrão de serviço deve servir de referência para a especificação de um novo serviço; um serviço deve ser criado para atender processos de negócio.

Figura 17: Elementos relacionados a padrões de serviços

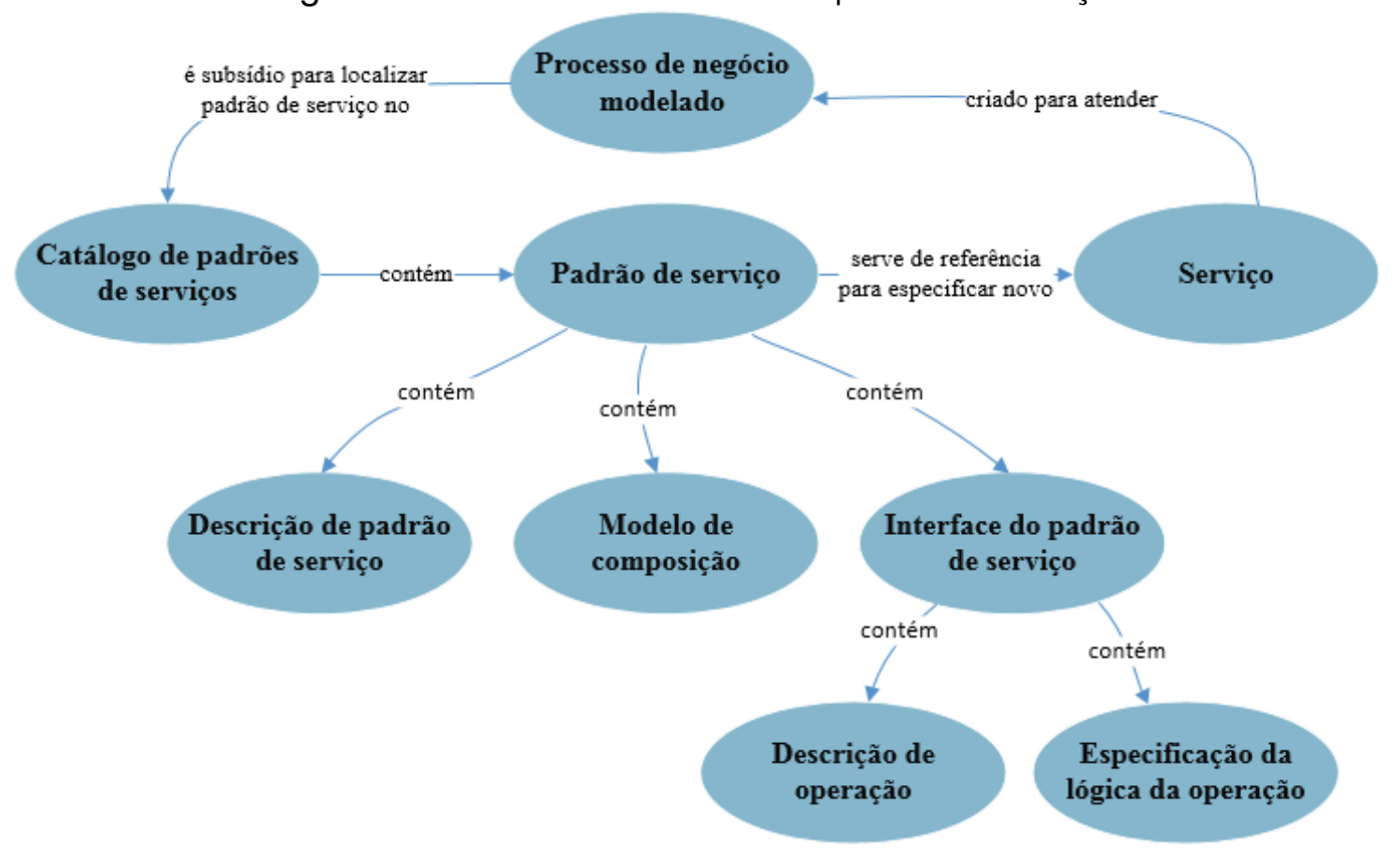

Fonte: Autor (2014) 


\subsection{Template Proposto para Especificação de Padrão de Serviço}

O esquema de descrição de padrões de serviços deve conter um conjunto de aspectos que subsidie o entendimento do padrão. Conforme Li et al. (2009), a principal vantagem de um esquema de descrição de padrão é que eles introduzem uma forma estruturada para compreender, explicar e raciocinar sobre padrões. Além disso, permitem uma comunicação mais eficaz entre os engenheiros de software e especialistas de domínio, porque um esquema de descrição de padrões, em particular, fornece a linguagem comum para falar sobre padrões.

Um serviço geralmente tem a sua abstração representada por meio de uma especificação de serviços. Na maioria dos casos, as especificações de serviços contêm detalhes dos serviços, até mesmo questões técnicas. Isso é importante para a descrição do serviço, porém as informações técnicas geralmente são utilizadas somente pela equipe de desenvolvimento dos serviços. Abstrair a essência do conceito de serviço, sem se prender a todos os detalhes contidos na descrição do serviço, não é uma tarefa simples.

Com o objetivo de definir um template para especificar os padrões de serviços, foi feita uma análise de atributos propostos por outros autores a fim de descrever serviços e padrões de serviços.

A análise dos atributos utilizados para descrever serviços foi realizada considerando as informações contidas no Documentação de Serviços de Interoperabilidade do Governo Federal do Brasil (BRASIL, 2013a) e nas informações recomendados por Erl (2009b) para descrever serviços, conforme apresentado na Seção 2.2.5.

A análise dos atributos utilizados para descrever padrões foi realizada considerando os trabalhos de Tchuta e Chunhua (2011), Li et al. (2009), Fu et al. (2009) e Fki, Tazi e Dupuy (2010), conforme descrito na Seção 2.3.2.2.

A partir da análise desses seis conjuntos de atributos, divididos em duas categorias, atributos para documentar serviços e para documentar padrões, foram selecionados alguns atributos para compor a descrição de um padrão de serviço, conforme apresentado na Tabela 9.

Os atributos Problema, Solução, Tipo, Padrões Relacionados, Palavras-chave, Versão, Nome da operação e Descrição da operação foram selecionados da literatura e usados sem alteração da nomenclatura e semântica. Outros atributos tiveram a sua semântica alterada ou foram originados da junção de outros atributos, conforme 
Tabela 9: Origem dos atributos do template Especificação de Padrão de Serviço

\begin{tabular}{|c|c|c|c|c|c|c|c|}
\hline Atributos & $\begin{array}{l}\text { Tchuta e } \\
\text { Chunhua } \\
\text { (2011) }\end{array}$ & $\begin{array}{l}\text { Li et al. } \\
(2009)\end{array}$ & $\begin{array}{l}\text { Fu et al. } \\
(2009)\end{array}$ & $\begin{array}{l}\text { Fki, Tazi } \\
\text { e Dupuy } \\
(2010)\end{array}$ & $\begin{array}{l}\text { Brasil } \\
(2013)\end{array}$ & $\begin{array}{l}\text { Erl } \\
(2009 b)\end{array}$ & $\begin{array}{l}\text { Template proposto } \\
\text { para especificaçăo } \\
\text { do padråo de serviço }\end{array}$ \\
\hline Nome do padrão & $x$ & $\mathrm{X}$ & $\mathrm{X}$ & $\mathrm{X}$ & - & - & \multirow{2}{*}{ Nome } \\
\hline Nome do serviço & & & & & $\mathrm{X}$ & $\mathrm{X}$ & \\
\hline Contexto & $\mathrm{X}$ & $\mathrm{X}$ & $\mathrm{X}$ & - & - & - & \multirow{2}{*}{ Descriçăo } \\
\hline Intenção & - & - & $\mathrm{X}$ & - & - & - & \\
\hline Problema & $\mathrm{X}$ & $\mathrm{X}$ & - & - & - & - & Problema \\
\hline Soluçăo & $\mathrm{X}$ & $\mathrm{X}$ & - & - & - & - & Soluçăo \\
\hline Tipo do serviço & - & - & - & $\mathrm{X}$ & $\mathrm{X}$ & - & Tipo \\
\hline $\begin{array}{l}\text { Padrōes } \\
\text { relacionados }\end{array}$ & $\mathrm{X}$ & - & - & - & - & - & $\begin{array}{l}\text { Padrōes } \\
\text { relacionados }\end{array}$ \\
\hline Modelo de Serviço & - & - & - & - & - & $\mathrm{X}$ & \multirow{3}{*}{$\begin{array}{l}\text { Modelo de } \\
\text { composiçåo }\end{array}$} \\
\hline $\begin{array}{l}\text { Papel da } \\
\text { composiçăo }\end{array}$ & - & - & - & - & - & $\mathrm{X}$ & \\
\hline $\begin{array}{l}\text { Capacidade dos } \\
\text { membros da } \\
\text { composiçăo }\end{array}$ & - & - & - & - & - & $\mathrm{X}$ & \\
\hline Catálogo & - & - & $\mathrm{X}$ & - & - & - & \multirow{2}{*}{ Catálogo } \\
\hline Assunto do serviço & & & & & $\mathrm{X}$ & - & \\
\hline Palavras-chave & - & - & - & - & - & $\mathrm{X}$ & Palavras-chave \\
\hline Versão do serviço & - & - & - & - & $\mathrm{X}$ & $\mathrm{X}$ & Versăo \\
\hline Contato do serviço & - & - & - & - & $\mathrm{X}$ & - & \multirow{2}{*}{ Contato } \\
\hline Administrador & - & - & - & - & - & $\mathrm{X}$ & \\
\hline $\begin{array}{l}\text { Nome da operaçăo } \\
\text { na interface do } \\
\text { serviço }\end{array}$ & - & - & - & - & $\mathrm{X}$ & $\mathrm{x}$ & \multirow[b]{2}{*}{ Interface } \\
\hline $\begin{array}{l}\text { Parâmetro(s) de } \\
\text { entrada e } \\
\text { parâmetro(s) de } \\
\text { saída }\end{array}$ & - & - & - & - & $\mathrm{x}$ & $\mathrm{x}$ & \\
\hline \multirow[t]{2}{*}{$\begin{array}{l}\text { Descrição da } \\
\text { operaçăo }\end{array}$} & - & - & - & - & $x$ & $\mathrm{x}$ & $\begin{array}{c}\text { Descrição da } \\
\text { operaçăo }\end{array}$ \\
\hline & & & & & & & $\begin{array}{c}\text { Especificação da } \\
\text { Lógica da operaçăo }\end{array}$ \\
\hline
\end{tabular}

Fonte: Autor (2014)

descrito a seguir:

O atributo Descrição foi originado do atributo Contexto, conforme proposto por Li et al. (2009) e do atributo Intenção. Dessa forma, o atributo Descrição contém o contexto de utilização do padrão de serviço e também o propósito de utilização do padrão de serviço.

O atributo Nome, que identifica o padrão de serviço, é originado da necessidade do nome do padrão e do nome do serviço, pois o padrão de serviço representa uma abstração de um serviço.

O atributo Modelo de Composição do padrão de serviço foi originado dos atributos Modelo de serviço, Papel da composição e Capacidade dos membros da composição.

O atributo Catálogo surgiu da junção dos atributos Catálogo e Assunto. O atributo Assunto proposto por BRASIL (2013a) identifica as áreas temáticas referentes as informações disponibilizadas no serviço. Essas áreas temáticas são baseadas no Vocabulário Controlado do Governo Eletrônico (VCGE) (BRASIL, 2013b) e serão 
utilizadas como referência para catalogar os padrões de serviços.

O atributo Versão, embora tenha uma relação direta com o atributo Versão do Serviço, não irá representar a versão do serviço, conforme proposto por (ERL, 2009a). O atributo Versão representa a versão da especificação do padrão, isso porque o padrão de serviços não é implementável.

Em vez de nome do servidor público, o atributo Contato representa o cargo e instituição responsável por documentar o padrão de serviço, por considerar que os servidores públicos podem mudar sua lotação na organização. Erl (2009b) enfatiza que as informações do contato devem ser do administrador oficial ou proprietário do serviço, enquanto BRASIL (2013a) registra que devem ser utilizados contatos institucionais, devem-se fornecer dados do departamento em vez de fornecer dados de um servidor.

O atributo Interface do serviço foi originado dos atributos Nome da operação na interface do serviço e Parâmetros de entrada e saída. No template Especificação de Padrão de Serviço, foi criado um atributo Interface do serviço, no qual são descritas todas operações e as informações de entrada e saída, mas sem descrever os detalhes da estrutura de dados.

O atributo Especificação da lógica da operação foi proposto para representar a visão geral da lógica executada pela operação do serviço. O uso de um diagrama é proposto com o objetivo de auxiliar o entendimento geral da operação realizada pelo serviço.

A partir da análise de duas estruturas de documentação de serviços e de quatro trabalhos que documentaram padrões, foi proposto o template nomeado de Especificação de Padrão de Serviço, como apresentado na Tabela 10.

\subsection{Modelo Conceitual de Especificação de Serviços de e-Governo}

Esta seção apresenta uma visão conceitual do modelo MESe-Gov e uma descrição em alto nível do contexto em que as diretrizes DESe-Gov são aplicadas.

Os principais objetivos do MESe-Gov e DESe-Gov são:

1. fornecer mecanismos para subsidiar o reuso de conceitos de serviços de e-governo;

2. agregar valor à atividade de especificação de serviço no ciclo de vida de serviços para o domínio de e-governo; e 
Tabela 10: Template Especificação de Padrão de Serviço

\begin{tabular}{|c|c|}
\hline Nome do Padrão & $<$ Nome que identifica o padrão de serviço> \\
\hline Descrição & $\begin{array}{l}\text { <Texto que descreve o contexto de utilização e os propósitos do } \\
\text { padrão de serviço> }\end{array}$ \\
\hline Problema & $\begin{array}{l}\text { <Descrição do problema recorrente para o qual a solução foi } \\
\text { definida> }\end{array}$ \\
\hline Solução & $\begin{array}{l}\text { <Descrição do princípio fundamental da solução proposta pelo } \\
\text { padrão de serviço> }\end{array}$ \\
\hline Tipo & $\begin{array}{l}\text { <Especifica o tipo de serviço prestado pelo padrão, se é atômico ou } \\
\text { composto> }\end{array}$ \\
\hline $\begin{array}{l}\text { Padrões } \\
\text { Relacionados }\end{array}$ & $<$ Nome de outros padrões relacionados com o padrão descrito $>$ \\
\hline $\begin{array}{l}\text { Modelo de } \\
\text { Composição }\end{array}$ & $\begin{array}{l}\text { <Representação gráfica do modelo de composição utilizado no } \\
\text { padräo de serviço> }\end{array}$ \\
\hline Catálogo & <Descreve o nome do catálogo que padrão de serviço pertence> \\
\hline Palavras-chave & $\begin{array}{l}\text { <Uma ou mais palavras-chave relacionadas a área de negócio do } \\
\text { serviço> }\end{array}$ \\
\hline Versão & <Versão do padrão de serviço> \\
\hline Contato & <Contato da instituição que documentou o padrão de serviço $>$ \\
\hline Interface & <Representação da interface do padrão de serviço > \\
\hline Operação & $<$ Nome da operação do serviço> \\
\hline $\begin{array}{l}\text { Descrição da } \\
\text { Operação }\end{array}$ & <Descrição da operação do serviço> \\
\hline $\begin{array}{l}\text { Especificação da } \\
\text { Lógica da Operação }\end{array}$ & $\begin{array}{l}\text { <Representação gráfica da lógica da operação do padrão de } \\
\text { serviço> }\end{array}$ \\
\hline$\ldots$ & $\ldots$ \\
\hline
\end{tabular}

Fonte: Autor (2014)

3. reduzir a redundância de esforços para a especificação de novos serviços com propósitos similares em outras esferas e poderes de governo.

O objetivo do modelo MESe-Gov é que serviços já existentes no governo, possam se tornar referência de consulta para auxiliar a criação de outros serviços. A Nota Fiscal Eletrônica (NF-e), é um exemplo, no Brasil, de um modelo de serviço que está sendo utilizado como referência para criação de outros serviços, com propósitos similares e também para criação do mesmo serviço em vários Estados e Municípios Brasileiros.

Conforme ilustrado na Figura 18, os padrões de serviços são especificados e catalogados a partir de serviços já utilizados nas organizações públicas. Esses padrões devem formar um catálogo de padrões de serviços de e-governo, para subsidiar a especificação e projeto de novos serviços. As implementações dos serviços originados a partir dos padrões de serviços compõem inventários de serviços de organizações públicas do governo.

No modelo MESe-Gov, conforme ilustrado na Figura 18, os padrões de serviços são especificados e catalogados a partir de serviços já utilizados nas organizações públicas, com objetivo de abstrair os conceitos de serviços existentes 
no domínio de e-governo e representá-los como padrões de serviços. Esses padrões devem formar um catálogo de padrões de serviços de e-governo, para subsidiar a especificação e projeto de novos serviços. Para se criar um novo serviço, o catálogo de padrões de serviços deve ser consultado e o padrão de serviço deve servir como referência para a especificação de um novo serviço. As implementações dos serviços originados a partir dos padrões de serviços compõem inventários de serviços de organizações públicas do governo.

Figura 18: MESe-Gov - Modelo para Especificação de Serviços de e-Governo

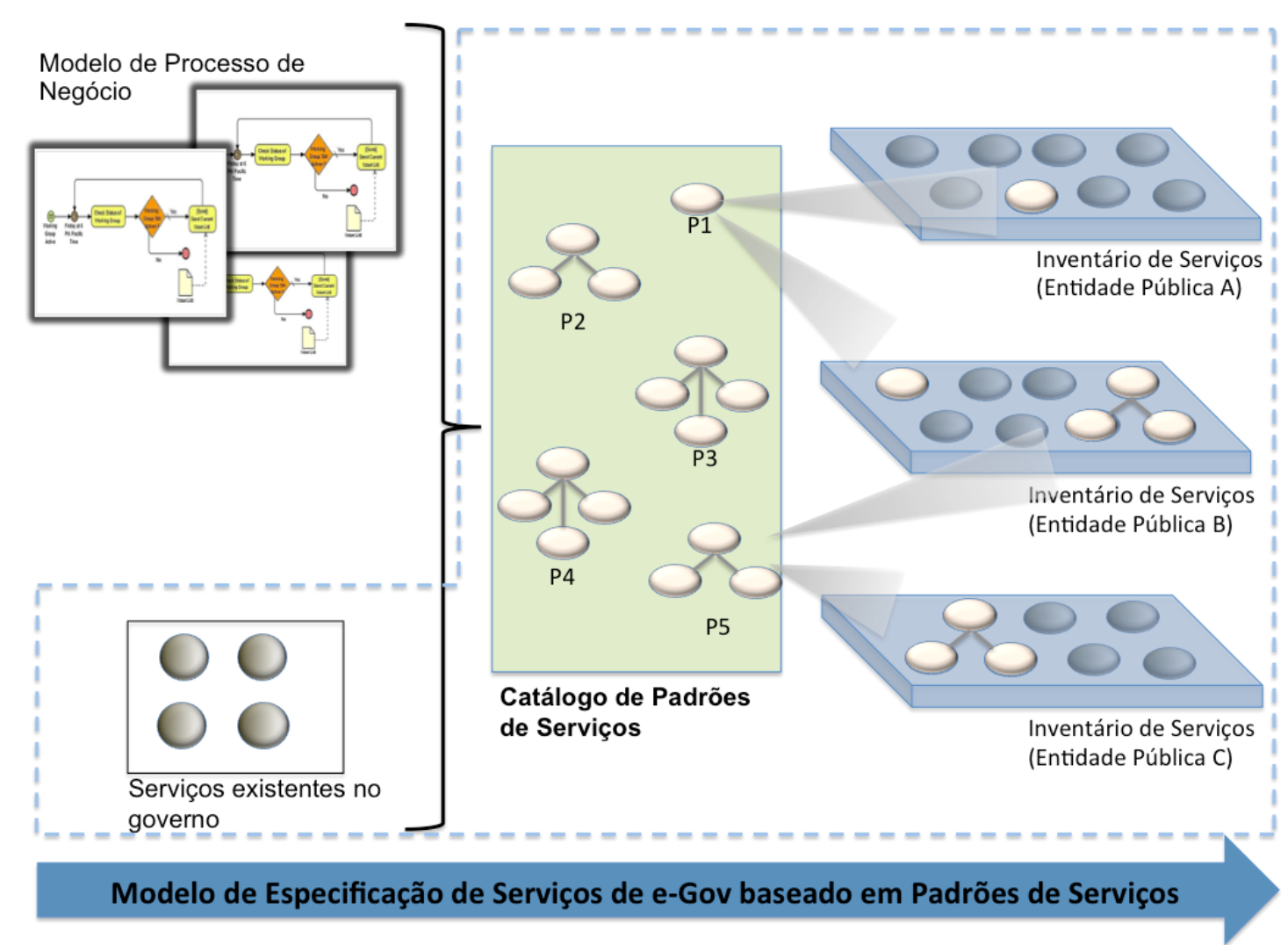

Fonte: Autor (2014)

Diante do modelo apresentado na Figura 18, surgem os seguintes questionamentos:

- Como especificar os padrões de serviços?

- Qual o nível de abstração devem ter os padrões de serviços?

- Como utilizar os padrões de serviços?

Para direcionar e apoiar a tarefa de especificação e utilização de padrões de serviços, foi proposto um conjunto de diretrizes, conforme ilustrado na Figura 19.

As diretrizes estão organizadas para subsidiar as seguintes atividades: 
Figura 19: MESe-Gov - Modelo de Especificação de Serviços de e-Governo e suas atividades

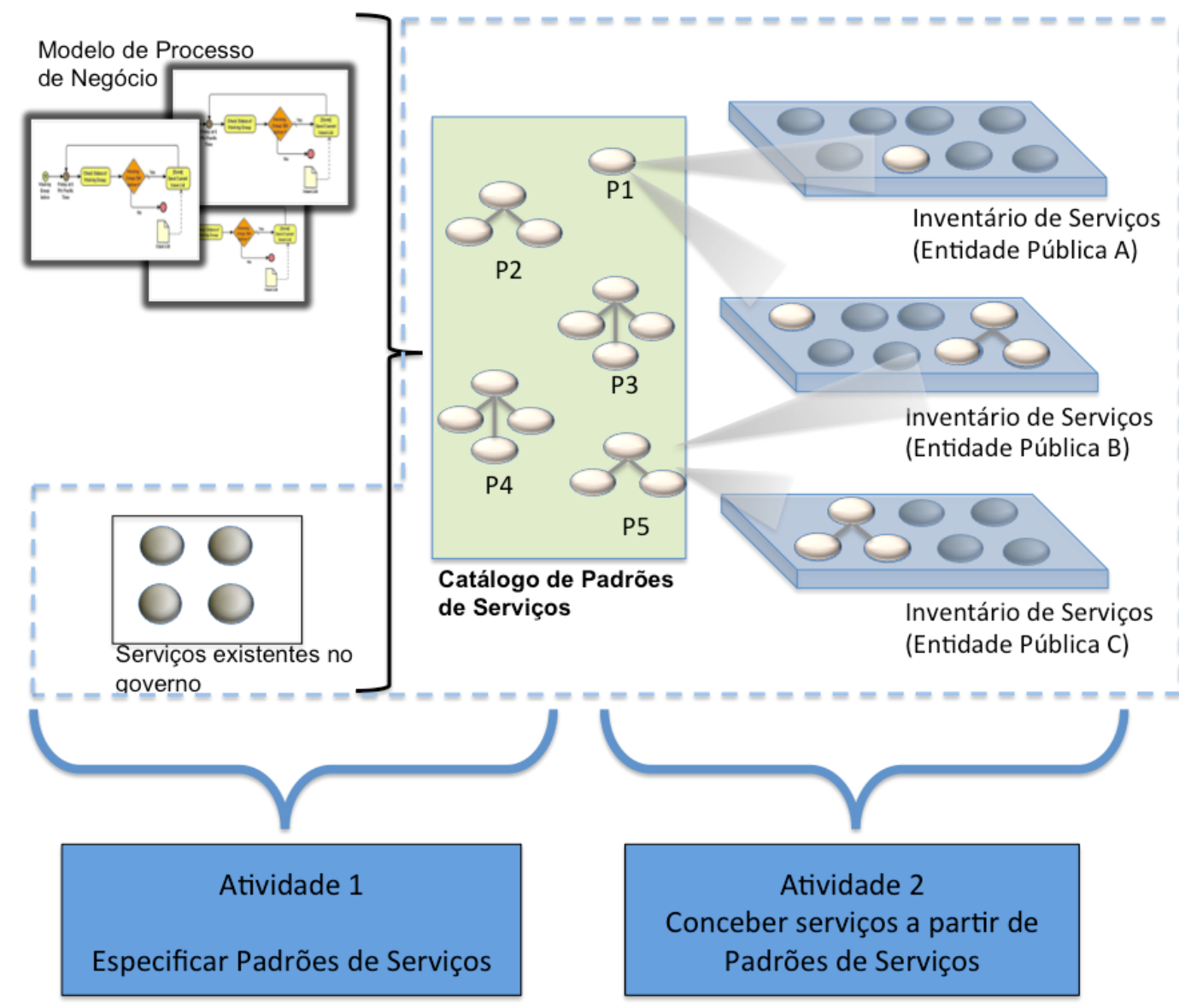

Fonte: Autor (2014)

1. Especificar os padrões de serviços: para especificar os padrões, deve-se abstrair o conceito vinculado ao serviço e representá-lo como um padrão de serviço e isso pode ser feito seguindo os passos:

(a) levantar os serviços existentes;

(b) documentar o padrão de serviço utilizando o template Especificação de Padrão de Serviço;

(c) catalogar o padrão de serviço e disponibilizá-lo em um catálogo de padrões de serviços;

2. conceber novos serviços a partir dos padrões de serviços catalogados.

\subsection{Definição das Diretrizes para Especificação de Serviços de e-Governo}

Nesta Seção, são apresentadas as diretrizes estabelecidas como um conjunto de instruções, para fornecer suporte ao modelo conceitual proposto e orientar os 
especialistas para especificar padrões de serviços e para criar serviços a partir desses padrões de serviços.

As diretrizes são apresentadas em dois grupos: diretrizes para especificação de padrões de serviços de e-governo e diretrizes que apoiam o uso de padrões de serviços na atividade de criação de novos serviços, conforme descrito nas duas seções seguintes.

\subsubsection{Especificação de Padrões de Serviços}

Especificar os padrões de serviços consiste em abstrair conceito vinculado a serviço e representá-lo como um padrão de serviço.

Figura 20: Atividade - especificar padrões de serviços

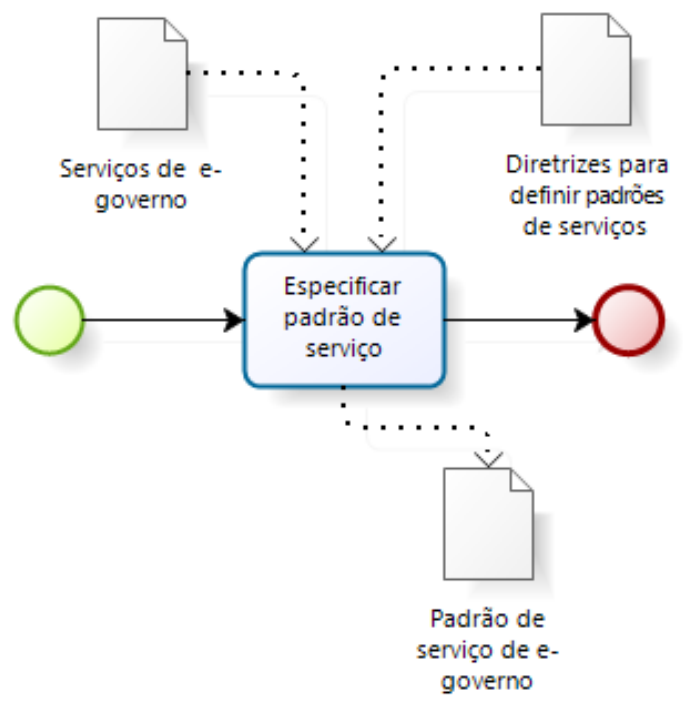

Fonte: Autor (2014)

O objetivo dessa atividade é que, a partir do artefato de entrada (o serviço de e-governo), as diretrizes possam ser aplicadas para especificar padrão de serviço e produzir como resultado o artefato de saída (o padrão de serviço de e-governo), conforme ilustrado na Figura 20.

A seguir são apresentadas as diretrizes propostas para a especificação de padrão de serviço.

\section{Diretriz 1. Análise dos serviços de negócio de governo}

Utilizando a classificação de tipos de serviços apresentada por Erl (2009b) e descrita na Seção 2.2.1, devem ser considerados para análise os serviços tarefa e os serviços entidade. Além dos tipos de serviços, devem ser considerados os serviços 
que atendam a processos de negócio semelhantes em diferentes esferas e poderes de governo.

Para especificar padrões de serviços é preciso conhecer os serviços. Quando o especialista que está especificando o padrão de serviço é o mesmo que definiu o serviço, o procedimento para especificar o padrão é mais fácil, por conta da experiência do especialista na área de negócio.

O artefato de entrada utilizado para representar um serviço pode ser a Especificação de Serviços ou o WSDL, caso o serviço tenha sido implementado utilizando essa abordagem.

\section{Procedimento}

Considerando, por exemplo, o template Documentação de Serviços de Interoperabilidade (BRASIL, 2013a) como entrada para a atividade de análise do serviço, devem-se obter as seguintes informações do serviço para a especificação de um padrão de serviço:

- Nome do serviço

- Descrição

- Assunto

- Operações

- Nome

- Descrição

- Parâmetro(s) de entrada(s) e saída(s)

As informações nome do serviço, operações com os respectivos parâmetros de entrada e saída também podem ser analisadas no WSDL. A análise dessas informações do WSDL pode ser feita diretamente no XML ou por meio de uma ferramenta que as extraia.

Quando o serviço é composto e a composição é implementada por meio do Business Process Execution Language (BPEL) ${ }^{2}$, a análise da composição deve levar em consideração também a extração de dados diretamente do BPEL.

\section{Diretriz 2. Padrão de serviço documentado de forma padronizada}

O uso do template Especificação de Padrão de Serviço, proposto na Seção 3.5, tem o objetivo de permitir que todos os padrões de serviços sejam documentados

\footnotetext{
${ }^{2} \mathrm{~A}$ especificação do padrão BPEL é constituído de elementos XML pré-definidos, que são usados em construções lógicas para a automação de processos de negócio das organizações/corporações (KUMAR; NARAYAN; NG, 2012).
} 
de forma padronizada. Além disso, tem como objetivo extrair o conceito básico do serviço, eliminando os detalhes de implementação, estrutura de dados e tecnologia de comunicação.

Antes de iniciar o procedimento de criação do padrão de serviço, é preciso consultar se no catálogo de padrões de serviços já existe um padrão de serviço para resolver o mesmo problema. Por isso, deve-se analisar a diferença entre a solução proposta e o novo padrão a ser documentado. Caso não haja diferença entre as soluções propostas para resolver o mesmo problema, deve-se considerar que o padrão de serviço candidato já está documentado. Caso contrário, deve-se documentar o novo padrão de serviço.

A solução fornecida por um determinado padrão pode não representar necessariamente a única solução adequada para o problema, ou seja, podem existir vários padrões que fornecem soluções alternativas para o mesmo problema. Cada solução terá suas próprias exigências e consequências, e cabe ao profissional escolher a solução (ERL, 2009a).

As informações devem ser preenchidas seguindo as instruções contidas no template Especificação de Padrão de Serviço. Em relação aos diagramas a serem elaborados para representar o modelo de composição, a interface do serviço e especificação da lógica da operação do serviço, são apresentadas as seguintes considerações:

\section{- Modelo de composição}

Neste trabalho, a representação do modelo de composição de serviço é realizada por meio do Diagrama de Arquitetura de Serviços da SoaML.

Os documentos de especificação de serviços geralmente registram os serviços atômicos, descrevendo todas as suas características, mas, na maioria das vezes, não registram aspectos referentes à composição de serviços. Embora a estrutura de descrição de serviço proposta por Erl (2009b) possua atributo para descrever o papel da operação do serviço na composição, nem sempre este é o padrão utilizado para documentar os serviços no governo. O padrão de especificação de serviços fornecido pelo Governo Federal (BRASIL, 2013a) também não possui informações sobre composição de serviços.

A princípio, é sugerida a análise de modelos que representam a composição de serviços do SoaML. Caso não exista essa documentação, deve-se utilizar o código BPEL para extrair informações de composição de serviços, caso a composição tenha sido implementada via BPEL. 


\section{- Interface}

A interface do padrão do serviço deve conter somente as informações de negócio e não conter informações técnicas ou de controle.

Para descrever a interface do serviço, é proposto o uso do diagrama de classe da UML, com o estereótipo Servicelnterface.

\section{- Especificação da lógica da operação}

Neste trabalho, a lógica da operação do serviço é representada por meio do Diagrama de Atividade da UML.

A lógica executada pela operação realizada no serviço pode ser extraída a partir da descrição da operação no documento de especificação de serviço.

Embora os padrões de serviços sejam especificados a partir de serviços existentes, não é garantido que os serviços tenham sido definidos e implementados seguindo os princípios e boas práticas de projeto. Nesse caso, recomenda-se:

1. Verificar se o serviço atende aos princípios de projeto propostos por Erl (2009b);

2. Seguir os padrões de projeto $S O A^{3}$ propostos por Erl (2009a) e descritos na Seção 2.3.1.

\section{Diretriz 3. Catálogo de padrões de serviços definido e mantido}

Com o objetivo de auxiliar na localização e acesso aos padrões de serviços, é observada a necessidade de usar catálogo de padrões de serviços para reunir os padrões de serviços de e-governo definidos e documentados.

Para catalogar os padrões de serviços, é proposto utilizar o Vocabulário Controlado do Governo Eletrônico (VCGE)4(BRASIL, 2013b), que é um vocabulário controlado para indexar informações (documentos, bases de dados, sites, etc) no governo federal. Cada padrão de serviço especificado deve pertencer a um catálogo nomeado segundo os termos descritos no VCGE.

Os catálogos de padrões de serviços têm como objetivo subsidiar o reuso do conceito de serviço representado por meio de padrões de serviços. A criação do catálogo de padrões de serviços por si só não garante o reuso, porém pode apoiar

\footnotetext{
${ }^{3}$ Catálogo de Padrões SOA disponível em http://soapatterns.org/

${ }^{4}$ Segundo BRASIL (2013b) o VCGE "foi projetado com dois objetivos básicos: interface de comunicação com o cidadão e ferramenta de gestão. Como interface de comunicação com o cidadão ele deve indexar as informações de governo de uma forma simples e entendível. Como ferramenta de gestão ele deve ajudar aos gestores a gerenciarem suas informações".
} 
o reuso e a concepção de serviços, pois o sucesso para obter o reuso não depende somente de questões técnicas, mas está fortemente relacionado a questões de gestão e cultura organizacional.

\section{Diretriz 4. Padrão de serviço criado e alterado conforme o fluxo de atualização}

Neste trabalho, propõe-se um fluxo de atualização dos padrões de serviços, contemplando desde a criação até o gerenciamento do padrão de serviço, ressaltando que os padrões de serviços devem ser identificados a partir dos serviços existentes no governo, pois o objetivo é reaproveitar o conceito associado ao serviço. Em seguida, os padrões de serviços devem ser documentados e posteriormente disponibilizados no catálogo de padrões de serviços, conforme ilustrado na Figura 21.

Após alteração realizada em um padrão de serviço, este deve novamente ser disponibilizado no catálogo de padrões de serviços.

Figura 21: Fluxo de atualização de padrões de serviços

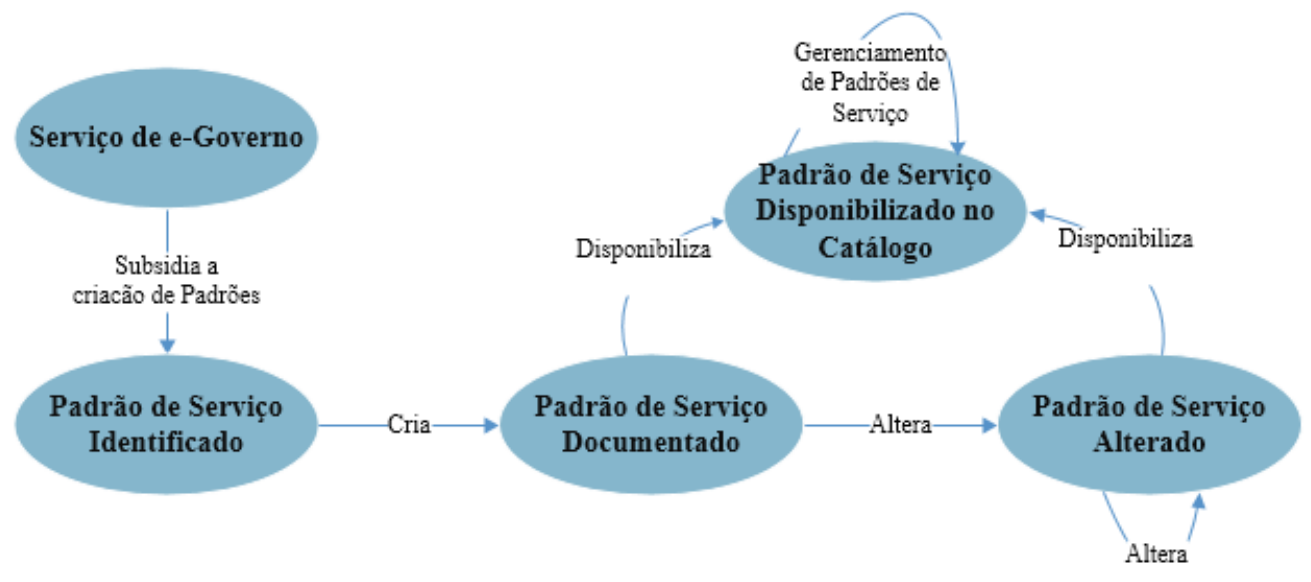

Fonte: Autor (2014)

Embora esse fluxo de atualização de padrões de serviços tenha sido proposto, está fora do escopo desta pesquisa discutir as diretrizes de Gestão de Padrões de Serviços.

\subsubsection{Criação de Serviços}

Os padrões de serviços catalogados servem de base para a concepção de novos serviços, conforme Figura 22. Dessa forma, o artefato de entrada dessa atividade é a Especificação de Padrões de Serviços, e o artefato de saída é a Especificação de Serviços. 
Figura 22: Atividade - criar serviços a partir de padrões de serviços.

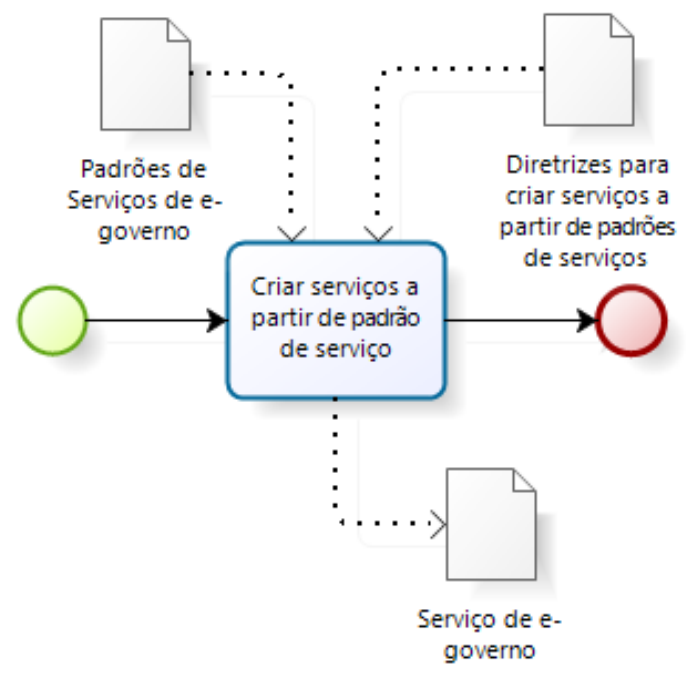

Fonte: Autor (2014)

As diretrizes estabelecidas para auxiliar a criação de novos serviços são descritas a seguir.

\section{Diretriz 5. Uso do ciclo de vida de desenvolvimento de serviços apoiado por padrões de serviços}

Marks e Bell (2006) afirmam que a falta de interoperabilidade de serviços pode ser resultado da aplicação de diferentes políticas, padrões e processos. É possível conseguir serviços interoperáveis impondo um conjunto de políticas de SOA em todo o ciclo de vida de serviços, que compreende as atividades de identificação, concepção e implementação.

De modo geral, os ciclos de vida de serviços (MARKS; BELL, 2006), (ARSANJANI et al., 2008) e (GU; LAGO, 2007) contemplam as fases de análise do processo de negócio, modelagem de serviços (análise e projeto), implementação, e implantação, monitoramento e gestão de serviços.

Neste trabalho, propõe-se fazer a inclusão da atividade Busca de Padrões de Serviços Candidatos no ciclo de vida de serviços, conforme ilustrado na Figura 23.

A atividade Busca de Padrões de Serviços Candidatos deve ser realizada por meio de consulta ao catálogo de padrões de serviços de e-governo, objetivando localizar padrões de serviços que atendam ao processo de negócio em questão. Os padrões de serviços serão utilizados como referência para criar os serviços.

Esse trabalho propõe uma evolução da atividade de identificação de serviços de negócio, proposto por Marks e Bell (2006), apresentado na Seção 2.2.3. O objetivo é que seja utilizado também o catálogo de padrões de serviços de e-governo 
Figura 23: Proposta de ciclo de vida de serviços com padrões de serviços.

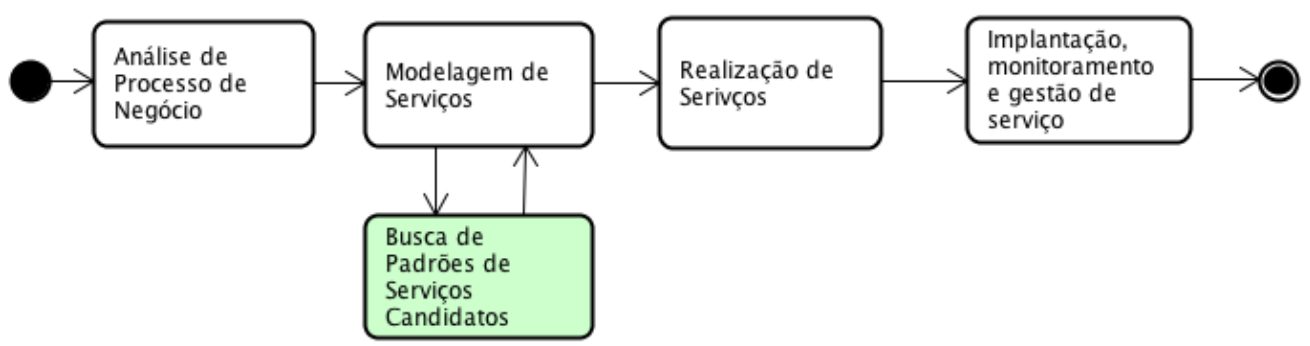

Fonte: Autor (2014)

como uma das formas de identificar potenciais serviços para atender a um modelo de negócio de organização governamental. Os padrões de serviços de e-governo serão utilizados em adição à análise de processo de negócios, análise de entidade de negócios, projetos orçados, experiência de negócio, serviços pré-existentes e aplicações existentes, conforme Figura 24. Enquanto a análise dos serviços pré-existentes é feita com objetivo de otimizar investimentos já realizados por meio do reuso, composição ou até mesmo reprojetar serviços de acordo com os requisitos de negócio, a análise do catálogo de padrões de serviços de governo é feita para subsidiar o reuso do conceito de serviços já idealizado em outra organização para atender ao processo de negócio.

Conforme Marks e Bell (2006), a experiência de domínio de negócio de um especialista pode contribuir para identificar os serviços de negócios candidatos em uma empresa. De forma similar, os padrões de serviços também estão relacionados à experiência do especialista, pois os padrões representam conceitos de serviços já idealizados por outros especialistas. Portanto, a análise dos padrões de serviços pode servir de subsídio para reaproveitar a experiência do especialista. Assim, conhecer o que já foi realizado em outra esfera ou poder de governo para executar um processo de negócio similar é um facilitador.

Um padrão de serviço pode servir de base para a concepção de serviços destinados para diferentes inventários, conforme Figura 25, ou também ser base para criação de vários serviços destinados para um mesmo inventário, conforme Figura 26. Um exemplo pode ser observado no estudo de caso referente a NF-e.

A decisão se um padrão de serviço dará origem a um serviço em um inventário ou a vários serviços no mesmo inventário vai depender do nível de granularidade desejado para o serviço a ser criado.

Embora a discussão sobre a granularidade de um serviço criado a partir de um padrão de serviço esteja fora do escopo dessa pesquisa, vale registrar as seguintes 
Figura 24: Identificação de serviços de negócios candidatos

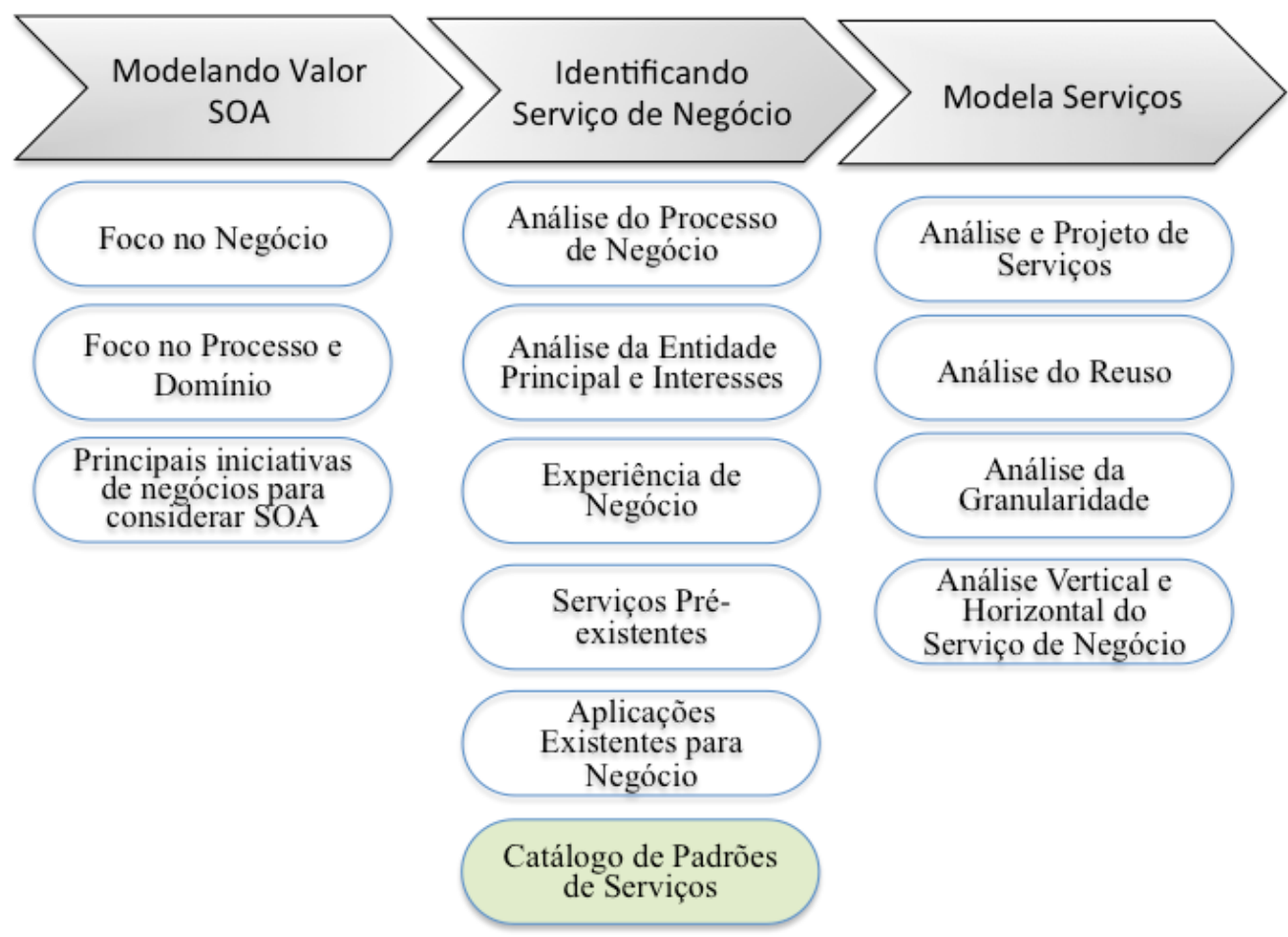

Fonte: Adaptado de Marks e Bell (2006)

considerações:

- Considerando que inventários de serviços das organizações públicas são para atender processos de negócios governamentais, esses inventários devem ter um nível de granularidade similar;

- Atualmente não existem diretrizes do governo quanto a granularidade dos serviços. As entidades governamentais na maioria das vezes são responsáveis por conceberem os serviços e realizar a governança SOA, cabendo a essas organizações decidirem sobre a granularidade.

\subsection{Considerações Finais do Capítulo}

Neste Capítulo, foi apresentada uma caracterização da utilização de SOA e serviços no cenário de governo, a fim de conhecer melhor o domínio de governo e ter uma coleção de serviços que pudesse servir de insumo para a especificação de padrões de serviços. Em função do número de organizações públicas que responderam ao questionário, não foi possível traçar o perfil das organizações públicas. No entanto, conhecer serviços de e-governo foi bastante enriquecedor para esta pesquisa. 
Figura 25: Criação de serviços para diferentes inventários a partir de um padrão de serviço

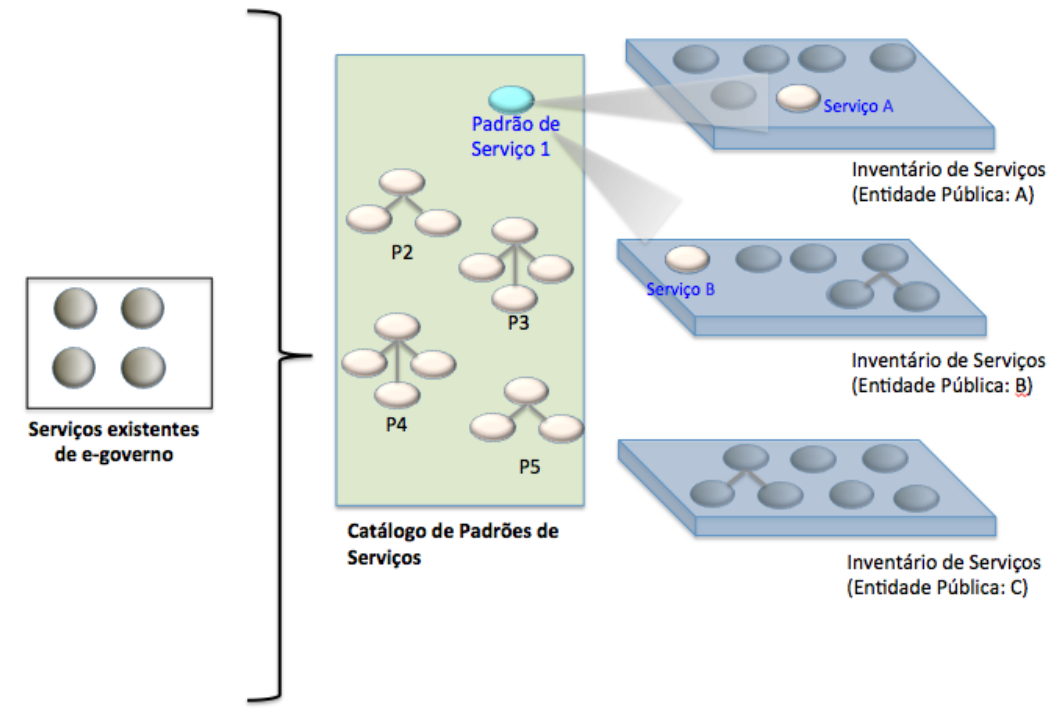

Fonte: Autor (2014)

Foram propostos e discutidos o modelo MESe-gov e as diretrizes DESe-gov para especificação de serviços no domínio de governo, apoiado pelo uso de padrões de serviços. O conjunto de diretrizes para especificação de serviços no domínio de governo foi proposto com o objetivo de auxiliar a especificação de padrões de serviços e também para conceber novos serviços a partir dos padrões de serviços catalogados. As diretrizes foram documentadas com base em estudos da literatura e na experiência da autora.

Para apoiar o modelo MESe-gov e as diretrizes DESe-gov foi proposto o template Especificação de Padrão de Serviço. Este template teve como objetivo: fornecer um modelo padrão de documentação e auxiliar a definição do nível de abstração a ser representado pelo padrão de serviço, para subsidiar o reuso de conhecimento de especialistas.

O MESe-Gov e DESe-gov apoiam a especificação de padrões de serviços para representar um serviço em alto nível de abstração, mas não tem o objetivo de auxiliar a especificação de padrões de processo de negócios. Está fora do escopo deste trabalho analisar padrões de processo de negócio para definir padrões de serviços. Outros trabalhos abordam o uso de padrões de processo de negócio, tais como: Thom et al. (2007) que abordam o reuso de padrões relacionados a workflow em ferramentas de modelagem de processo de negócios; Thom, Reichert e lochpe (2009) apresentam padrões de atividades relacionados a workflow e ainda destacam o potencial de reutilizá-los no contexto de modelagem de processo de negócio.

O reuso do conhecimento de especialistas incorporado nos artefatos é um dos 
Figura 26: Criação de vários serviços para um inventário a partir de um padrão de serviço.

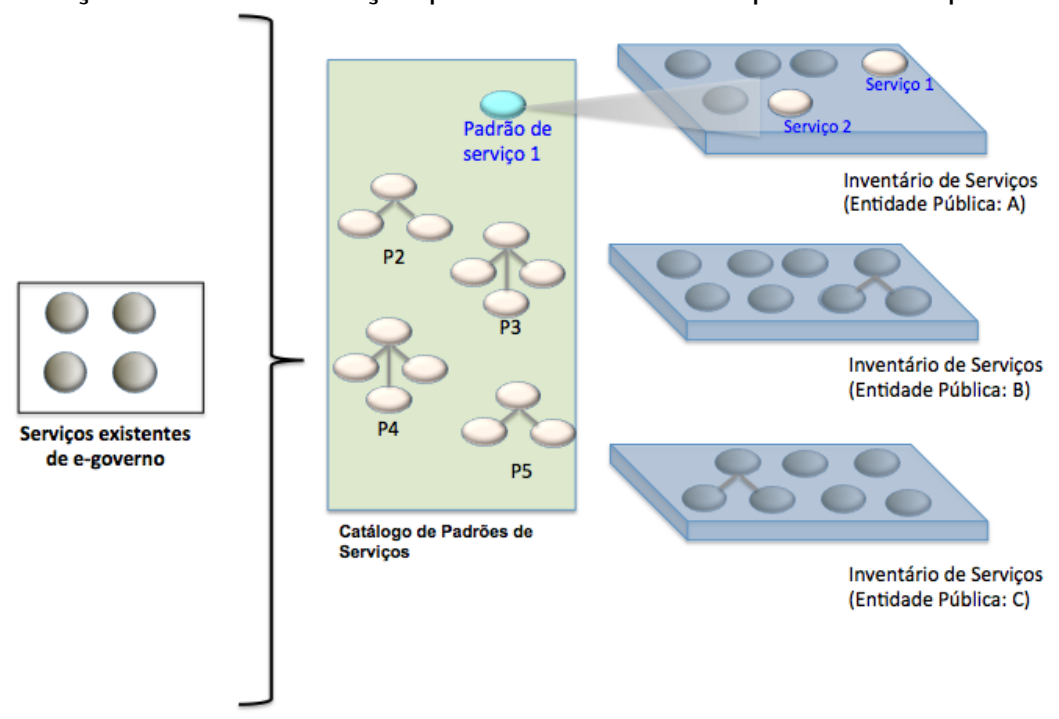

Fonte: Autor (2014)

benefícios do reuso de artefatos de software, conforme Sommerville (2007), além de outros benefícios, como maior confiabilidade no artefato reusado e redução do tempo total de entrega, pois tanto o tempo de desenvolvimento quanto o tempo de validação tendem a ser menores. 


\section{ESTUDO DE CASO}

\subsection{Considerações Iniciais}

Este Capítulo tem como propósito aplicar as diretrizes apresentadas no Capítulo 3 para especificar os padrões de serviços e ainda mostrar outros possíveis cenários de utilização dos padrões especificados.

Os estudos de casos apresentados são referentes à área financeira e área de recursos humanos. Nesses estudos de casos foram eleitos alguns serviços já existentes no domínio de governo e, em seguida, foram aplicadas as diretrizes propostas para especificação dos padrões de serviços. Para cada estudo de caso, foram descritos: o cenário de negócio, a especificação do padrão de serviço e um potencial cenário de reuso do padrão de serviço.

O modelo MESe-gov contempla duas atividades:

- Especificar padrões de serviços - foram analisados serviços coletados e, posteriormente, foram gerados alguns padrões de serviços a partir dos serviços analisados;

- Criar serviços a partir dos padrões de serviços - foram exemplificados serviços que podem ser criados a partir dos padrões especificados na atividade anterior.

Com base no levantamento de serviços descrito na Seção 3.2, os cenários dos estudos de casos foram selecionados devido aos fatos de:

- os serviços terem sido coletados no levantamento de serviços;

- a área de negócio ser de conhecimento da autora do trabalho;

- os serviços Previsão de Pagamento de Diárias e Aprovar Férias possuírem regras de negócio similares às existentes na área privada $e$

- a NF-e ser um projeto de conhecimento de muitos brasileiros. 


\subsection{Caso Registro de Despesas}

\subsubsection{Descrição do Cenário de Negócio}

O cenário deste estudo de caso refere-se a um processo de negócio de Gestão de Diárias, especificamente ao registro de despesas. No Poder Executivo, o processo de negócio Gestão de Diárias é de responsabilidade da Secretaria de Estado de Administração (SAD), e o processo negócio Financeiro, responsável pelo controle e execução das despesas, é de responsabilidade da Secretaria de Fazenda de Estado (SEFAZ).

Quando um servidor público realiza um trabalho fora da cidade onde está lotado, este recebe um valor diário para suas despesas pessoais, denominado Diárias. Esse processo permeia duas áreas de negócio do Governo. Ao realizar o registro de uma diária para um servidor público no Sistema de Gestão de Diárias, há a necessidade de se obter informações da área de Gestão de Pessoas, também de responsabilidade da SAD e, ao se registrar uma diária no Sistema de Diárias, é preciso gerar um lançamento financeiro no Sistema de Gestão Financeira, de responsabilidade da SEFAZ. Assim, a ação de agendamento de diárias envolve a busca de informações no cadastro do servidor público, o registro da diária no próprio Sistema de Diárias e o registro dos custos das diárias no Sistema Financeiro da respectiva despesa, conforme representado na Figura 27.

Figura 27: Processo de negócio Agendamento de Diárias

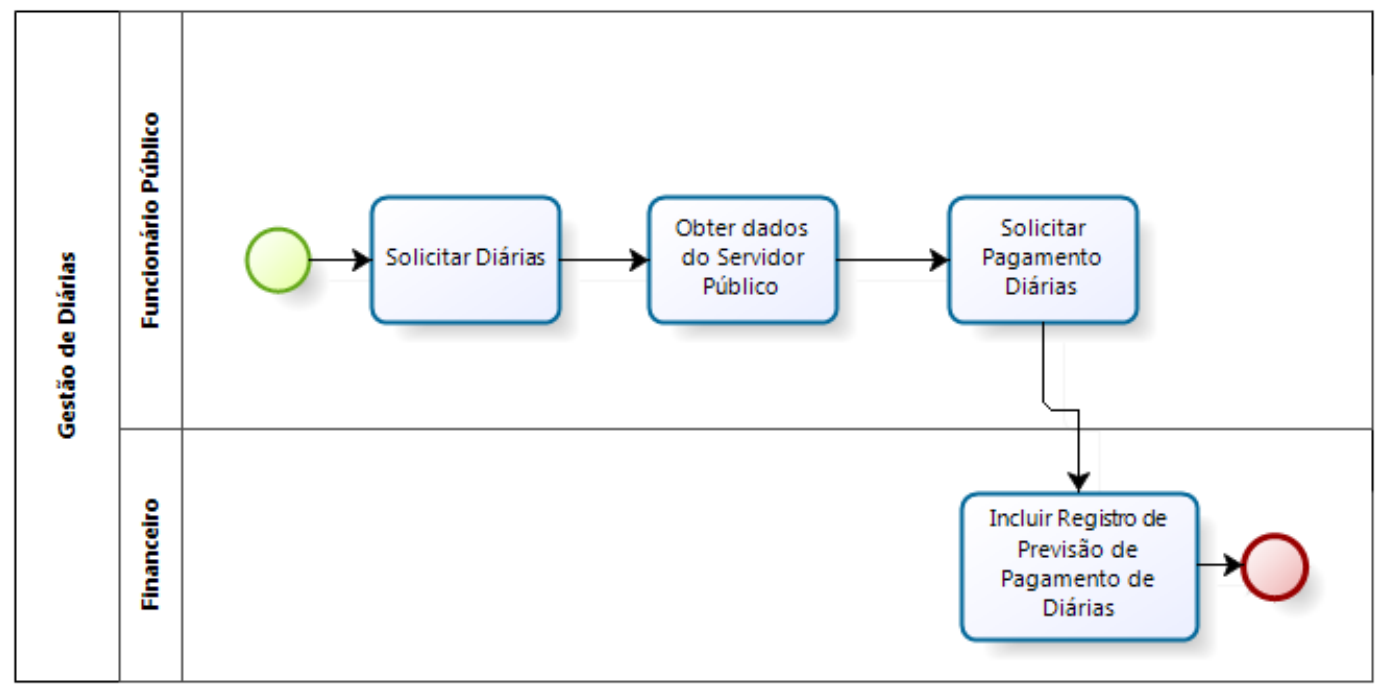

Fonte: Autor (2014)

Atualmente, o Sistema Financeiro disponibiliza um serviço parar registrar a previsão de pagamento de diárias, conforme a Figura 28. O serviço Previsão de 
Pagamento de Diárias foi implementado e implantado para atender especificamente à demanda de negócio relacionada ao controle de diárias, pois o serviço é consumido pelo Sistema de Gestão de Diárias.

Figura 28: Processo de negócio Agendamento de Diárias consumindo serviços

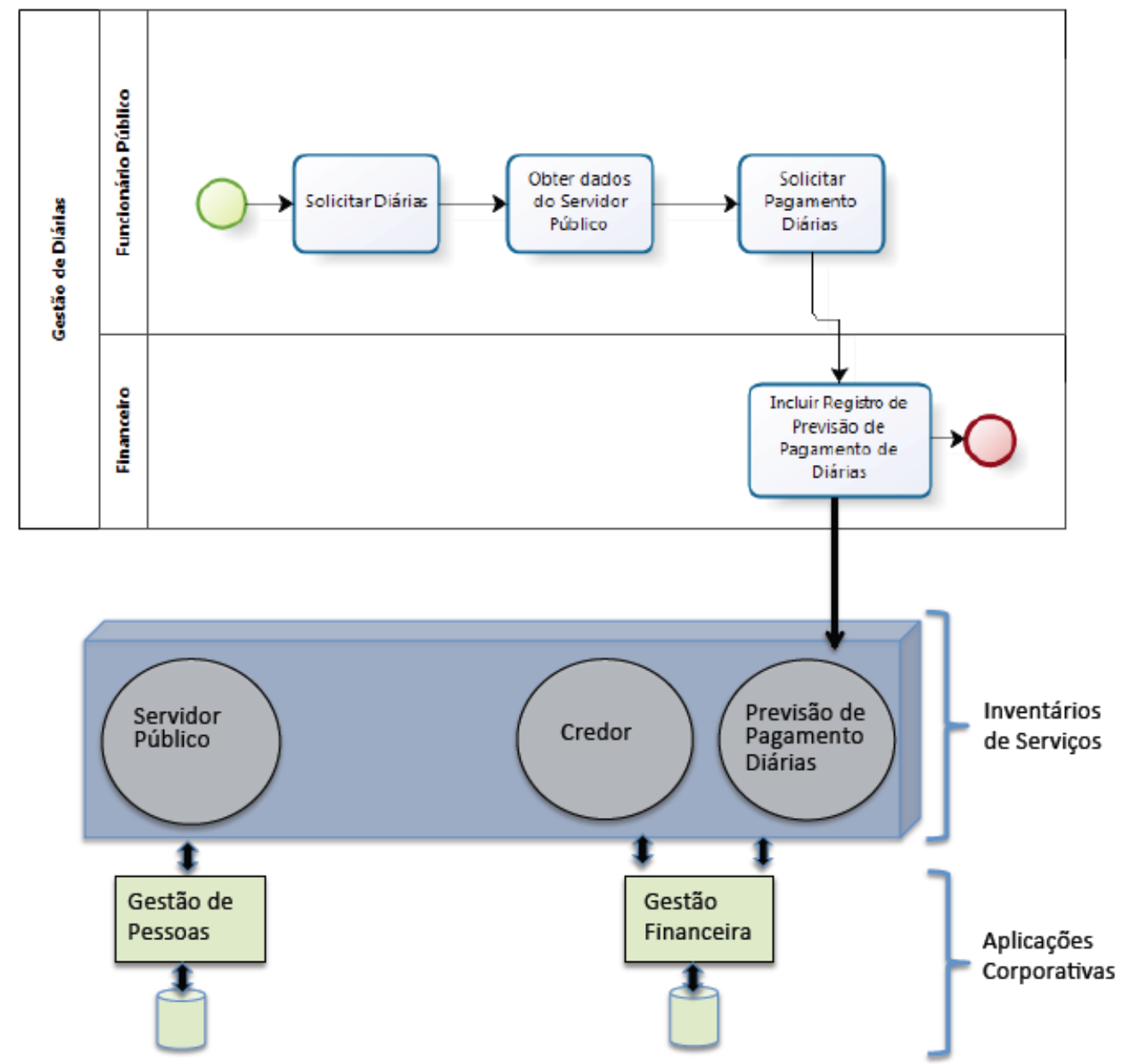

Fonte: Autor (2014)

\subsubsection{Especificação do Padrão de Serviço}

O serviço Previsão de Pagamento de Diárias é um serviço de negócio, conforme previsto na diretriz D1 - Análise dos serviços de negócio de governo. Este serviço foi inicialmente localizado no levantamento de serviços e em seguida foi analisado a partir do WSDL. Trata-se de um serviço atômico que irá, portanto, resultar em um padrão de serviço também atômico, não contendo as informações sobre composição de serviço.

Considerando o serviço Previsão de Pagamento de Diárias, duas estratégias foram adotadas para representar o padrão de serviço. 
- Abstração do conceito de serviço - realizar a abstração do conceito associado ao serviço e representá-lo como padrão de serviço são objetivos fundamentais da atividade de especificação de padrões;

- Generalizar o serviço Previsão de Pagamento de Diárias - em função de o serviço Previsão de Pagamento de Diárias ter sido concebido e disponibilizado visando somente ao atendimento das demandas originadas do processo de negócio Gestão de Diárias, vislumbrou-se a possibilidade de generalizar o escopo do serviço para que este possa também ser reutilizado em outros processos de negócio.

A decisão de generalizar o serviço está totalmente associada ao conhecimento da área de negócio do especialista que está especificando o padrão de serviço. Dessa forma, o serviço Previsão de Pagamento irá atender, além da demanda do processo de negócio Gestão de Diárias, a outros processos de negócios como, por exemplo, Gestão de Viagens.

Aplicando a diretriz D2 - Padrão de serviço documentado de forma padronizada, o padrão de serviço Previsão de Pagamento foi documentado seguindo o template Especificação de Padrão de Serviço, conforme ilustra a Tabela 11. A interface do serviço foi representada com Diagrama de Classe da UML, e a especificação da lógica da operação do serviço foi representada por meio do Diagrama de Atividade da UML.

O padrão de serviço foi registrado no catálogo Sistema-financeiro, conforme previsto na diretriz D3 - Catálogo de padrão de serviço definido e mantido.

A criação do padrão de serviço seguiu o fluxo de atualização proposto para padrões de serviços, conforme D4 - Padrão de serviço criado e alterado conforme o fluxo de atualização, ou seja, analisou-se o serviço existente no governo, criou-se o padrão e o disponibilizou no catálogo, para servir como referência a fim de se criar outros serviços.

\subsubsection{Criação do Serviço a partir do Padrão de Serviço}

O cenário de governo eleito para criar serviços a partir de padrões de serviços refere-se à Gestão de Viagens. O processo de negócio Gestão de Viagens é composto de vários subprocessos, dentre eles o Agendar Viagens e Agendar Diárias. Quando um servidor público realiza um trabalho fora da cidade onde está lotado, além do valor da diária, o órgão público também deve registrar gastos com as passagens (aéreas e/ou terrestres). 
Tabela 11: Padrão de serviço: Previsão de Pagamento

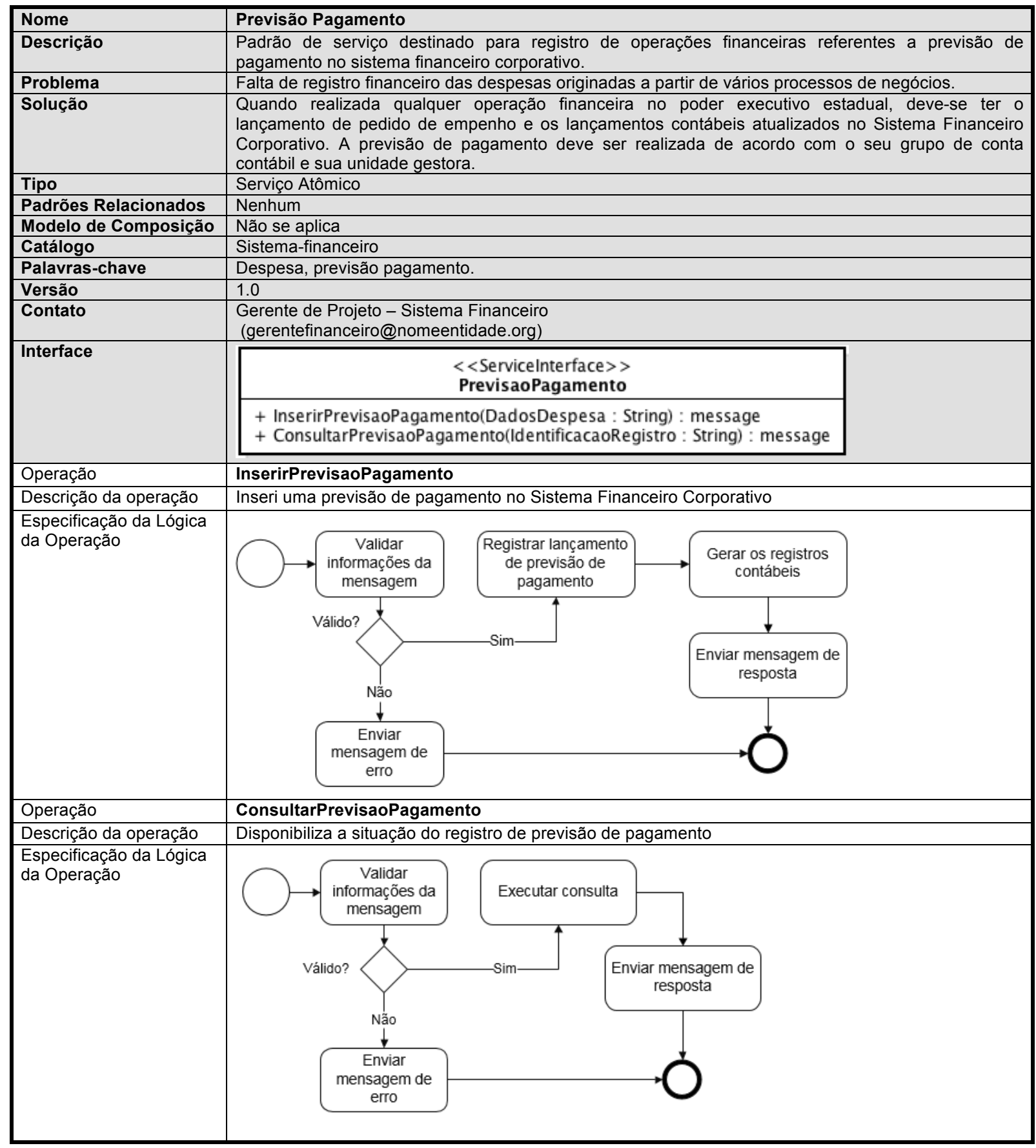

Fonte: Autor (2014)

O ciclo de desenvolvimento de serviços utilizado para a concepção de serviços para o processo de negócio Gestão de Viagens foi realizado seguindo a diretriz D5 - Uso do ciclo de vida de desenvolvimento de serviços apoiado por padrões de serviços. Considerando a execução da atividade de "Busca de Padrões de Serviços Candidatos" conforme Figura 23, o padrão de serviço Previsão Pagamento é localizado no catálogo de padrões de serviços e serve de referência para a criação 
de um serviço Previsão Pagamento.

No processo de negócio Agendar Viagens, conforme ilustrado na Figura 29, pode-se observar que é necessário registrar duas previsões de pagamento no sistema financeiro, uma referente ao pagamento de passagens e outra referente ao agendamento de diárias.

Figura 29: Processo de negócio Agendamento de Viagem

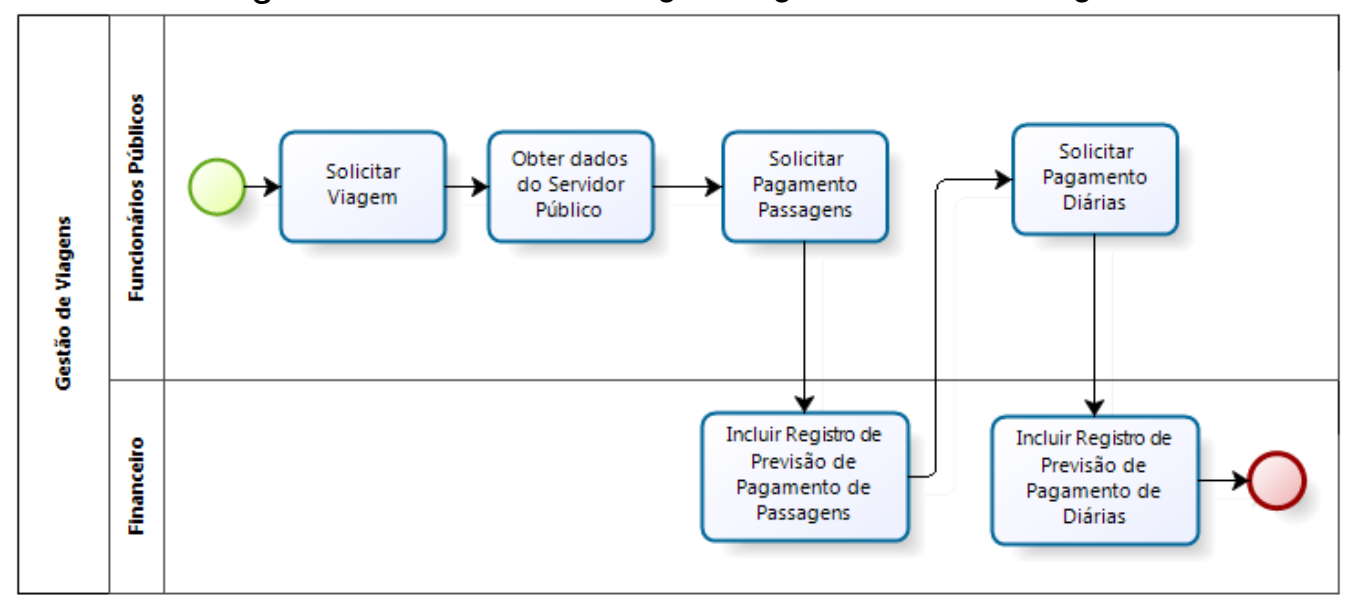

Fonte: Autor (2014)

O serviço criado a partir do padrão Previsão de Pagamento pode atender aos dois processos de negócio, conforme está ilustrado na Figura 30.

Neste estudo de caso, pode-se observar que, além dos benefícios propostos com a abstração e padronização de um serviço, também houve benefício ao generalizar o serviço, aumentando assim o potencial de reuso do serviço criado a partir do padrão de serviço, uma vez que o padrão de serviço catalogado pode ser consultado e servir como referência para a criação de novos serviços.

Os serviços criados a partir do padrão de serviço Previsão Pagamento podem ser para inventários distintos, conforme a Figura 31, ou podem ser criados serviços para um mesmo inventário, conforme a Figura 32, porém cada um para contextos mais específicos. Nesse caso, os serviços concretos foram criados para atender às duas áreas de negócio, um serviço para Previsão de Pagamento de Diárias e um serviço para Previsão de Pagamento de Viagens. Embora o padrão tenha sido generalizado, isso não impede que o projetista decida a granularidade do serviço a ser criado a partir do padrão de serviço. 
Figura 30: Processo de negócio Agendamento de Viagens consumindo serviços

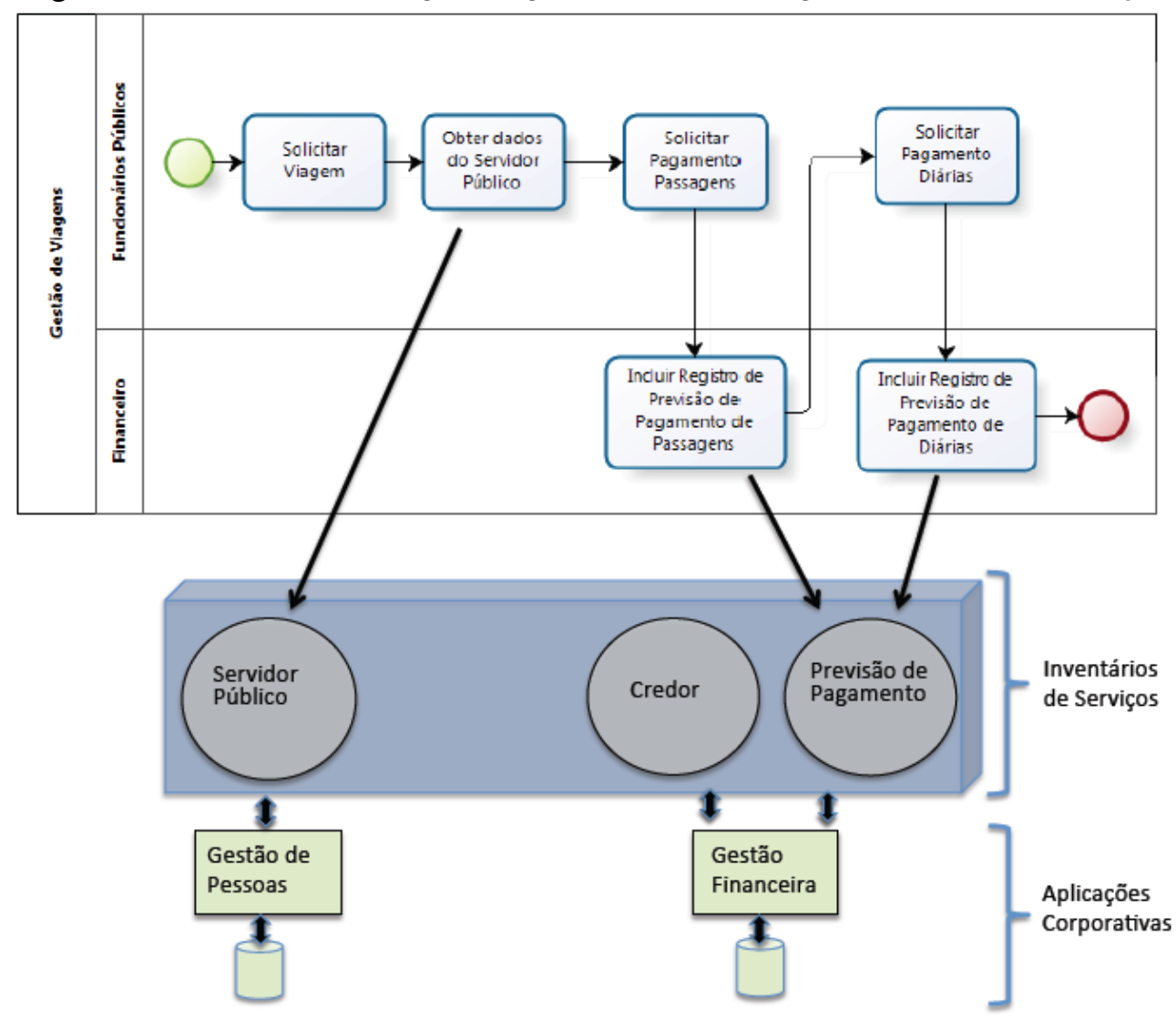

Fonte: Autor (2014)

Figura 31: Criação de serviços para diferentes inventários de serviços a partir do padrão de serviço Previsão Pagamento.

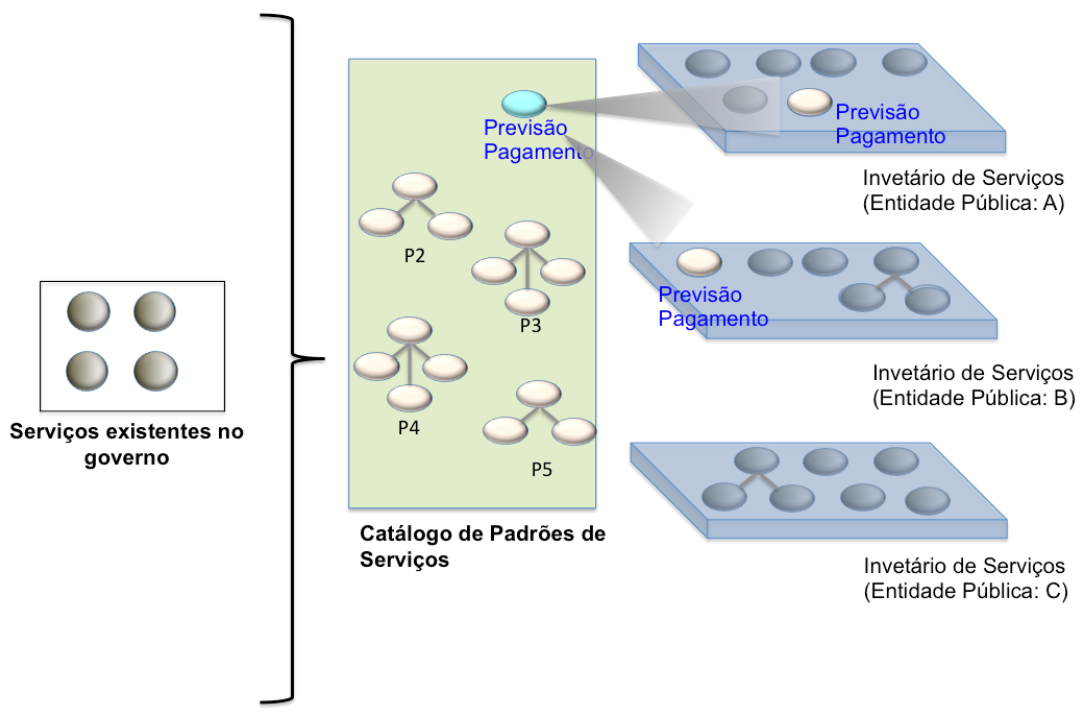

Fonte: Autor (2014) 
Figura 32: Criação de serviços para o mesmo inventário de serviços a partir do padrão de serviço Previsão Pagamento.

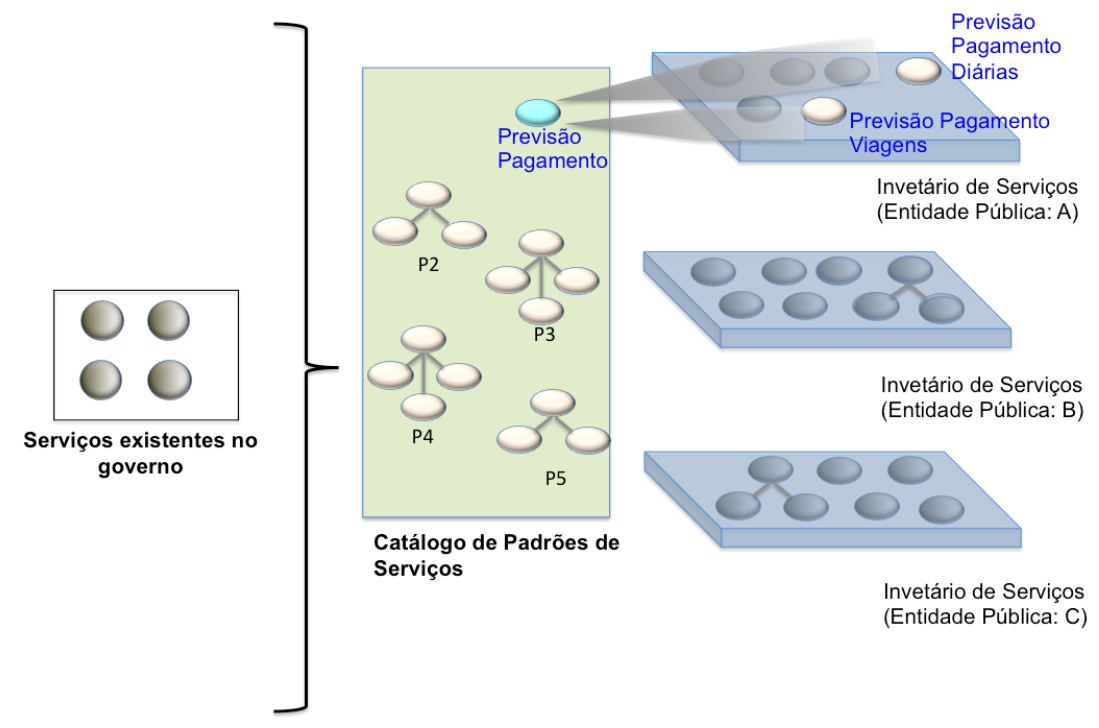

Fonte: Autor (2014)

\subsection{Caso Aprovação Férias}

\subsubsection{Descrição do Cenário de Negócio}

O cenário deste estudo de caso refere-se a um processo de negócio de Gestão de Pessoas, especificamente o subprocesso Aprovar Férias. O subprocesso para aprovar férias contém as atividades descritas, conforme representado na Figura 33.

Uma das atividades previstas, no processo Escala de Férias, é a atividade automatizada Aprovar Férias. Essa atividade invoca o serviço Aprovar Férias, disponível no inventário de serviços, conforme ilustrado na Figura 34.

\subsubsection{Especificação do Padrão de Serviço}

O serviço Aprovar Férias é um serviço de negócio, conforme previsto na diretriz D1 - Análise dos serviços de negócio de governo. Este serviço foi inicialmente localizado no levantamento de serviços e em seguida foi analisado a partir do WSDL. Trata-se de um serviço composto que irá, portanto, resultar em um padrão de serviço também composto.

A partir do serviço Aprovar Férias foi realizada a abstração do conceito associado ao serviço para representá-lo como padrão de serviço Aprovar Férias.

Aplicando a diretriz D2 - Padrão de serviço documentado de forma padronizada, o padrão de serviço Aprovar Férias foi documentado seguindo o 
Figura 33: Processo de negócio Escala de Férias

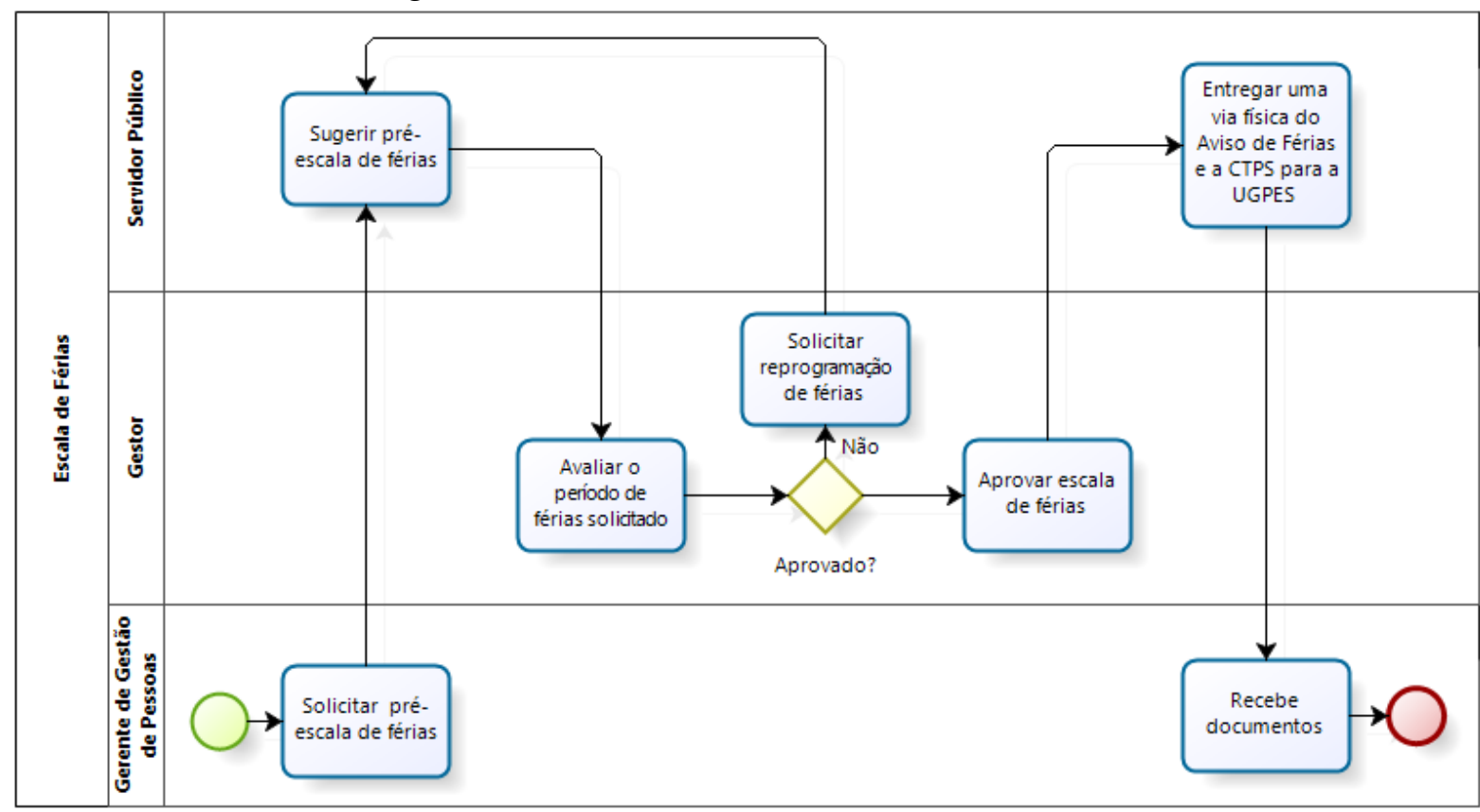

Fonte: Autor (2014)

template Especificação de Padrão de Serviço, conforme ilustra a Tabela 12. A interface do serviço foi representada com Diagrama de Classe da UML, e a especificação da lógica da operação do serviço foi representada por meio do Diagrama de Atividade da UML.

O padrão de serviço foi registrado no catálogo Recursos humanos, conforme previsto na diretriz D3 - Catálogo de padrão de serviço definido e mantido.

A criação do padrão de serviço seguiu o fluxo de atualização proposto para padrões de serviços, conforme D4 - Padrão de serviço criado e alterado conforme o fluxo de atualização, ou seja, analisou-se o serviço existente no governo, criou-se o padrão e o disponibilizou no catálogo, para servir como referência a fim de se criar outros serviços.

\subsubsection{Criação do Serviço a partir do Padrão de Serviço}

Utilizando a diretriz D5 - Uso do ciclo de vida de desenvolvimento de serviços apoiado por padrões de serviços, pode-se exemplificar a criação de serviço a partir do padrão de serviço Aprovar Férias. Após a busca do padrão no catálogo de padrões de serviços, ele pode servir de base para a criação de serviços.

Este estudo de caso, mostra o exemplo de um padrão de serviço que representa uma abstração do conceito de serviço Aprovar Férias, não teve como objetivo representar uma generalização. Portanto em outros cenários de governo os 
Figura 34: Processo de negócio Escala de Férias consumindo serviço

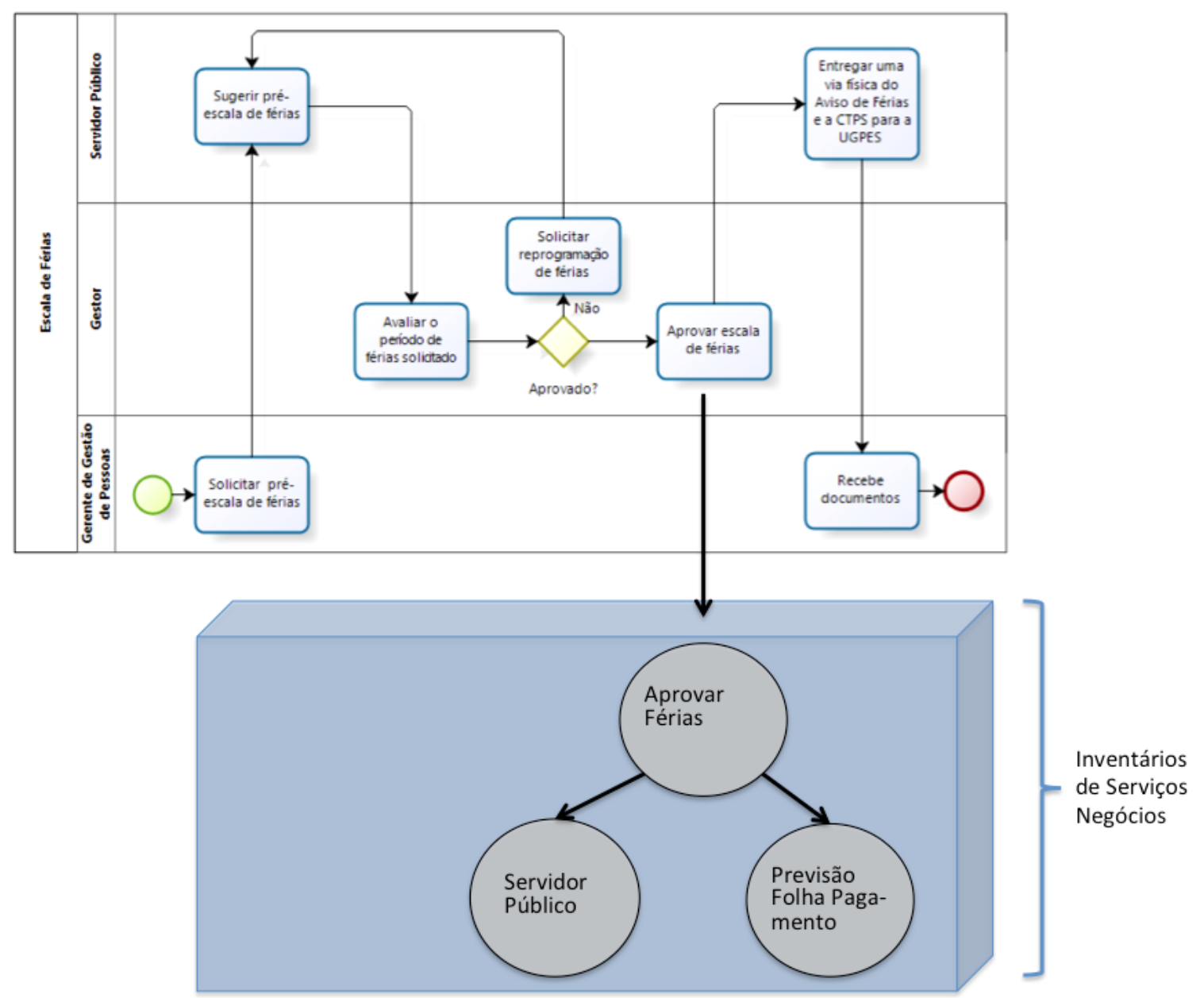

Fonte: Autor (2014)

serviços criados a partir desse padrão não precisam ser especializados para atender um processo de negócio específico. 
Tabela 12: Padrão de serviço: Aprovar Férias

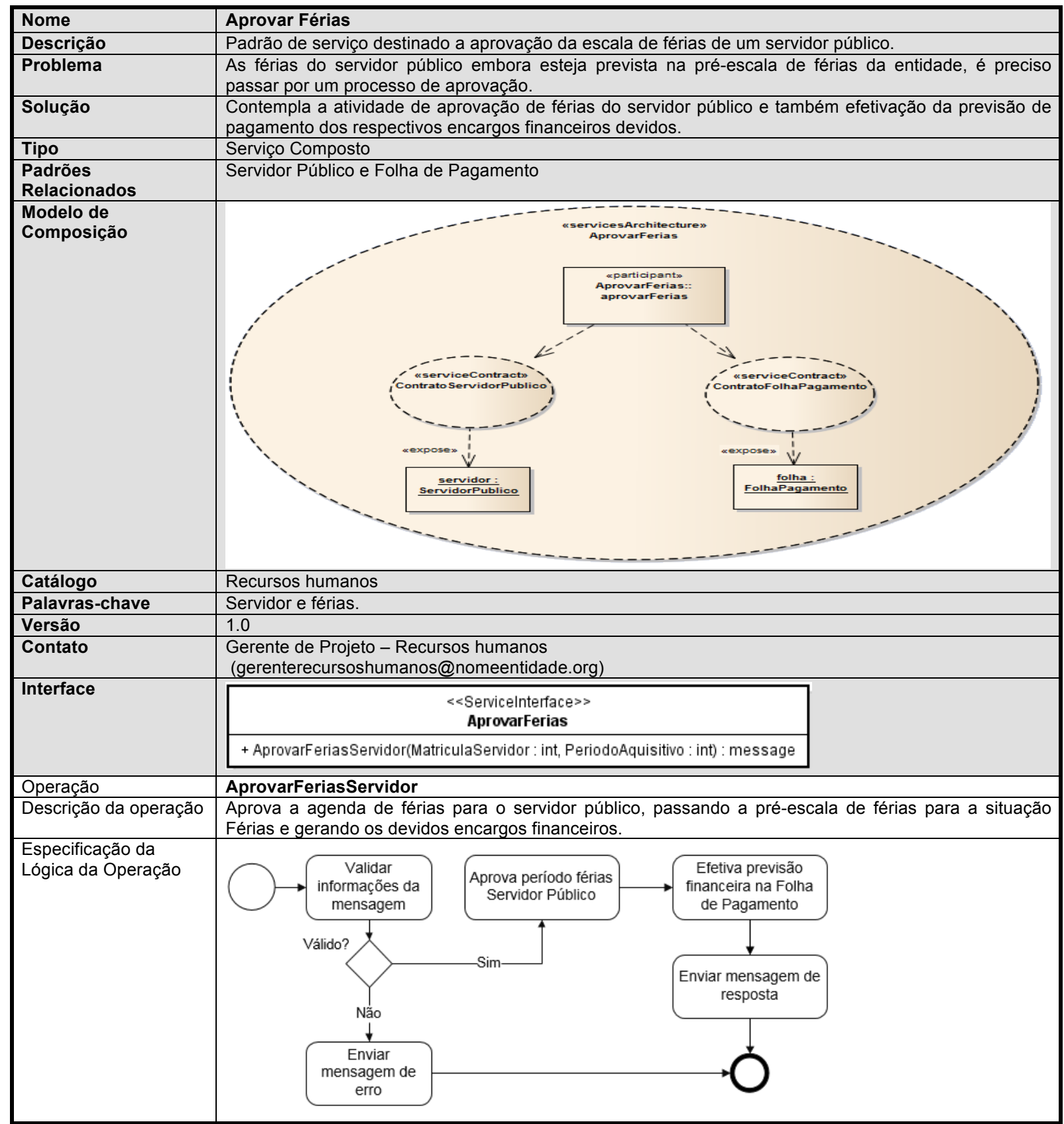

Fonte: Autor (2014)

\subsection{Caso NF-e}

\subsubsection{Descrição do Cenário de Negócio}

A substituição da emissão de documento fiscal em papel para um modelo nacional de documento fiscal eletrônico deu origem ao projeto Nota Fiscal Eletrônica (NF-e). A NF-e é desenvolvida de forma integrada entre as unidades da Federação e 
a Receita Federal do Brasil.

O objetivo é que a empresa emissora de NF-e gere e encaminhe um arquivo eletrônico por meio da Internet, contendo as informações fiscais da operação comercial e também possa realizar as demais operações, como: cancelamento, inutilização e consultas de NF-e. A comunicação entre o aplicativo do contribuinte e a Secretaria de Fazenda Estadual se baseia em Web Services disponibilizados pelo Sistema de Recepção de Nota Fiscal eletrônica. O aplicativo do contribuinte invoca um serviço disponibilizado pela Secretaria de Fazenda Estadual. Para cada serviço oferecido, existe um Web Service específico. Os serviços disponibilizados relativos à NF-e são: 1) Recepção de Lote de NF-e; 2) Consulta Processamento de Lote NF-e; 3) Cancelamento de NF-e; 4) Inutilização de Numeração de NF-e; 5) Consulta da Situação atual da NF-e; 6) Consulta do Status do Serviço; 7) Consulta Cadastro do Contribuinte; 8) Registro de Eventos para correção de informações da NF-e.

\subsubsection{Especificação do Padrão de Serviço}

Nesse estudo de caso, foi especificado um padrão de serviço a partir do serviço Recepção de Lote de NF-e. Este é um serviço de negócio conforme descrito na diretriz D1 - Análise dos serviços de negócio de governo.

Para especificar o padrão de serviço, foram consideradas duas estratégias: abstração do conceito de NF-e e generalização do serviço NF-e para contemplar a recepção de um Documento Fiscal Eletrônico (DF-e), produzindo como resultado um padrão de serviço denominado Recepção de Lote de DF-e. Considerando que existem outros tipos de Documentos Fiscais Eletrônicos que precisam ser enviados ao governo, esse padrão de serviço tem potencial de reuso.

Aplicando a diretriz D2 - Padrão de serviço documentado de forma padronizada, o padrão de serviço Recepção de Lote de DF-e foi documentado seguindo o template Especificação de Padrão de Serviço, conforme ilustrado na Tabela 13. Outros padrões também foram especificados, como: Consulta Processamento Lote DF-e, Cancelamento DF-e, Inutilização DF-e e Situação DF-e.

O padrão de serviço foi disponibilizado no catálogo, conforme previsto na diretriz D3 - Catálogo de padrão de serviço definido e mantido.

A criação do padrão de serviço seguiu o fluxo de atualização proposto, conforme D4 - Padrão de serviço criado e alterado conforme o fluxo de atualização. Um serviço de governo existente foi analisado e depois o padrão foi criado e disponibilizado no catálogo. 
Tabela 13: Padrão de serviço: Recepção de Lote de DF-e

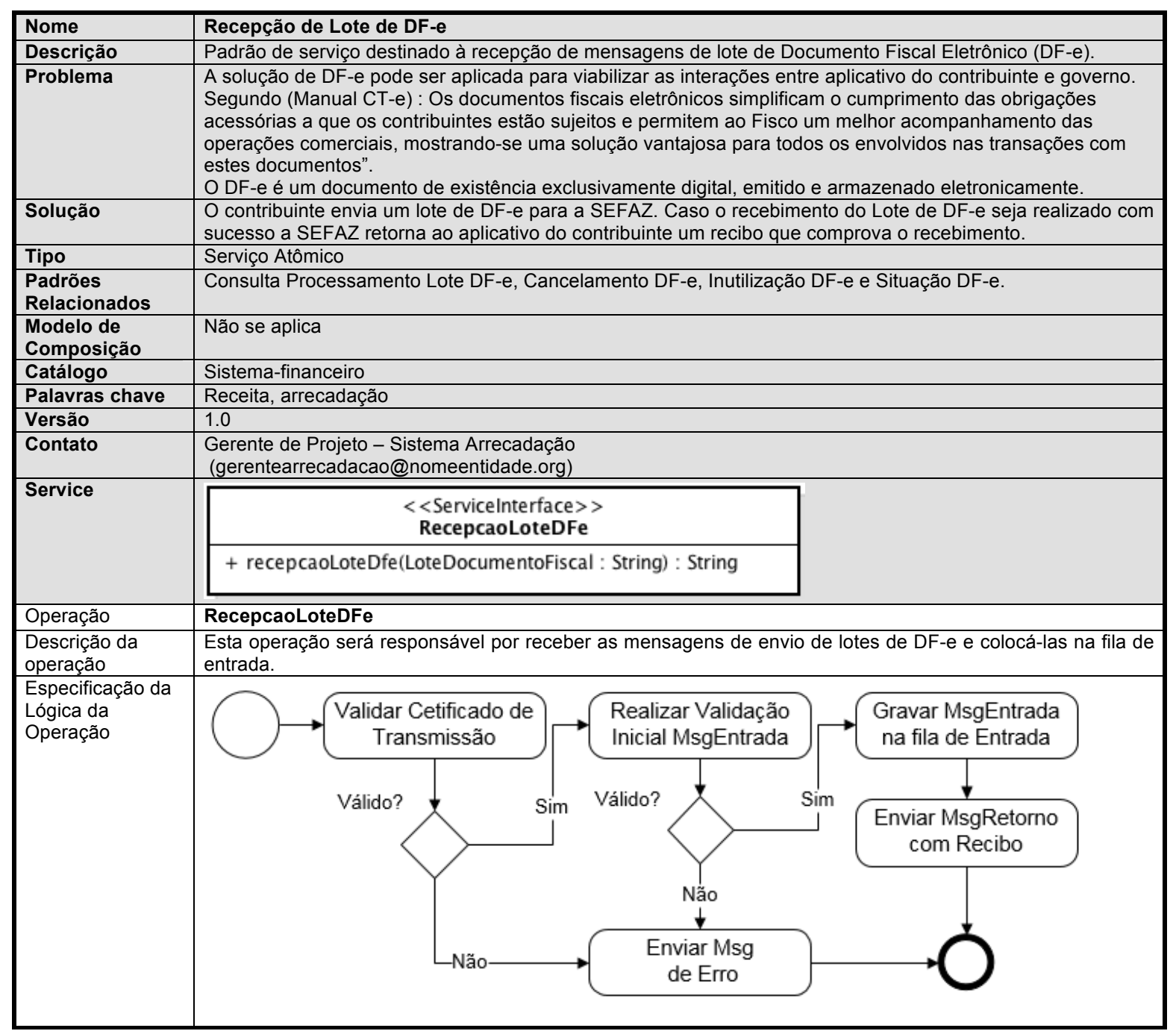

Fonte: Autor (2014)

\subsubsection{Criação do Serviço a partir do Padrão de Serviço}

Utilizando a diretriz D5 - Uso do ciclo de vida de desenvolvimento de serviços apoiado por padrões de serviços, pode-se exemplificar a criação de serviço a partir do padrão de serviço Recepção de Lote de DF-e. Após a busca do padrão no catálogo de padrões de serviços, ele pode servir de base para a criação de serviços. Os serviços criados a partir do padrão de serviço podem ser destinados para diferentes inventários, conforme a Figura 35, ou pode servir de base para criação de serviços destinados para um mesmo inventário, conforme Figura 36.

No exemplo de criação de serviços a partir do padrão de serviço Recepção de Lote de $D F-e$, foi necessário fazer uma especialização do padrão para gerar os serviços concretos, pois o padrão de serviço havia sido generalizado. 
Figura 35: Criação de serviços para diferentes inventários de serviços a partir do padrão de serviço Recepção de Lote de DF-e.

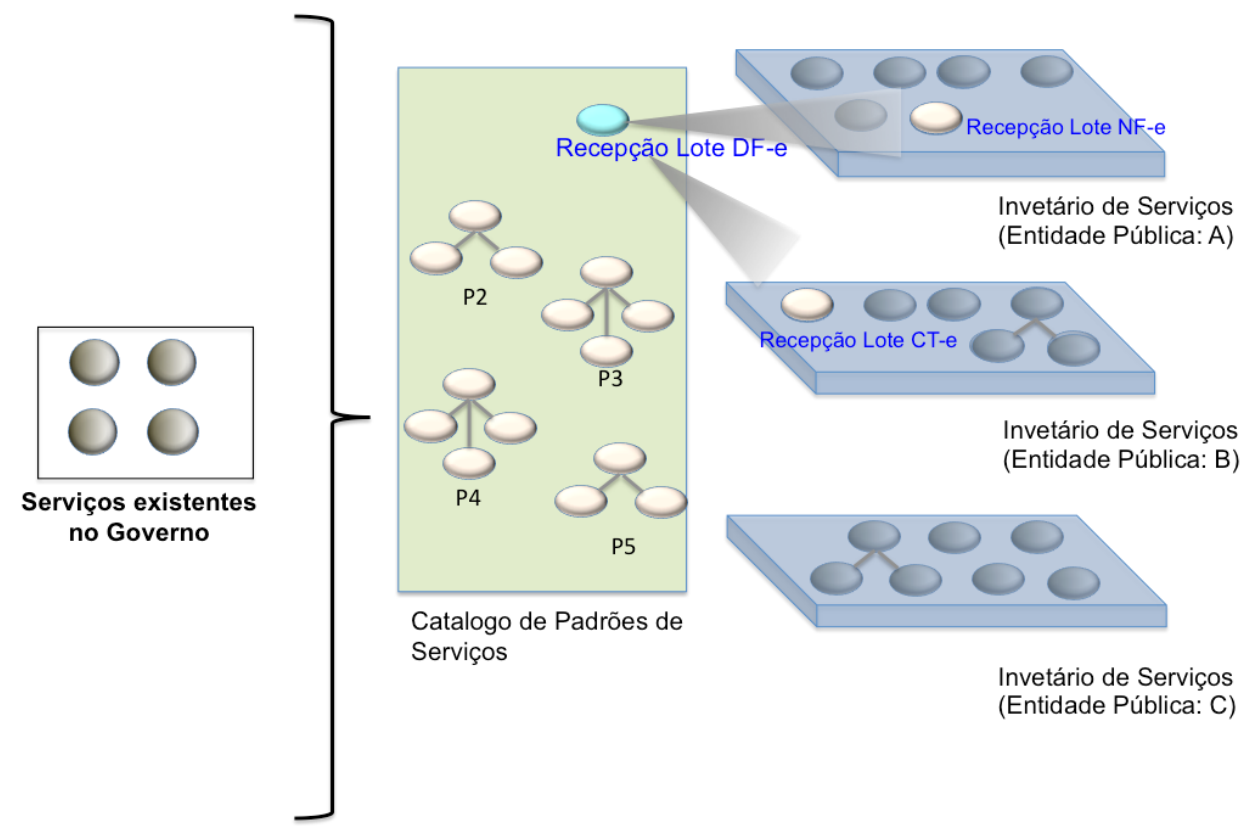

Fonte: Autor (2014)

Figura 36: Criação de serviços para o mesmo inventário de serviços a partir do padrão de serviço Recepção de Lote de DF-e.

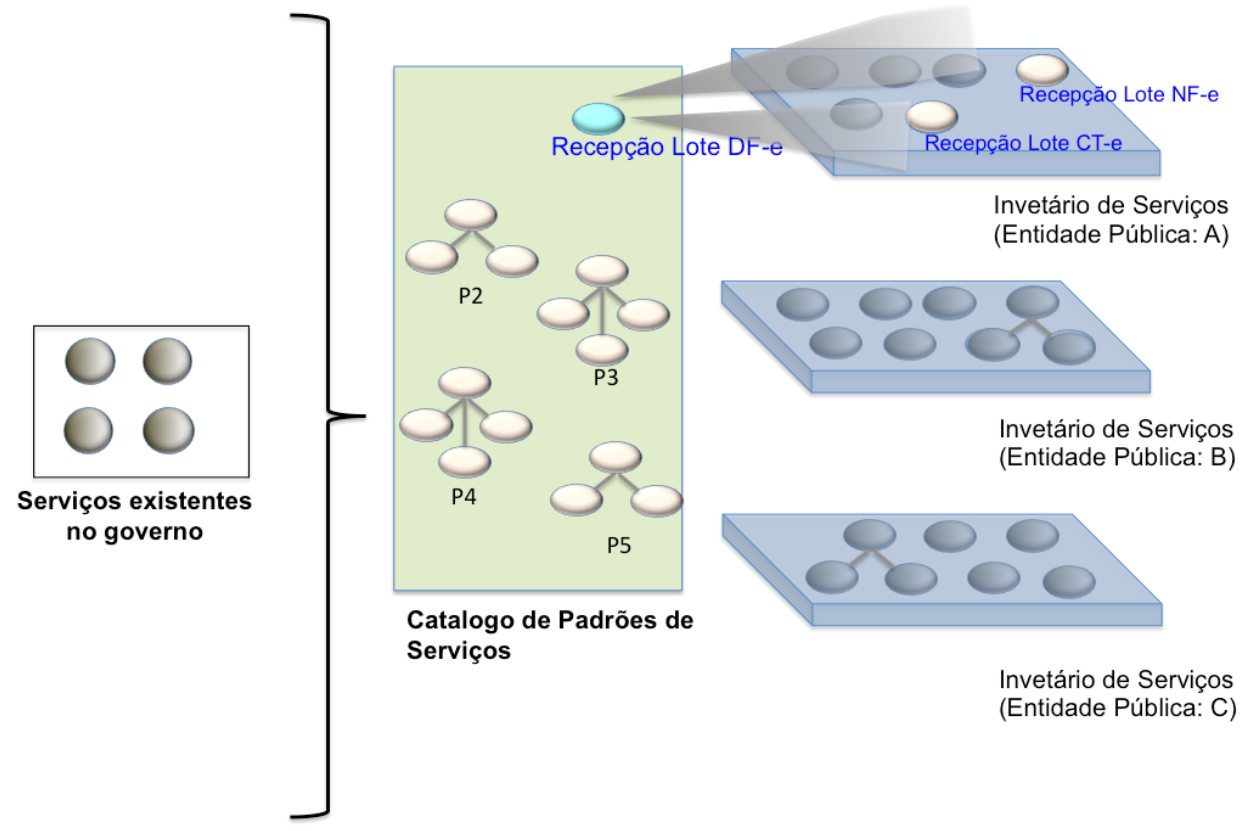

Fonte: Autor (2014)

Atualmente, outros projetos utilizam soluções semelhantes à NF-e para o trâmite de documento eletrônico entre aplicativo do contribuinte e Secretaria de Estado de Fazenda. Um exemplo é o Conhecimento de Transporte Eletrônico (CT-e), que é um documento de existência exclusivamente digital, emitido e armazenado 
eletronicamente com o intuito de documentar prestações de serviço de transporte. Conforme Rehem e Oller (2012), esse projeto surgiu a partir do Projeto da Nota Fiscal eletrônica. Os serviços do projeto CT-e têm praticamente a mesma estrutura dos serviços do projeto NF-e, pois os conceitos são similares. Os serviços relativos ao CT-e são: 1) Recepção de Lote de CT-e; 2) Consulta Processamento de Lote CT-e; 3) Cancelamento de CT-e; 4) Inutilização de Numeração de CT-e; 5) Consulta da Situação atual da CT-e e 6) Consulta do Status do Serviço.

Outro projeto que também pode ser citado é da Nota Fiscal Eletrônica do Varejo (NFC-e). Um dos fatores motivadores para a NFC-e é a experiência de sucesso com a NF-e (REHEM; OLLER, 2012). Esses exemplos de criação de serviços a partir de outros serviços reforçam o entendimento de que o estabelecimento de padrões de serviços pode subsidiar o reuso do conceito do serviço.

Após a análise desses projetos e consequentemente dos serviços concebidos para atender essas áreas de negócio, constata-se que os conceitos dos serviços especificados para o projeto NF-e foram reaproveitados no projeto CT-e, mesmo sem o uso de padrões de serviços. Os seguintes fatores podem ter facilitado o reuso deste conceito:

1. O projeto NF-e possui documentação da especificação dos serviços. O projeto Nota Fiscal Eletrônica (NFe) (BRASIL, 2012b) foi devidamente documentado, descrevendo, por exemplo, Arquitetura de Interação com Consumidor do Serviço (Modelo Conceitual, Padrões Técnicos, Modelo Operacional, Padrão de Mensagens dos Web Services, Schemas XML, etc). Para cada serviço tem-se descrito, de modo geral, o leiaute de Mensagem de Entrada, Leiaute Mensagem de Retorno, regras de Validação (Certificado de Transmissão, Mensagem no Web Service, Informações de Controle da Chamada ao Web Service, Área de Dados) e Processamento do Serviço. Embora a documentação do projeto seja destinada somente ao consumidor do serviço, essa não é uma realidade de todos os projetos, pois muitos serviços são concebidos e disponibilizados sem documentação. $O$ projeto CT-e (BRASIL, 2012a) também possui documentação similar.

2. Como as instituições e os gestores responsáveis pelas duas soluções eram os mesmos, facilitou-se o compartilhamento de experiências, uma vez que conheciam os conceitos dos serviços de um projeto e aplicaram em outro projeto similar. Caso exista um catálogo de padrões de serviços no governo, o reuso do conceito de serviço pode ser potencializado.

3. NF-e é um exemplo de um projeto modelo brasileiro tanto da área de 
governo como de outras áreas de aplicação, pois, de certa forma, afeta, direta ou indiretamente, várias áreas de negócio do governo brasileiro.

No caso de projetos específicos da área interna de governo (G2G), as soluções concebidas não têm o mesmo impacto e repercussão como ocorreu com NF-e. Esses fatores estimulam e facilitam o reuso de conceito de serviço, mas não garantem o reuso do conceito.

\subsection{Considerações Finais do Capítulo}

Os cenários de negócio selecionados para elaborar os estudos de casos, mostraram-se favoráveis para exemplificar a criação de padrões de serviços.

O uso do template Especificação de Padrão de Serviço permitiu especificar o padrão de serviço de forma abstrata, delimitando o escopo da descrição do padrão do serviço.

De modo geral, os exemplos de padrões de serviços especificados evidenciam que estes podem auxiliar engenheiros de software a especificar novos serviços no cenário de governo. Dessa forma, é possível especificar os padrões de serviços a partir da análise dos serviços existentes no governo bem como aproveitar a experiências desses especialistas. 


\section{CONCLUSÃO}

Este Capítulo apresenta as considerações finais deste trabalho de pesquisa, levando em consideração os objetivos propostos e evidenciando as contribuições. Em seguidas, são apresentadas as sugestões para trabalhos futuros que poderão dar continuidade à pesquisa. Algumas dificuldades encontradas durante o trabalho também estão registradas, assim como desafios e oportunidades que também são discutidos.

O uso de padrões de serviços traz benefícios ao ciclo de desenvolvimento de software orientado a serviços em uma organização, destacando-se como principal o reuso de conceitos. Outros benefícios são:

- os desenvolvedores não precisam dedicar esforço e tempo para analisar uma especificação longa de serviço; em vez disso, analisam inicialmente o padrão de serviço;

- um único padrão de serviço pode ser utilizado como referência para criar serviços para atender a processo de negócio de vários setores públicos. 0 crescente aumento do uso de serviços interoperáveis no domínio de governo, conforme descrito na Seção 3.2, é um fator que pode justificar os esforços necessários para criar padrões de serviços;

- a busca de um padrão de serviço tende a ser rápida, considerando que estes estão no catálogo de padrões de serviços;

- manter as especificações de padrões de serviços não requer alto investimento em tecnologia.

No estágio atual da pesquisa e em função dos benefícios já visualizados, vislumbra-se a necessidade de participar de comitês abertos como a OASIS, visando discutir esse novo modelo de abstração de serviços. Assim como, a necessidade de participar dos trabalhos do e-PING, especificamente na área de Integração para e-Governo, que aborda diretrizes e políticas de melhoria de gestão pública na visão de plataformas tecnológicas interoperáveis. 


\subsection{Contribuições}

Este trabalho apresentou como contribuição a proposição do MESe-Gov e DESe-Gov, para realizar a concepção de serviços, apoiada pelo uso de padrões de serviços. Entre as principais contribuições da tese, destacam-se:

- definição do template Especificação de Padrão de Serviço - não foi observado na literatura um consenso sobre a forma de descrever um padrão de serviço, por isso, foi proposto este template;

- definição dos elementos relacionados a padrões de serviços - como os conceitos de padrões de serviços, obtidos na literatura, são utilizados de formas diferentes, neste trabalho foi estabelecido um conceito para padrão de serviços e um conjunto de elementos que auxiliam na sua definição;

- definição do MESe-Gov - o objetivo do modelo é abstrair os conceitos de serviços e representá-los como padrões de serviços, visando diminuir a redundância de esforços para a concepção e projeto de novos serviços de e-governo;

- definição do DESe-Gov - as diretrizes propostas têm o objetivo de auxiliar a especificação e utilização dos padrões de serviços para e-governo;

- adaptação de um ciclo de vida de desenvolvimento orientado a serviços para contemplar a utilização dos padrões de serviços - foi proposta a evolução da atividade de identificação de serviços descrita por Marks e Bell [8], a fim de considerar o catálogo de padrões de serviços como uma fonte para reconhecer serviços que atendam ao processo de negócio.

Dessa forma, contribui-se com o processo de desenvolvimento orientado a serviços no domínio de governo, auxiliando no reuso de conceito de serviços.

As contribuições científicas produzidas no decorrer da pesquisa são: Reutilização de conceitos de serviços no cenário de governo eletrônico (FONSECA; CORRÊA, 2013), publicação internacional premiada como um dos melhores artigos da conferência; (2) Service patterns in the process of service-oriented development (FONSECA; CORRÊA; CORRÊA, 2014) artigo publicado no International Journal of e-Education, e-Business, e-Management and e-Learning, Qualis B1 Interdisciplinar; (3) Use of Service Patterns as an Approach to Modelling of Electronic Government Services (FONSECA; CORRÊA, 2014C), Qualis B3 em Ciência da Computação; e (4) Reuse of Service Concepts Based on Service Patterns (FONSECA; CORRÊA, 2014a), Qualis B1 em Ciência da Computação. 
Outros trabalhos também foram importantes para a pesquisa:

Computação orientada a serviços - ênfase em métodos de identificação de serviços (FONSECA; MELNIKOFF, 2011) publicação regional; e (2) apresentação da proposta de pesquisa no evento PhD Colloquium at IFIP eGov/ePart 2012, Noruega, em 2012. A participação nesse evento foi importante para a validação da proposta de pesquisa idealizada, já que os membros da mesa avaliadora, composta por pesquisadores da área de e-governo, contribuíram muito para a pesquisa.

Artigos também foram escritos e apresentados na forma de resumo e pôster a respeito do andamento da pesquisa nas instituições de ensino vinculadas ao doutorado interinstitucional (DINTER) EPUSP/UFMT.

\subsection{Desafios de Pesquisa}

Apesar dos esforços já realizados, existem desafios a serem superados em relação ao uso de padrões de serviços no domínio de governo.

A disseminação do conceito de padrões de serviços no governo, por exemplo, é um desafio, considerando que atualmente não existe um ciclo de vida de serviço instituído no domínio de e-governo brasileiro. Mesmo existindo processos de desenvolvimento de software definidos e disponíveis, como, por exemplo, o Processo de Software para o SISP (BRASIL, 2012), estes não são específicos para processo de desenvolvimento orientado a serviços.

Outro desafio é a constatação de que serviços atualmente são fortemente desenvolvidos no cenário de governo visando à integração de aplicações, tornando um desafio a discussão de padrões de serviços onde não existe, de forma institucionalizada, o uso da computação orientada a serviços.

\subsection{Trabalhos Futuros}

Ao longo desta pesquisa foram identificadas algumas possíveis extensões deste trabalho, visando a sua complementação. Algumas propostas são:

- aspectos de criação e busca de padrões de serviços no catálogo de serviços, como, por exemplo, o uso de heurísticas para localizar os padrões de serviços;

- definição de critérios para estabelecer o nível de granularidade do serviço a ser criado a partir dos padrões de serviços; 
- considerar o uso da abordagem de linha de produto para especificar padrões de serviços;

- considerar outras origens como fontes para análise e especificação de padrões de serviços, como, por exemplo, os modelos de processos de negócios;

- considerar outros ciclos de vida e o posicionamento do uso de padrões de serviços nesses ciclos de vida, sendo que, dentre estes, podem ser analisados os propostos por Arsanjani et al. (2008) e Gu e Lago (2007);

- definir uma gestão de mudança dos padrões de serviços, já que o presente trabalho aborda somente as diretrizes para a criação de padrões de serviços, mas não aborda as diretrizes relacionadas à mudança de padrões de serviços;

- desenvolver um ambiente automatizado para gerenciar os catálogos de padrões de serviços e definir mecanismos de busca de padrões nesse ambiente, sendo importante também considerar a infraestrutura computacional para armazenamento dos padrões de serviços;

- realizar experimentos para que se verifique a viabilidade de uso das diretrizes para especificar e utilizar padrões de serviços em um cenário real de desenvolvimento de software.

- definir critérios para análise de serviços existentes, a partir de processos de negócio semelhantes para subsidiar a especificação de padrões de serviços.

\subsection{Dificuldades Encontradas}

A primeira dificuldade encontrada foi referente à falta de documentação dos serviços, uma vez que o modelo proposto prevê a criação de padrões de serviços a partir da análise de serviços existentes no governo, e a maioria dos serviços não possui documentação específica. Esse foi um obstáculo para a compreensão dos serviços.

Especificamente no estudo de caso referente à Nota Fiscal Eletrônica, os serviços possuem documentação. Para os demais estudos de casos realizados durante a pesquisa, a autora optou por selecionar serviços de uma área de negócio de seu conhecimento, com a finalidade de resolver o problema acerca da falta de documentação.

Para solucionar essa dificuldade, uma alternativa vislumbrada é que o 
próprio engenheiro de software responsável por definir o serviço, também faça a documentação do padrão de serviço, com base nas diretrizes.

A segunda dificuldade foi estabelecer o nível de abstração para representar um padrão de serviço. Embora existam trabalhos que abordem o uso padrões de serviços, não existe uma regra estabelecida a respeito do nível de abstração ideal para especificação de padrão de serviço. Alguns padrões são altamente abstratos a ponto de possuir somente um nome (título); já outros representam todos os detalhes quanto ao conceito e tecnologia.

Para resolver o problema relacionado ao nível de abstração necessário para representar o serviço, foi criado o template Especificação de Padrão de Serviço, contendo as informações necessárias para representar a abstração.

A terceira dificuldade foi referente à forma de realizar o levantamento de serviços. O primeiro levantamento de serviços realizado nos órgãos públicos do Governo do Estado do Mato Grosso, no ano de 2010, envolveu diretamente as equipes que implementaram os serviços, o que demandava disponibilidade de agenda do entrevistado.

O levantamento a respeito de uso de SOA e serviços, realizado no ano de 2013, foi via questionário eletrônico. Embora o levantamento tenha sido realizado via questionário eletrônico, o número de resposta foi insuficiente para traçar o perfil das organizações em relação ao uso de serviços no governo. Assim, ações foram realizadas para que mais entidades públicas respondessem ao questionário, como, por exemplo, envio de e-mails e telefonemas. No entanto, mesmo assim o número de questionários respondidos não foi suficiente para traçar um perfil das organizações públicas.

\subsection{Considerações Finais}

Este trabalho apresentou uma forma de organização e reuso de conceitos de soluções orientadas a serviços no domínio de e-governo. A concepção de serviços, aliada ao conceito de padrões de serviços, visa diminuir a redundância de esforços para a concepção e projeto de novos serviços com propósitos similares. A ausência de subsídios para fomentar o reuso de soluções orientadas a serviços e a similaridade de processos de negócio no domínio de e-governo foram fatores que justificaram a abordagem proposta.

O reuso de conceito de serviços não depende somente de questões técnicas, pois está fortemente relacionado à questão de gestão e da cultura organizacional. 
Dessa forma, a criação do catálogo de padrões de serviços não garante o reuso, mas apoia o reuso de conceitos de serviços no domínio de governo. 


\section{REFERÊNCIAS}

AGUAIR, E. L. et al. Padrões tecnológicos - o uso na prestação de serviços públicos e no relacionamento com o governo federal. In: MESQUITA, C. S. F.; BRETAS, N. L. (orgs.). Panorama da Interoperabilidade no Brasil. Ministério do Planejamento, Orçamento e Gestão - Secretaria de Logística e Tecnologia da Informação Brasília: MP/SLTI, 2010. p. 50-63.

ALEXANDER, C. et al. A pattern language: towns, buildings, construction. New York: Oxford University Press, 1977. p. 1171.

ALMEIDA, E. et al. RiSE project: towards a robust framework for software reuse. In: International Conference on Information Reuse and Integration. Proceedings... Las Vegas: IEEE, 2004. p. 48-53.

ARSANJANI, A. et al. SOMA: a method for developing service-oriented solutions. In: IBM Systems Journal, 2008. v. 4, p. 377-396. Disponível em: <http://dx.doi.org/10.1147/sj.473.0377>. Acesso em 04 abr. 2014.

ASSAR, S.; BOUGHZALA, I.; BOYDENS, I. Back to practice, a decade of research in e-government. Practical Studies in E-Government, 2011. p. 1-12. Disponível em: <http://dx.doi.org/10.1007/978-1-4419-7533-1 1>. Acesso em 17 mar. 2013.

AZEVEDO, L. G. et al. A method for service identification from business process models in a SOA approach. In: KROGSTIE, J. et al. (eds.). Enterprise, Business-Process and Information Systems Modeling. Berlin Heidelberg: Springer, 2009. $\quad$ p. $299-112 . \quad$ Disponível em: <http://link.springer.com/chapter/10.1007\%2F978-3-642-0186269>. Acesso em 11 mar. 2013.

BAQIR, M. N.; IYER, L. E-government maturity over 10 years: a comparative analysis of e-government maturity in select countries around the world. Comparative E-Government, v. 25, New York: Springer, 2010. p. 3-22.

BARROS, A.; CEPIK, M. A. C.; CANABARRO, D. R. Para além da e-PING o desenvolvimento de uma plataforma de interoperabilidade de e serviços no Brasil. In: MESQUISTA, C. S. F.; BRETAS, N. L. (orgs.). Panorama da Interoperabilidade no Brasil. Ministério do Planejamento, Orçamento e Gestão Secretaria de Logística e Tecnologia da Informação Brasília: MP/SLTI, 2010. p. 137-157

EKKERS, V. The governance of back office integration in e-government: some dutch experiences. In: WIMMER, M. A. et al. (eds.). Electronic Government. Springer Berlin Heidelberg, 2005. p. 12-25. Disponível em: <http://link.springer.com/chapter/10.1007/11545156 2>. Acesso em $08 \mathrm{mar}$. 2014. 
BELL, M. Modelação orientada ao serviço - SOA análise, design e arquitetura de serviços. Rio de Janeiro: Alta Book, 2008.

BIGGERSTAFF, T.; RICHTER, C. Reusability framework, assessment, and directions. IEEE Software, 1987. v. 4, n. 2, p. 41-49. Disponível em: <http://dx.doi.org/10.1109/MS.1987.230095>. Acesso em 26 set. 2013.

BOERNER, R.; GOEKEN, M. Service identification in SOA governance literature review and implications for a new method. In: 3rd IEEE International Conference on Digital Ecosystems and Technologies (DEST'09). Istanbul: IEEE, 2009. p. 588-593.

BRASIL. MINISTÉRIO DO PLANEJAMENTO, ORÇAMENTO E GESTÃO. SECRETARIA DE LOGÍSTICA E TECNOLOGIA DA INFORMAÇÃO. Processo de software para o SISP, 2012. Disponível em: <http://www.sisp.gov.br/pswsisp/wiki/Apresentacao>. Acesso em 15 fev. 2014.

SECRETARIA DE FAZENDA DE ESTADOS. Projeto Conhecimento de Transporte Eletrônico (Manual de integração contribuinte - padrões técnicos de comunicação). In: Encontro Nacional de Coordenadores e Administradores Tributários Estaduais (ENCAT), 2012. Versão 1.0.4c.

SECRETARIA DE FAZENDA DE ESTADOS. Sistema Nota Fiscal Eletrônica (Manual de orientação do contribuinte - padrões técnicos de comunicação). In: Encontro Nacional de Coordenadores e Administradores Tributários Estaduais (ENCAT), 2012. Versão 5.0.

. MINISTÉRIO DO PLANEJAMENTO, ORÇAMENTO E GESTÃO. Catálogo de interoperabilidade. 2013. Governo Brasileiro. (Template Documentação de Serviço Interoperáveis). Disponível em: <http://catalogo.governoeletronico.gov.br/>. Acesso em 13 mai. 2013.

MINISTÉRIO DO PLANEJAMENTO, ORÇAMENTO E GESTÃO. Vocabulário controlado do governo eletrônico (VCGE) - programa de governo eletrônico Brasileiro. SLTI, 2013. Disponível em: <http://www.governoeletronico.gov.br/acoes-e-projetos/e-ping-padroes-deinteroperabilidade/vcge>. Acesso em 01 nov. 2014.

COMITE EXECUTIVO DE GOVERNO ELETRÔNICO. Padrões de Interoperabilidade de Governo Eletrônico - E-PING. Governo Brasileiro. Documento de Referência - Versão 2014, 2014. Disponível em: <http://www.governoeletronico.gov.br>. Acesso em 02 jan. 2014.

BUSCHMANN, F. et al. Pattern-oriented software architecture: a system of patterns. England: John Wiley, 1996.

CALDIERA, G.; BASILI, V. Identifying and qualifying reusable software components. Computer, 1991. v. 24, n. 2, p. 61-70.

CHEN, F. et al. Service identification via ontology mapping. In: International 
Computer Software and Applications Conference. Proceedings... WA: IEEE, 2009. v. 1, p. 486-491.

CSTRANSFORM. E-Government Interoperability - a comparative analysis of 30 countries. CITIZEN SERVICE TRANSFORMATION, 2011. Disponível em: <http://www.cstransform.com/resources/index.htm>. Acesso em 03 jan. 2014.

DIJK, J. V. et al. E-services for citizens: the dutch usage case. Electronic Government, 2007. v. 4656, p.155-166.. Disponível em: <http://dx.doi.org/10.1007/978-3-540-74444-3 14>. Acesso em 17 jun. 2012.

DU, L. SOA-based integration of enterprise vertical applications. In: Computer Application and System Modeling (ICCASM), International Conference on Computer Application and System Modeling. Taiyuan: IEEE, 2010. v. 12, p. 122-125.

DWIVEDI, V.; KULKARNI, N. A model driven service identification approach for process centric systems. In: Congress on Services Part II, 2008. SERVICES-2. IEEE. Beijing: IEEE, 2008. p. 65-72.

EmailMeForm. Online Form Builder. Online surveys, Web Forms, 2013. Disponível em: <http://www.emailmeform.com/>. Acesso em 01 ago. 2013.

ERL, T. SOA design patterns. Boston: Prentice Hall, 2009.

SOA: princípios de design do serviço. São Paulo: Pearson Prentice Hall, 2009.

FEENSTRA, R.; JANSSEN, M. Service portfolios for managing modular networks. In: International conference on Digital government research. Proceedings... Canada: Digital Government Society of North America, 2008. dg.o'08, p. 357-358.

FKI, E.; TAZI, S.; DUPUY, C. S. Towards a user intention aware service composition. In: 10th Annual International Conference on New Technologies of Distributed - NOTERE, Tozeur: IEEE, 2010. p. $113-120$.

FONSECA, W. R.; CORREAA, P. L. P. Reutilização de conceitos de serviços no cenário de governo eletrônico. In: Conferência IADIS Ibero-Americana WWW/INTERNET. Porto Alegre: IADIS Press, 2013. p. 37-44.

Reuse of service concepts based on service patterns. In: $16^{\text {th }}$ International Conference on Enterprise Information System. Portugal: [s.n.], 2014.

Use of service patterns as an approach to modelling of electronic government services. In: MERTINS, K. et al. (eds.). Enterprise Interoperability VI. Springer International Publishing, In: I-ESA Conferences. Proceedings... 2014. p. 113-124. DOI: 10.1007/978-3-319-04948-9_10. Disponível em: <http://link.springer.com/chapter/10.1007/978-3-319-04948-910>. Acesso em 02 abr. 2014.

FONSECA, W. R.; CORRÊA, P. L. P.; CORRÊA, A. S. Service patterns in the 
process of service-oriented development. In: International Journal of eEducation, e-Business, e-Management and e-Learning (IJEEEE), 2014. v. 4, n. 3, p. 232-237. Disponível em: http://www.ijeeee.org/>. Acesso em 16 fev. 2014.

FONSECA, W. R.; MELNIKOFF, S. S. S. Computação orientada a serviços ênfase em métodos de identificação de serviços. In: Escola Regional de Informática - ERI/MT. Cuiabá: SBC, 2011.

FOWLER, M. Padrões de arquitetura de aplicações corporativas. Porto Alegre: Bookman, 2006.

FREEMAN, P. Reusable software engineering: Concepts and research directions. In: ITT of the Workshop Reusability in Programming. Proceedings... 1983. p. 216.

FU, J. et al. Using service patterns to achieve web service composition. In: International Conference on Semantic Computing (ICSC'09). Berkeley: IEEE, 2009. p. $402-407$.

GAMMA, E. et al. Padrões de projeto. Porto Alegre: Bookman, 2000.

GIL-GARCIA, J.; PARDO, T. Multi-method approaches to digital government research: value lessons and implementation challenges. In: 39th Annual Hawaii International Conference on System Sciences (HICSS'06). Proceedings... Hawaii: IEEE, 2006. v. 4.

GOTTSCHALK, P.; SOLLI-SAETHER, H. E-government interoperability and information resource integration: frameworks for aligned development. Hershey: IGI Global, 2009.

GRÖNLUND, A. Electronic government: design, applications and management. Hershey: Idea Group, 2002.

GU, Q.; LAGO, P. A stakeholder-driven service life cycle model for SOA. In: 2nd international workshop on Service oriented software engineering: in conjunction with the 6th ESEC/FSE joint meeting. IW-SOSWE'07, Croatia: ACM, 2007. p. 1-7.

HUBBERS, J.; LIGTHART, A.; TERLOUW, L. Ten ways to identify services. The SOA Magazine, 2007. Disponível em: <http://www.servicetechmag.com/l13/1207-1>. Acesso em 25 de fev. 2012.

INAGANTI, S.; BEHARA, G. K. Service Identification - BPM and SOA Handshak. BPTrends, 2007. Disponível em: <www.bptrends.com>. Acesso em 04 mar. 2013.

KANG, D.; SONG, C.-y.; BAIK, D.-K. A method of service identification for product line. In: 3rd International Conference on Convergence and Hybrid Information Technology (ICCIT). Proceedings..., 2008. Seattle: IEEE, 2008. v. 2, p. 1040 1045.

KANNAN, K.; SRIVASTAVA, B. Promoting reuse via extraction of domain 
concepts and service abstractions from design diagrams. In: IEEE International Conference on Services Computing (SCC'08), Honolulu: IEEE, 2008. v. 1 , p. $265-272$.

$\mathrm{KIM}$, Y.; DOH, K.-G. Formal identification of right-grained services for service-oriented modeling. In: Web Information Systems Engineering WISE 2009. Poznan: Springer Berlin Heidelberg, 2009. v. 5802, p. 261-273. Disponível em: <http://link.springer.com/chapter/10.1007\%2F978-3-642-04409-0 29>. Acesso em 19 mai. 2010.

KLISCHEWSKI, R.; ASKAR, E. Success factors of developing G2G services: the case of Egypt. In: 4th International Conference on Theory and Practice of Electronic Governance (ICEGOV'10). Proceedings... New York: ACM, 2010., p. 152-160. Disponível em: <http://doi.acm.org/10.1145/1930321.1930354>. Acesso em 15 fev. 2012.

KRUEGER, C. W. Software reuse. In: Journal ACM Computing Surveys (CSUR), 1992. v. 24, p. 131-183. Disponível em: <http://doi.acm.org/10.1145/130844.130856>. Acesso em 26 set. 2013.

KUMAR, B. V.; NARAYAN, P.; NG, T. Implementando SOA usando Java EE. Rio de Janeiro: Alta Books, 2012.

LAMPATHAKI, F. et al. E-government services composition using multi-faceted metadata classification structures. Electronic Government, 2007. v. 4656, p. 116-126.

LARMAN, C. Utilizando UML e Padrões. Porto Alegre: Bookman, 2007.

LEWIS, G. A.; SMITH, D. B.; KONTOGIANNIS, K. A research agenda for service-oriented architecture (SOA): maintenance and evolution of serviceoriented systems. Hanscom, 2010. Disponível em: <http://www.sei.cmu.edu>. Acesso em 30 mar. 2012.

LI, P. et al. A reputation pattern for service oriented computing. In: 7th International Conference on Information, Communications and Signal Processing (ICICS), Macau: IEEE, 2009. p. $1-5$.

LIMA, A. R.; MEDEIROS, F. M.; FALCÃO, T. Estruturação da arquitetura de sistemas de informação do governo de Pernambuco por meio da orientação a serviços - relato de experiência da ATI-PE. In: MESQUISA, C. S. F.; BRETAS, N. L. (orgs.). Panorama da Interoperabilidade no Brasil. Ministério do Planejamento, Orçamento e Gestão - Secretaria de Logística e Tecnologia da Informação Brasília: MP/SLTI, 2010. p. 160-175.

LIN, P. et al. An ontology-based \& distributed service model for EG. In: International Conference on Internet Computing in Science and Engineering (ICICSE'08), Harbin: IEEE Computer Society, 2008. p. 485 - 491.

LUCRÉDIO, D. Uma abordagem orientada a modelos para reutilização de software. 2009. 287 p. Tese (Doutorado) - Instituto de Ciências Matemáticas e de Computação. Universidade de São Paulo, São Carlos, 2009. 
LUCRÉDIO, D.; PRADO, A.; ALMEIDA, E. A survey on software components search and retrieval. In: 30th EUROMICRO Conference (EUROMICRO'04). Proceedings... Rennes: IEEE, 2004. p. 152-159.

MA, Q. et al. Evaluating service identification with design metrics on business process decomposition. I $n$ : IEEE International Conference on Services Computing (SCC). Bangalore: IEEE, 2009. p. 160-167.

MACIEL, C. Um método para mensurar o grau de maturidade na tomada de decisão e-democracia. 2008. 209 p. Tese (Doutorado) - Programa de PósGraduação em Computação, Universidade Federal Fluminense, Niterói. 2008.

MANI, S. et al. Using user interface design to enhance service identification. In: IEEE International Conference on Web Services (ICWS). Proceedings. . . 2008. Beijing: IEEE, 2008. p. 78-87.

MARKS, E. A.; BELL, M. Service-oriented architecture (SOA) - a planning and implementation guide for business and technology. Hoboken: John Wiley \& Sons, 2006.

MIYAMARU, F. et al. Task patterns for e-government services. In: VIII Brazilian Symposium on Human Factors in Computing Systems (IHC'08). Proceedings... Porto Alegre: SBC, 2008. p. 276-279.

MOON, M.; HONG, M.; YEOM, K. Two-level variability analysis for business process with reusability and extensibility. In: Annual IEEE International Computer Software and Applications Conference (COMPSAC'08). Turku: IEEE, 2008. p. 263-270.

NAZIH, M.; ALAA, G. Generic service patterns for web enabled public healthcare systems. In: 2011 7th International Conference on Next Generation Web Services Practices - NweSP. Salamanca: IEEE, 2011. p. 274279.

OASIS. ORGANIZATION FOR THE ADVANCEMENT OF STRUCTURED INFORMATION STANDARDS. Reference model for service oriented architecture 1.0, 2006. Disponível em: <https://www.oasis-open.org/>. Acesso em 22 abr. 2011.

ORGANIZATION FOR THE ADVANCEMENT OF STRUCTURED INFORMATION STANDARDS. Reference architecture foundation for service oriented architecture, Committee Specification, 2012. Disponível em: <https://www.oasis-open.org/>. Acesso em: 2012-04-12.

OECD. ORGANISATION FOR ECONOMIC CO-OPERATION AND DEVELOPMENT. The e-government imperative, 2003. Disponível em: <http://www.oecd.org/gov/>. Acesso em 01 fev. 2013.

ORGANISATION FOR ECONOMIC CO-OPERATION AND DEVELOPMENT. E-government studies e-government for better government, 2005. Disponível 
em: <http://www.oecd.org/gov/>. Acesso em 13 fev. 2013.

PAPAZOGLOU, M. et al. Service-oriented computing - state of the art and research challenges. Computer, 2007. v. 40, n. 11, p. 38-45.

PAPAZOGLOU, M. P.; HEUVEL, W.-J. v. d. Service oriented architectures: approaches, technologies and research issues. In: The VLDB Journal, 2007. v. 16, n. 3, p. 389-415.

PAPAZOGLOU, M. P. et al. Service-oriented computing: a research roadmap. In: International Journal of Cooperative Information Systems, 2008. v. 17, p. 223-255.

PARK, J. et al. An approach to enhancing reusabilities in service development. In: 2009 International Conference on Hybrid Information Technology ICHIT'09. Proceedings... New York: ACM, 2009. p. 143-150. Disponível em: <http://doi.acm.org/10.1145/1644993.1645019>. Acesso em 11 jul. 2012.

RAY, D. et al. A critical survey of selected government interoperability frameworks. Transforming Government: People, Process and Policy, 2011. v. 5, p. 114-142. Disponível em: <http://www.emeraldinsight.com/journals.htm?articleid=1926557>. Acesso em 13 nov. 2013.

REHEM, A.; OLLER, N. Projeto nota fiscal eletrônica do varejo NFC-e. [apresentação], Porto Alegre: Secretaria de Estados de Fazenda. 2012. Disponível em: <www.encat.org>. Acesso em 30 nov. 2013.

SAMETINGER, J. Software engineering with reusable components. Softcover reprint of hardcover. Berlin: Springer-Verlag, 1997.

SANTOS, E. M. Desenvolvimento e implementação da arquitetura e-PING estratégias adotadas e possíveis implicações. In: MESQUITA, C. S. F.; BRETAS, N. L.; (orgs.). Panorama da Interoperabilidade no Brasil. Ministério do Planejamento, Orçamento e Gestão - Secretaria de Logística e Tecnologia da Informação, Brasília: MP/SLTI, 2010. p. 22-36.

SCUPOLA, A.; HENTEN, A.; NICOLAJSEN, H. W. E-services: characteristics, scope and conceptual strengths. Networking and Telecommunications: Concepts, Methodologies, Tools and Applications, 2010. p. 107-120.

SHIRAZI, H.; FAREGHZADEH, N.; SEYYEDI, A. A combinational approach to service identification in SOA. In: Journal of Applied Sciences Research, 2009. v. 5, n. 10, p. 1390-1397.

SILVA, O. J. XML: aplicações práticas. São Paulo: Editora Érica, 2001.

SOMMERVILLE, I. Engenharia de software. 8 ed. São Paulo: Pearson AddisonWesley, 2007.

SONIC. A new service-oriented architecture (SOA) maturity model, 2005. 
Disponível em: <http://soa.omg.org/>. Acesso em 03 nov. 2011.

TCHUTA, L.; CHUNHUA, G. Atomic new service pattern. In: International Journal of Software Engineering and Its Applications, 2011. v. 5, p. 1-20.

THOM, L.; REICHERT, M.; IOCHPE, C. Activity patterns in process-aware information systems: basic concepts and empirical evidence. In: International Journal of Business Process Integration and Management (IJBPIM), 2009. v. 4, n. 2, p. 93-110. Disponível em: <http://dbis.eprints.uni-ulm.de/473/>. Acesso em 06 jan. 2014.

THOM, L. H. et al. Extending business process modeling tools with workflow patterns reuse. In: International Conference on Enterprise Information Systems (ICEIS). Angers: ICEIS Press, 2007.

UK. E-government interoperability framework (e-GIF). United Kingdom, v. 6.0, 2004. Disponível em: <edina.ac.uk/projects/interoperability/e-gif-v6-0.pdf>. Acesso em 01 mai. 2012.

UNDP. UNITED NATIONS DEVELEPMENT PROGRAMME. E-government interoperability: guide. Thailand, 2007. Disponível em: $<$ http://www.unapcict.org/ecohub/resources/e-government-interoperability-guide>.

Acesso em 30 mai. 2013.

UNPAN. UNITED NATIONS DEPARTMENT OF ECONOMIC AND SOCIAL AFFAIRS. United Nations e-government survey 2012 - E-government for the people, 2012. Disponível em: <http://www.unpan.org/>. Acesso em 05 mar. 2013.

W3C Web of service. Service description. 2014. Disponível em: <http://www.w3.org/standards/webofservices/description>. Acesso em 02 fev. 2014.

WANG, A. J. A.; QIAN, K. Component-oriented programming. Hoboken: John Wiley \& Sons, 2005.

WAZLAWICK, R. S. Metodologia de pesquisa para ciência da computação. Rio de Janeiro: Campus, 2009.

WIMMER, M. A. Integrated service modelling for online one-stop government. Electronic Markets, 2002. v. 12, p.149-156. Disponível em: $<$ http://www.tandfonline.com/doi/abs/10.1080/101967802320245910>. Acesso em 06 jun. 2014.

YOUSEF, R. et al. BPAOntoSOA: a generic framework to derive software service oriented models from business process architectures. In: Applications of Digital Information and Web Technologies (ICADIWT'09), London: IEEE, 2009. p. 50-55. 


\section{APÊNDICE A - INTERFACE DO QUESTIONÁRIO ON-LINE PARA LEVANTAMENTO DE SERVIÇOS}

Neste Apêndice é apresentada a interface do questionário on-line utilizado para realizar o levantamento de serviços no domínio de e-governo. O questionário é composto por três partes: a primeira é a Carta de apresentação, representado na Figura 37, a segunda é referente as informações da organização, conforme apresentado na Figura 38 e, a terceira parte é constituída por informações dos serviços, conforme apresentado na Figura 39. 
Figura 37: Carta de apresentação

\section{Questionário}

\section{Levantamento de Serviços}

\section{Carta de apresentação}

Prezado $\operatorname{Sr}(a)$.

Com o objetivo de subsidiar uma pesquisa de doutorado em andamento na Escola Politécnica da Universidade de São Paulo (EPUSP), a respeito de desenvolvimento de sistema para Governo, pedimos o preenchimento deste questionário.

Este questionário visa obter informações sobre o uso de serviços (web services) e Arquitetura Orientada a Serviços (SOA) no âmbito do Governo, no sentido de auxiliar na pesquisa referente a um Método de Especificação de Serviços de Governo Eletrônico Baseado em Padrões de Serviços.

Os resultados e análises desse levantamento serão disponibilizados assim que os mesmos forem consolidados. Na divulgação dos resultados não serão expostos os nomes das entidades públicas, tão pouco os nomes das pessoas fornecedoras das informações.

Solicitamos que o preenchimento deste questionário seja realizado até o dia $\mathbf{3 1 / 1 2 / 2 0 1 3}$ (Terça-Feira).

O registro dos serviços no questionário pode ser interrompido a qualquer momento respondendo "não" à pergunta "Informar outro serviço?" no final do questionário. Caso deseje informar outros serviços posteriormente, pedimos a gentileza de reiniciar o questionário.

Em caso de dúvidas, entre em contato pelo e-mail: wannessafonseca@usp.br

Desde já, agradecemos sua participação. Sua colaboração é de extrema importância para alcançarmos o sucesso neste projeto de pesquisa.

Atenciosamente,

Wannessa Rocha da Fonseca (Aluna Pesquisadora da Escola Politécnica da Universidade de São Paulo e Funcionária do Centro de Processamento de Dados do Estado do Mato. wannessafonseca@usp.br )

Pedro Luiz Pizzigatti Corrêa (Professor Pesquisador da Escola Politécnica da Universidade de São Paulo. pedro.correa@usp.br)

Andreivid Corrêa (Aluno Pesquisador da Escola Politécnica da Universidade de São Paulo. andreivid@usp.br )

Iniciar questionário

Fonte: Autor (2014) 
Figura 38: Interface do questionário - questões sobre o perfil da organização

Questionário

Levantamento de Serviços

\section{Informações da Organização}

Nome da organização *

Sigla da organização

A organização atua principalmente na esfera?
Municipal
Estadual
Federal

A organização atua principalmente no poder?

Executivo

Legislativo

Judiciário

A organização já implantou ou tem alguma experiência

Sim

Não

Não Sei

em SOA (Arquitetura

Orientada a Serviços)?

Próximo Anterior

Fonte: Autor (2014) 
Figura 39: Interface do questionário - questões sobre o perfil dos serviços da organização

\section{Questionário}

Levantamento de Serviços

\section{Informações do Serviço}

Nome do serviço

\section{Objetivo}

Nome do sistema

fornecedor (provedor) do serviço

o serviço é para atender a esfera?

$\square$ Estadual

Federal

Qual o contexto de utilização do serviço?

$\square$ Saúde

Educação

Segurança

Outros (quais?)

o serviço é monitorado com apoio de alguma
Sim
Não
Não sei

ferramenta?

O serviço é composto?

กล̃o

Não sei

Sim (quais serviços?)

Qual a forma de publicação do serviço?

A tecnologia utilizada para

UDDI

URL específico

Não sei

implementar o serviço é

$\operatorname{Sim}$

Não

Não sei

Web Service?

\section{Capacidade 1}

PARA INSERIR outra capacidade clique em qualquer área do formulário

Exemplos de capacidades para o serviço Contribuinte: incluirContribuinte

alterarSituacaocontribuinte

consultarDebitosContribuinte

Informar outro serviço? *
Sim (continua respondendo)

Não (finaliza questionário)

Próximo Anterior 


\section{APÊNDICE B - CARACTERIZAÇÃO DO USO DE SERVIÇOS E SOA NO GOVERNO - REALIZADO NO ANO DE 2013}

Neste Apêndice são apresentados dados quantitativos da coleta de dados a respeito do uso de serviços e SOA no domínio de governo. Este levantamento foi realizado no ano de 2013.

\section{B.1 Cenário}

O questionário foi submetido às organizações públicas, nos poderes, executivo, legislativo e judiciário, e nas esferas, municipal, estadual e federal.

\section{B.2 Metodologia}

A coleta de dados foi realizada por meio de um questionário eletrônico elaborado com a ferramenta EmailMeForm (2013). O questionário permitiu que os especialistas em serviços da área de governo registrassem as informações de serviços existentes no ambiente de produção. Conforme registrado no Apêndice A, o questionário contém dois formulários, um a respeito de informações gerais sobre a instituição pública e outro, informações sobre os serviços.

\section{B.3 Dados Coletados}

O levantamento de serviços teve como objetivo buscar informações sobre:

- Organização - nome/sigla da organização, esfera e poder que a organização atua e se a organização já implantou ou tem alguma experiência em SOA; 
- Serviços - nome e objetivo do serviço, nome do sistema fornecedor do serviço, qual a esfera o serviço atende, qual o contexto (área de governo) que o serviço é utilizado, se o serviço é monitorado com apoio de alguma ferramenta, se o serviço é composto, a forma de publicação do serviço, qual a tecnologia de implementação do serviço e quais são as operações do serviço.

Os gráficos a seguir resumem as informações obtidas a respeito das 14 organizações que responderam o questionário e a respeito dos 57 serviços identificados por meio do questionário.

\section{B.3.1 Informações Sobre as Organizações que Responderam o Questionário}

O questionário foi respondido por 14 organizações, sendo $64 \%$ das organizações da esfera estadual, $22 \%$ da esfera municipal e $14 \%$ da esfera federal. $100 \%$ das organizações são do poder executivo, conforme as Figuras 40 e 41 respectivamente.

Os números apurados na pesquisa indicam que 35\% possui experiência com SOA, $47 \%$ não tem experiência e $18 \%$ não responderam a pergunta, conforme registrado na Figura 42.

Figura 40: Esfera de atuação das organizações

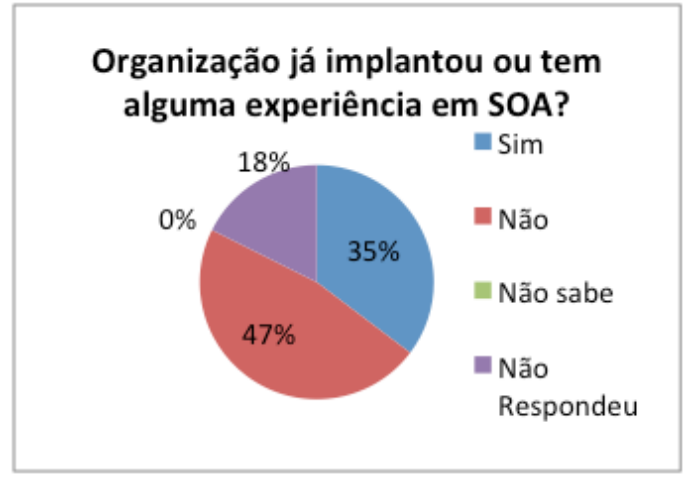

Fonte: Autor (2014)
Figura 41: Esfera de atuação das organizações

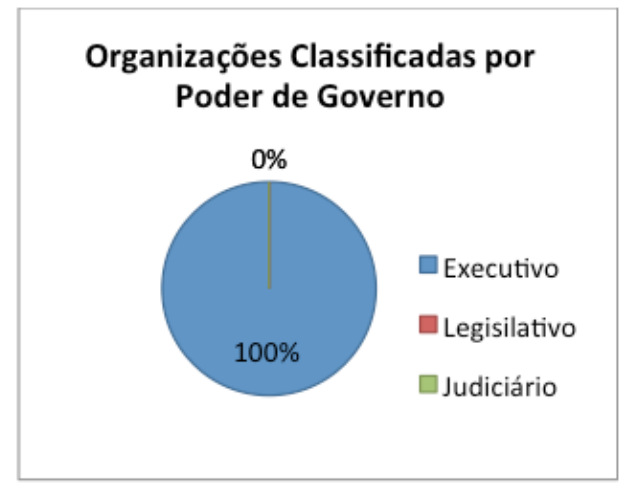

Fonte: Autor (2014) 
Figura 42: Experiência com SOA no domínio de governo

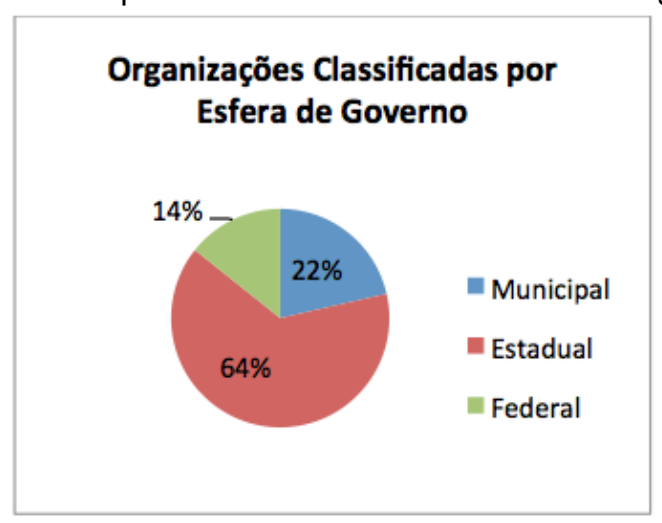

Fonte: Autor (2014)

\section{B.3.2 Informações Sobre os Serviços Identificados via Questionário}

Em relação ao escopo de utilização do serviço foram observados, conforme ilustrado na Figura 43, que 6\% dos serviços são para atender a esfera municipal, $73 \%$ dos serviços são para atender a esfera estadual, $4 \%$ são disponibilizados para a esfera Federal, e 11\% das organizações não responderam este item do questionário.

Em relação a área de negócio de governo que o serviço está vinculado, foram observados, conforme a Figura 44, que $58 \%$ são de uso da área financeira, $21 \%$ dos serviços são específicos da área administração interna. Serviços de outras áreas também foram apresentados, como saúde, segurança e educação, mas em uma proporção menor. Esse item do questionário não foi respondido por $6 \%$ das organizações.

Conforme ilustrado na Figura 45, 20\% dos serviços são monitorados com o apoio de ferramentas, enquanto $77 \%$ dos serviços não estão sendo monitorados com apoio de ferramentas e $3 \%$ não responderam a pergunta do questionário.

Outra característica observado é que $90 \%$ dos serviços não utilizam a composição de serviços, $6 \%$ utilizam a composição de serviços e $4 \%$ não responderam essa pergunta do questionário, conforme observado na Figura 46. Pode-se concluir que os serviços estão sendo pouco reutilizados.

A pesquisa evidenciou que no universo explorado é pouco utilizado mecanismos de armazenamento e localização de serviços. Conforme representado na Figura 47, 92\% dos serviços são localizados/invocados diretamente pelo endereço de acesso (URL, Portas, etc), e somente 1\% utiliza repositório para catalogação e descoberta de serviços, como por exemplo, UDDI. Esse item do questionário não foi respondido por $2 \%$ das organizações e $4 \%$ não sabiam responder a pergunta. 
Entre os serviços identificados, $96 \%$ são implementados por meio da tecnologia de Web Services, 2\% usam componentes particulares de integração desenvolvidos pelas próprias instituições, $2 \%$ não responderam esta pergunta do questionário, conforme representado na Figura 48.

Figura 43: Esfera de uso dos serviços

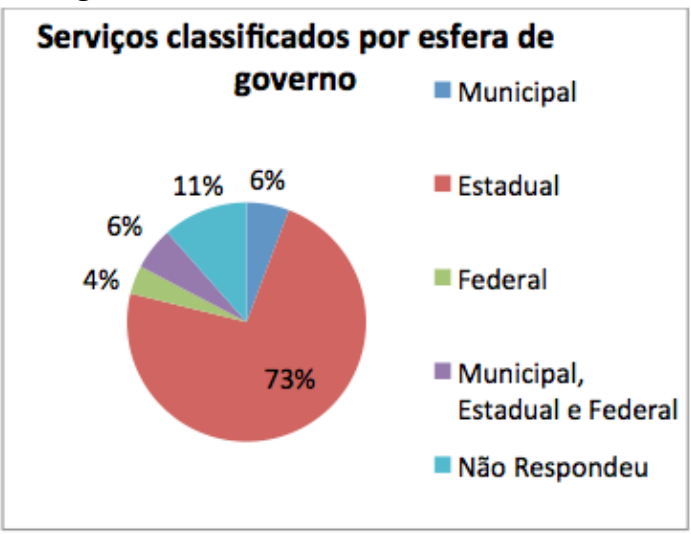

Fonte: Autor (2014)
Figura 44: Serviços por áreas de governo

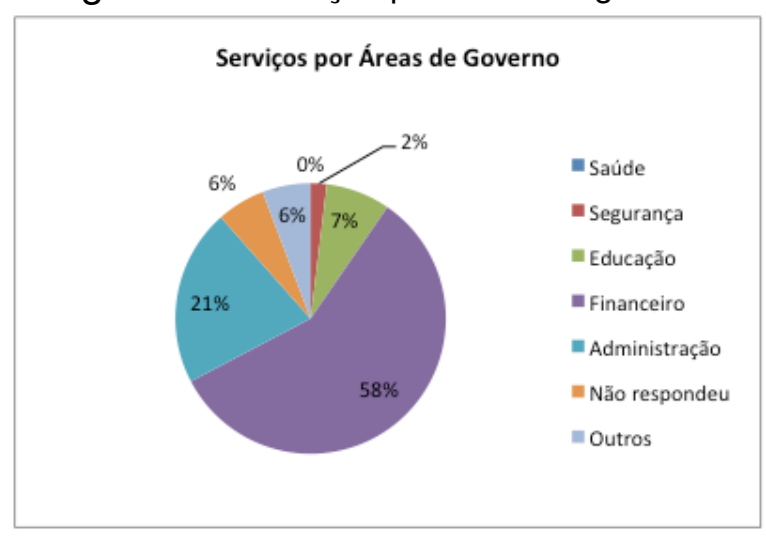

Fonte: Autor (2014)

Figura 46: Serviços compostos

Figura 45: Serviços monitorados por ferramentas

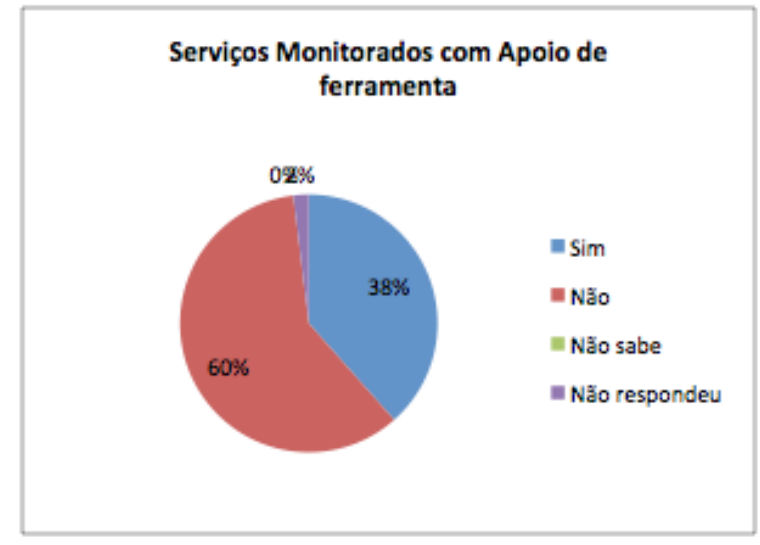

Fonte: Autor (2014)

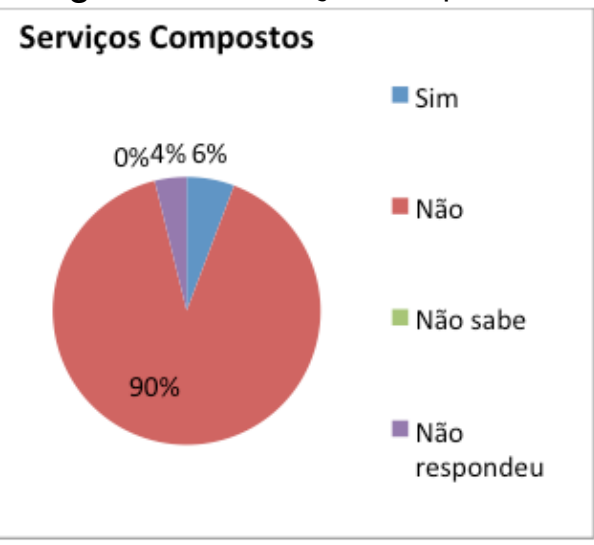

Fonte: Autor (2014) 
Figura 47: Serviços classificados por forma de publicação

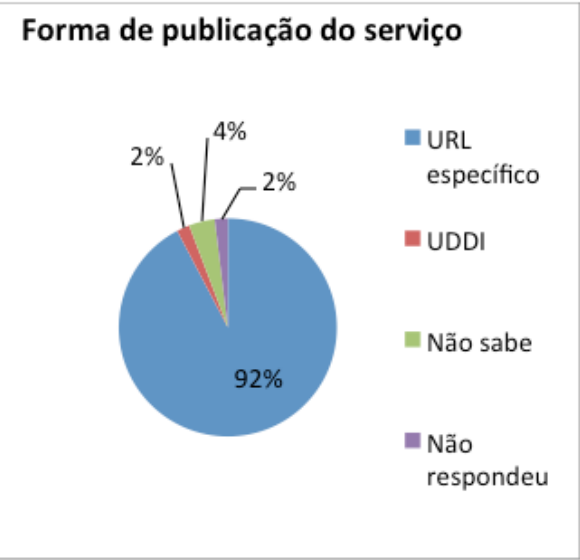

Fonte: Autor (2014)
Figura 48: Serviços implementados utilizando Web Services

\section{Serviços que utilizam a tecnologia Web Services}

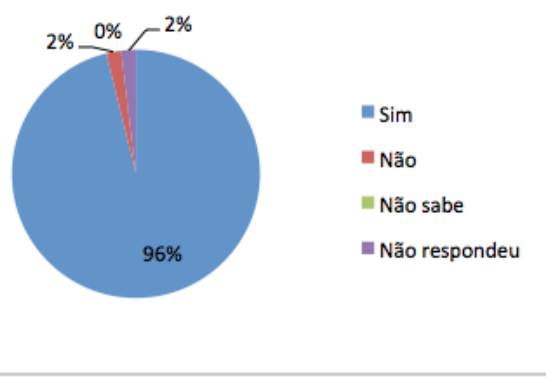

Fonte: Autor (2014) 


\section{APÊNDICE C - LEVANTAMENTO DE SERVIÇOS E INTEGRAÇÕES - REALIZADO NO ANO DE 2010}

Neste Apêndice são apresentados os resultados obtidos em um levantamento a respeito do uso de serviços e integrações entre os sistemas no cenário da Administração Pública do Estado de Mato Grosso, especificamente, no poder executivo estadual. Este levantamento foi realizado no ano de 2010.

\section{C.1 Cenário}

A presente pesquisa não teve o objetivo de analisar todos os sistemas da administração pública do Estado de Mato Grosso, principalmente por questões de tempo e esforço necessário para atingir tal resultado. Foram escolhidos órgãos estaduais e nesses foram investigados sistemas que possuem integrações.

\section{C.2 Metodologia}

A coleta de informações foi realizada por meio de um questionário aplicado em entrevistas com integrantes das equipes de desenvolvimento e manutenção de sistemas. Foi elaborado um questionário específico para tratar o levantamento de integrações realizadas por meio de chamadas de serviços entre aplicações e outro para cobrir o universo de outras alternativas de integração, tais como, trocas de arquivos e compartilhamento de acesso a banco de dados.

\section{C.3 Dados Coletados}

O levantamento teve como objetivo buscar informações sobre:

- As tecnologias utilizadas para implementar os serviços; 
- O escopo de utilização dos serviços - se os serviços são de uso público (externa a administração estadual), se são disponibilizados apenas para as instituições da administração estadual ou se são de uso interno da instituição que os implementou;

- Forma de implementação de serviços - se o serviço implementa a lógica do processo de negócio ou se o serviço expõe as funcionalidades já existentes em sistema legado;

- Existência de documentação específica para a descrição de serviços - foram desconsideradas documentações convencionais de desenvolvimento de softwares, tais como: descrição de casos de uso, diagramas de classes, diagramas de projeto de banco de dados, etc. As descrições pretendidas dizem respeito a documentos que descrevem, dentre outros, os seguintes aspectos dos serviços: a interface dos serviços, políticas de uso, questões de segurança e resultados obtidos com o uso dos serviços;

- Uso de monitoramento automático de serviços - refere-se à capacidade de monitorar o ambiente de execução/produção de serviços. Normalmente o monitoramento é realizado com o auxílio de ferramentas que colhem informações a respeito da execução ou falha dos serviços;

- Uso de composição de serviço;

- Tipos de serviço. Os serviços identificados nesse levantamento serão classificados em serviço tarefa, entidade e utilitário.

\section{C.4 Análise dos Dados}

Foram levantados 69 serviços, sendo que $25 \%$ deles foram implementados usando a tecnologia de Web Service, 59\% usando componentes particulares de integração desenvolvidos pelas próprias instituições e 16\% usando a tecnologia EntireX Broker (middleware desenvolvido pela Software AG para disponibilizar rotinas do ambiente Natural/ADABAS na forma de serviços cliente/servidor), conforme representado na Figura 49.

Em relação ao escopo de utilização dos serviços, $9 \%$ dos serviços são de uso público (externa a administração estadual), 65\% dos serviços são de uso interno da instituição que os implementou e $26 \%$ são disponibilizados apenas para as instituições da administração estadual, conforme a Figura 50.

Em relação a solução arquitetural (implementação) dos serviços, os números 
apurados na pesquisa indicam que $68 \%$ dos serviços resolvem a lógica no próprio corpo do serviço e que em $32 \%$ a lógica foi separada do corpo do serviço, conforme registrado na Figura 51. Não houve uso de composição de serviços, conforme observado na Figura 54.

Outro aspecto apurado é que $100 \%$ dos serviços foram desenvolvidos e disponibilizados sem a produção de documentações específicas, conforme a Figura 52.

Conforme observado na Figura 53, 16\% dos serviços são monitorados com o apoio de ferramentas e $84 \%$ dos serviços não estão sendo monitorados com apoio de ferramentas, sendo a falta de disponibilidade ou o baixo desempenho, muitas vezes, diagnosticado pelo consumidor do serviço.

Por fim, observou-se que $83 \%$ dos serviços disponibilizados são do tipo Entidade, ou seja, são serviços utilizados para realizar as operações CRUD, conforme a Figura 55.

Figura 49: Percentual de serviços por tecnologia

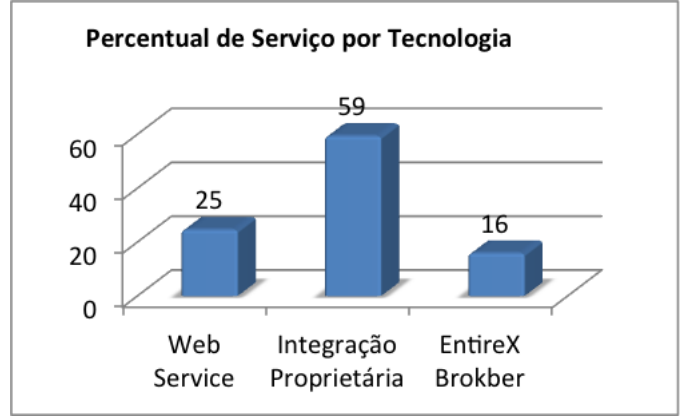

Fonte: Autor (2010)

Figura 51: Forma de implementação de serviços

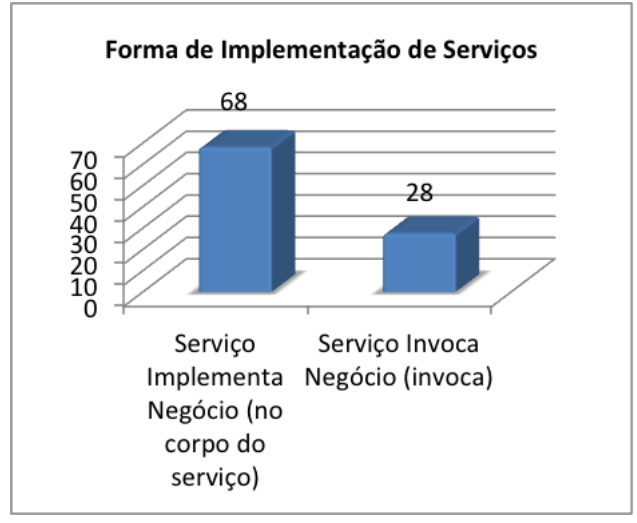

Fonte: Autor (2010)
Figura 50: Forma de uso de serviços

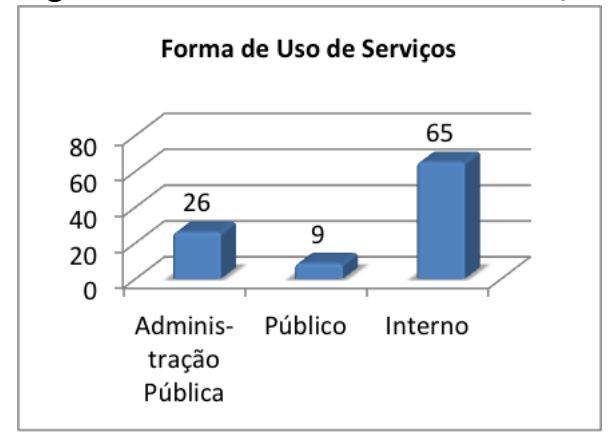

Fonte: Autor (2010)

Figura 52: Documentação de serviços

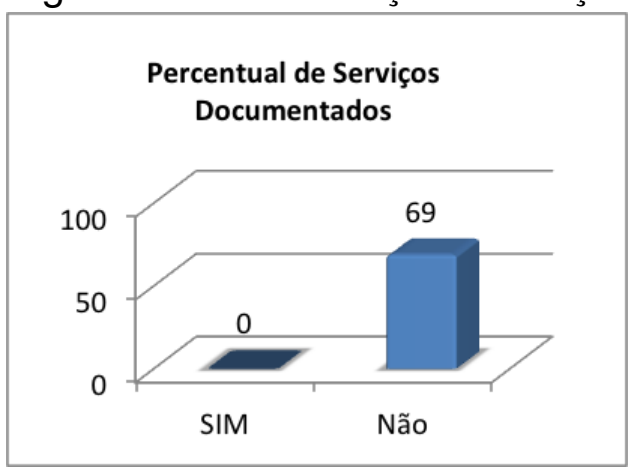

Fonte: Autor (2010) 
Figura 53: Monitoramento automático de serviços

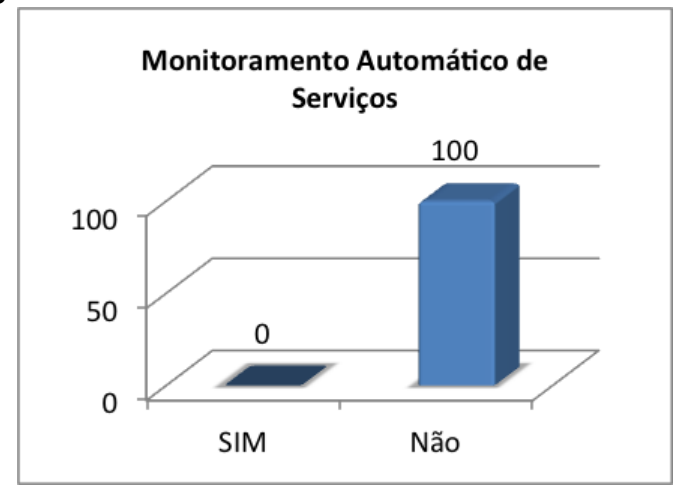

Fonte: Autor (2010)
Figura 54: Composição de serviços

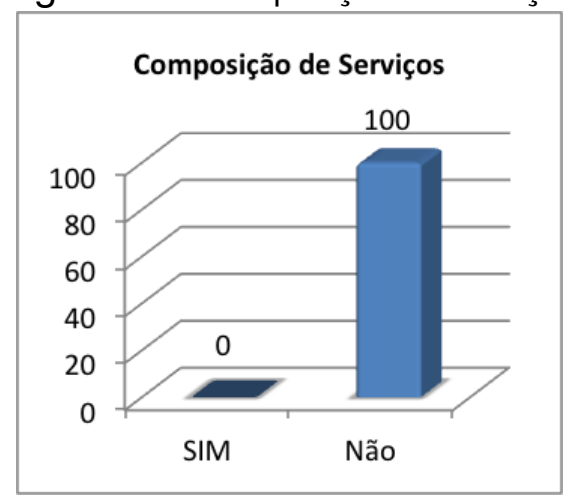

Fonte: Autor (2010)

Figura 55: Percentual de tipo de serviço

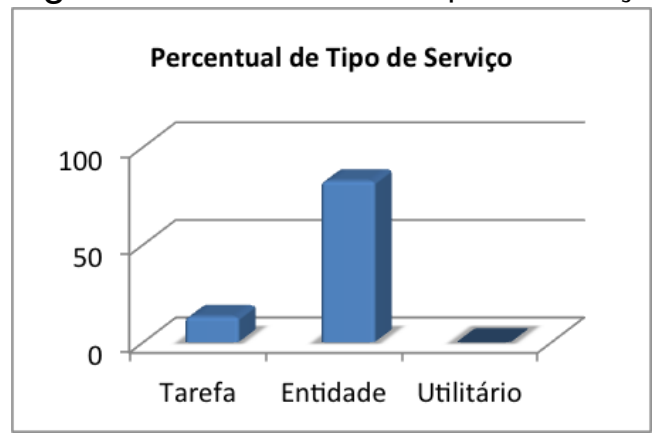

Fonte: Autor (2010)

Os dados da pesquisa evidenciam, dentro do universo explorado, que a computação orientada a serviços, quando está presente, está sendo usada fundamentalmente como instrumento de integração de aplicações e não como elementos de uma arquitetura projetada e desenvolvida sob o paradigma da computação orientada a serviços. Isso pode ser evidenciado por alguns exemplos de dados obtidos, são eles:

- Inexistência centralizada de gestão de serviços. Não foi verificado o uso de repositório de serviços. Não há um padrão de documentação específico para serviços. Evidências de baixo percentual de monitoramento de serviços por meio de ferramentas;

- Não foi observado mapeamentos de fluxos de negócio. Não foi observado o uso de ferramentas tais como: Enterprise Service Bus (ESB) e Business Process Modeling (BPM);

- Não foi observado o uso de composição de serviços;

- Não foi observada a gestão centralizada, e padronizações de serviços;

- Baixa disponibilização de serviços ao público em geral. Percentual baixo de serviços disponíveis ao público (outras instituições governamentais, 
não governamentais e comerciais). Há sem dúvida um universo grande de serviços que podem ser disponibilizados a esses públicos, facilitando a interação do Estado como essas organizações. 


\section{APÊNDICE D - DETALHAMENTO DO ESQUEMA DE DESCRIÇÃO DE SERVIÇOS}

Os serviços devem ser documentados de forma padronizada para garantir que o mesmo conjunto de dados sejam utilizados para descrever os serviços. Erl (2009b) recomenda um conjunto de atributos para descrever o serviço. Como um serviço é composto por operações o autor recomenda também um conjunto de atributos para descreve-las.

\section{D.1 Atributos para Descrever o Serviço}

- Nome do serviço - nome que identifica o serviço.

- Descrição do propósito (curta) - frase que sintetize o contexto e o propósito do serviço.

- Descrição do propósito (detalhada) - explicação mais detalhada do contexto do serviço e seus limites funcionais.

- Modelo de serviço - modelos para representar entidade, recurso, tarefa e tarefa orquestrada.

- Requisitos QoS - qualidade esperada dos requisitos, características ou limitações que afetam o serviço como um todo.

- Capacidades - relação de capacidades do serviço, sinalizando quais já estão desenvolvidas e planejadas.

- Palavras-chave - uma ou mais palavras chave definidas com base na taxonomia ou vocabulário oficial do inventário de serviços.

- Versão - número da versão do serviço.

- Status - situação do serviço quanto a fase do ciclo de vida de desenvolvimento do serviço.

- Administrador - informações a respeito do administrador ou proprietário do serviço. 


\section{D.2 Atributos para Descrever as Operações do Serviço}

- Nome da capacidade - nome que identifica a capacidade do serviço.

- Descrição do propósito - descrição que sintetize o contexto funcional e propósito geral da capacidade.

- Descrição da lógica (textual ou fluxo) - descrição detalhada da lógica executada pela capacidade. Com o objetivo de auxiliar no entendimento da lógica podem ser inseridos diagramas de fluxo de trabalho, algoritmos ou mesmo definição do processo de negócio.

- Entrada/Saída - valores de entrada admissíveis e/ou valores de saída.

- Papel da composição - a execução da lógica da capacidade do serviço pode adicionar papéis temporários ao serviço, como por exemplo: membro da composição, controlador da composição, subcontrolador da composição, etc.

- Capacidade dos membros da composição - quando a capacidade que está sendo documentada depende de outras capacidades de serviço, estas devem ser listadas nesse item.

- Requisitos de QoS - descrição dos detalhes da qualidade da capacidade do serviço. Em alguns casos, qualidade da capacidade precisa ser derivada dos detalhes dos requisitos no nível do serviço.

- Palavras-chave - as vezes as mesmas palavras-chave do serviço são aplicadas as capacidades, mas é comum a adição de novas palavras-chave para classificar melhor o propósito da capacidade.

- Versão - versão da capacidade do serviço. Em função do sistema de controle de versão, as vezes a versão pode ser aplicável somente na capacidade do serviço.

- Status - descrição da situação da capacidade. Pode ser definida com base nas mesmas fases do ciclo de vida de desenvolvimento utilizadas para o serviço.

- Administrador - nome do administrador da capacidade. Frequentemente o administrador do serviço é o administrador das capacidades, mas quando vários peritos do negócio e especialistas em tecnologia trabalham em conjunto em um dado serviço, pode haver responsáveis distintos para as capacidades do serviço. 


\section{APÊNDICE E - DETALHAMENTO DO ESQUEMA DE DESCRIÇÃO DE PADRÕES}

Alguns atributos utilizados para apresentar os padrões possuem descrições informais e outras são formais. Os atributos contidos na Tabela 6 têm os seus significados descritos a seguir:

- Nome - descreve um nome para se referir ao padrão. Li et al. (2009) propõem também descrever outros nomes pelos quais o padrão é descrito, se houver;

- Contexto - descreve situações em que o problema ocorre. Conforme Li et al. (2009), essa informação também representa o contexto em que o padrão é utilizado;

- Problema - define o problema recorrente para o qual a solução foi definida;

- Solução - descreve o princípio fundamental da solução proposta pelo padrão;

- Estrutura - conforme Li et al. (2009), a estrutura descreve uma especificação detalhada dos aspectos estruturais do padrão. Tchuta e Chunhua (2011) apresentam a estrutura de implementação do serviço utilizando o modelo de classes;

- Dinâmica - essa informação foi apresentada somente por Li et al. (2009) e refere-se a descrição de cenários típicos do comportamento do padrão em tempo de execução. Para representar a dinâmica do padrão do serviço foi utilizado o diagrama de sequência;

- Implementação - essa informação foi apresentada somente por Li et al. (2009) e descreve diretrizes para implementar o padrão;

- Consequências - descreve os benefícios que o uso do padrão oferece, bem como potenciais riscos. 
- Intenção - descrição sobre o propósito do padrão;

- Catálogo - representa o nome do catálogo a que o padrão pertence;

- Template do serviço - esta informação foi apresentada somente por Fu et al. (2009), representa uma subestrutura que descreve de maneira formal a especificação do serviço, contendo a interface, o corpo e as restrições do serviço, com pré e pós-condições para descrever o comportamento semântico do padrão de serviço;

- Objetivo - representa a identificação do padrão. Os autores Fki, Tazi e Dupuy (2010) optaram por utilizar a descrição do objetivo para identificar os padrões de serviços, pois a abordagem proposta para a concepção de padrões de serviços é baseada na perspectiva do usuário. Dessa forma, o usuário pode localizar o padrão por meio da descrição do objetivo proposto pelo padrão;

- Atividades - especifica as possíveis atividades que podem ser executadas pelo padrão;

- Tipo do serviço - descreve o tipo de serviço representado pelo padrão de serviço. Conforme apresentado por Fki, Tazi e Dupuy (2010), os tipos de serviços são: serviço atômico, serviço composto e serviço condicional;

- Regras - no trabalho apresentado por Fki, Tazi e Dupuy (2010), as regras são utilizadas para conduzir a seleção das atividades que podem ser realizadas pelo padrão de serviço, visando auxiliar a composição de serviços. As regras são estabelecidas por especialistas e podem ser adaptadas após o feedback e aprendizagem com o uso do serviço;

- Requisito - uma declaração concisa que apresenta a exigência fundamental abordada pelo padrão sob a forma de uma pergunta.

Os atributos Justificativa, Exemplo de Código, Participantes e Responsáveis, Estratégia, Considerações sobre os Testes e Padrões Relacionados foram apresentados somente por Tchuta e Chunhua (2011) e não possuem definições explicitas de seus significados. Porém, analisando o conteúdo que descreve o padrão apresentado pelos autores, tem-se o seguinte entendimento:

- Justificativa - contem os motivos que justificam o uso do padrão proposto;

- Exemplo de Código Fonte - código fonte de interface de serviço e da implementação de serviços;

- Participantes e Responsáveis - descreve as camadas de serviços e suas responsabilidades; 
- Estratégia - descreve a estratégia para uso do padrão proposto, por exemplo, utilizar ferramentas geradoras das estruturas dos serviços atômicos a partir do modelo de domínio descrito em UML;

- Considerações sobre os Testes - refere-se às recomendações sobre as atividades de teste;

- Padrões Relacionados - nome dos padrões relacionados ao padrão descrito.

Os autores Fki, Tazi e Dupuy (2010) ressaltam que independente dos atributos utilizados para descrever um padrão de serviço, o objetivo é descrevê-lo como um serviço abstrato para que possa ser implementado e disponibilizado como um serviço. 